\title{
Deconstructing Decriminalization: \\ A Genealogy of the Provincial Offences Administration, the Modern Fine, and Penalization in Ontario
}

\author{
by
}

\section{David Paul Fernand Séguin}

A thesis submitted to the Faculty of Graduate and Postdoctoral Affairs in partial fulfillment of the requirements for the degree of

Master of Arts

In

Sociology

Carleton University

Ottawa, Ontario

(C) 2018

David Paul Fernand Séguin 


\begin{abstract}
:
Labelled the "face of the justice system" (Law Commission of Ontario 2011 as cited by the Ministry of the Attorney General of Ontario 2015d), the Provincial Offences Administration of Ontario (POA) - a regulatory system created to decriminalize minor offences - remains an understudied program and field. Addressing this gap, this thesis analyzes the politico-juridical problematizations of cost, volume, and revenue at the center of the POA and the 'modern fine's' (Bottoms 1983) construction. Understanding punishment as both a by-product and shaper of social structures (Garland 1990), it observes the dialectic role of the POA as perpetuating neoliberal structures, consequently reinforcing the Administration's monetization. Located within this regressive economic model, this study also observes the emergence of a new 'debtor prison'. In delineating the outcomes and limitations of decriminalization, this thesis calls for a re-imagining of the POA so that it may in fact achieve the proportionality it purports to pursue.
\end{abstract}




\section{Acronym List:}

AGO - Auditor General of Ontario

AMO - Association of Municipalities of Ontario

B - Billion

CAIA - Compulsory Automobile Insurance Act

CJS - Criminal Justice System

FAF - First Attendant Facility

FOI/ATI - Freedom of Information/Access to Information

FOP - Fine Option Program

HTA - Highway Traffic Act

LCO - Law Commission of Ontario

$\mathrm{M}-$ Million

MAG - Ministry of Attorney General of Ontario

MBC - Management Board of Cabinet

MCS - Ministry of Correctional Services

MSGCS - Ministry of Solicitor General and Correctional Services

MTO - Ministry of Transportation of Ontario

OAPSB - Ontario Association of Police Services Boards

OCJ - Ontario Court of Justice

OLL - Ontario Legislative Library

OLRC - Ontario Law Reform Commission

POA - Provincial Offences Administration of Ontario

ROC - Region of Ottawa-Carleton

SCRC - Summary Conviction Review Committee

SSA - Safe Street Act

WDW - Who Does What Panel

WPR - What's the Problem Represented to Be 


\section{Acknowledgements:}

Embracing my inner Foucault with a subtle Lord of the Rings reference, I am fully aware that the person (i.e., 'subject') I am today, and consequently the 'burden' I carried and 'strength' I channeled to complete this 'journey' (i.e., thesis), has and does still come from many places and people to whom I am always utterly grateful and indebted to.

Much like a fellowship that has existed over my entire life, there are countless people some whom I have known most of my life, others I simply had the pleasure of meeting once - but whom regardless have had a lasting impact on my life. Unfortunately, I cannot personally thank them all here, they mainly include friends, fellow grad colleagues, friends' parents, undergrad professors, former and current work colleagues, and high school teachers. Restricted to one page (maybe two now...), I want to nevertheless thank these people, you have helped make me into the person I am today and please know that I do not forgot the contribution you provided in helping me reach this moment. Most importantly, you are big part of the reason I have such a strong belief in the power and potential of humanity, collectivism, and people, this is an insight and debt I cannot repay but thank you for helping me find and for showing me how it can materialize.

To my thesis supervisor Dr. Nicolas Carrier, thank you for your patience, support, guidance, and mentorship throughout this process. While I have faced many challenges in writing this thesis, not to mention these last months during the 'final sprint', you have never once wavered in your support or willingness to promptly read and return my drafts with insightful comments. I have great respect for the work you do in ensuring the field of criminology and criminal justice is self-reflexive, providing important critiques that help to improve its research and consequently the knowledges it seeks to inject in the issues, debates, and challenges facing our societies. Thank you for always being there for me, words cannot express my gratitude.

To my other committee members, Dr. Jeffrey Monaghan and Dr. Steven Bittle, thank you for agreeing to be a part of reviewing my thesis. Dr. Jeffrey Monaghan, your comments, enthusiasm, and engagement with my thesis has been both insightful and significantly helped to refine it, thank you. Dr. Steven Bittle, having you as a professor while doing my undergrad in Criminology at the University of Ottawa was one of the highlights of my time there, thank you for your insight and contribution to both my thesis and critical thinking skills.

At this moment, I would like to take the opportunity to also acknowledge the contributions of various professors and administrators at the University of Carleton. Dr. Justin Paulson, Dr. William Walters, Dr. Bruce Curtis, Dr. Janet Siltanen, Dr. Aaron Doyle, and Dr. Alexis Shotwell, thank you for your mentorship, along with the knowledges and critical lenses that you have bestow upon and exposed me to, they are glasses I carried with me in this thesis and intend to use in my life going forward. Paula Whissell and Darlene Moss, thank you for all your support during this process, you guys are what make this department run and we could not function without you!

To my sisters Jennifer and Kimberly, twin brother Christopher, and mother Sharlene, what a journey our lives have taken. I want you each to know how resilient you all are and the inspiration it gave me to write this thesis and confront the many challenges we continue to face both together and individually. Chris, my best friend and twin, I have great admiration for you, your work ethic, 
and ability to reason through the various complex issues we face, while you always seem to hold me up to some higher standard, nothing could be father from the truth. You are always by my side, pushing me on just as much as I push you. Mom, thank you for your strength, courage, wit, humour, and love, as always it is unwavering and something I will always cherish.

Finally, to the most important person in my life (sorry brother), my partner, my fellow gadfly, my Buddha: Shanisse Kleuskens. Alas, I do not know what the world would be like without you. While my brain at times like Abed considers the potential of multiple timelines and the existence of parallel universes, I am fully aware that the one in which we are currently existing, your love and support - much like Samwise Gamgee to Frodo Baggins - was vital to me realizing this goal and dream, and thus, does not go unnoticed. I never imagined finding a partner who would share my love for criminology, belief in people, justice, and openness for adventure while simultaneously helping me become a better man and person, introduce me more intimately to the works of David Garland and Georg Rusche, all while being a younger yet wiser individual. I know your genealogy extends just like mine (as Foucault reminds us!), from your Kleuskens clan (i.e., sisters, parents, Nana) and beyond, but I am so proud of everything you do. I love you and cannot wait to see where our life journey takes us next.

With that said, I would lastly like to point out that I take full responsibility for any errors or inadequacies that may remain in this thesis. 
TABLE OF CONTENTS

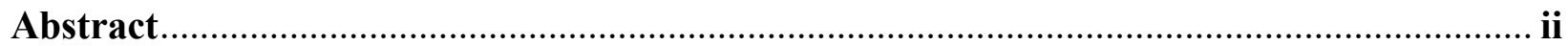

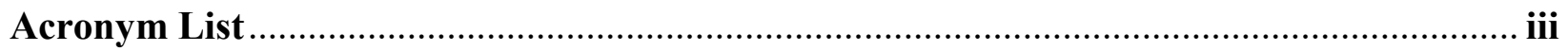

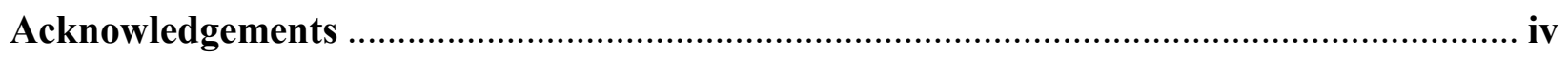

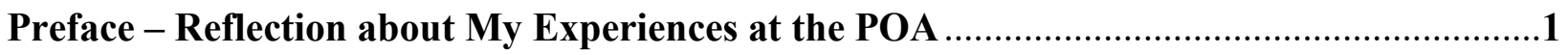

Chapter 1: Introduction - Locating the Roots of Decriminalization ........................................

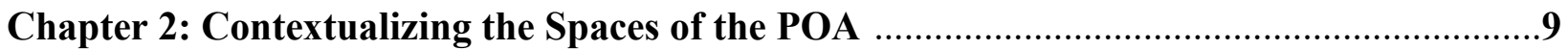

2.1 - Visions of Social Control and Punishment in the Post-Industrial Society............................10

2.1.1 - The Expanding 'Soft Machine' of Social Control - A Story of Inclusion and Exclusion....11

2.1.2 - The Capillaries of Power-Knowledges within Systems of Social Control ........................14

2.1.3 - Beyond Foucault: Social Control in the Post-Industrial City .......................................18

2.2 - Exploring the Boundaries of Punishment in the Administrative World ...............................19

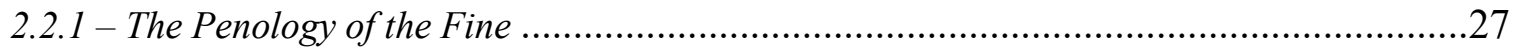

2.3 - Situating Social Control and Punishment within the Regulatory Field of Canada .................34

Conclusion: A Contemporary Map of Punishment, 'Monetized Justice', and Social Control

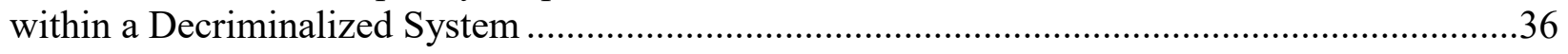

Chapter 3: Re-Orienting the Criminological Gaze into Unchartered Waters .........................38

3.1 - Adopting a Critical Criminology Framework and Pushing the Boundaries of our

'Criminological Imagination'

3.2 - Re-introducing a Sociology of Punishment with a Focus on the Study of Problematizations

Chapter 4: Methodology .50

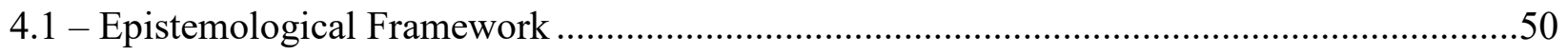

4.2 - The Search, Pursuit, and Collection of Data in Cultivating a Genealogy ..............................52

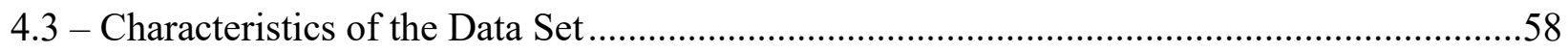

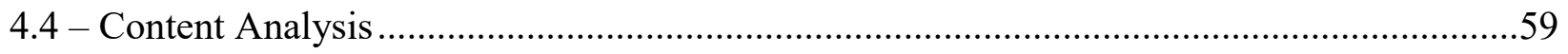

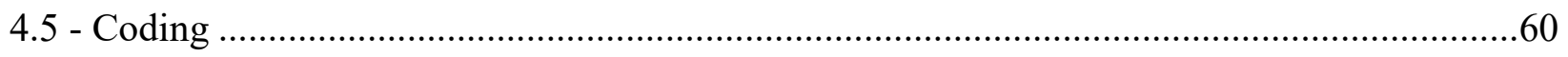

Chapter 5: The Sociology of the POA, Decriminalization, and its Problematizations ..........62

5.1 - 1977-1980: The Emergence of Administrative Justice (The Creation of the POA) .............64

5.2 - 1996-1999: The Emergence of the Redistributive Feature (The Business Case of the POA)

5.3 - 2014-2017: The Emergence of 'The Billion Dollar Problem' (The Modernization Period of the POA) 
5.4 - The Dialectic Roles of the POA, Decriminalization, and Modern Fine within our Social Structures

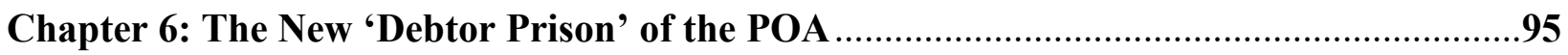

6.1 - The 'Polysemy of Punishment' and the 'Revenue Trap' in the POA...............................96

6.2 - The Construction of 'Simple' and 'Local' Justice in a Monetized System .......................103

6.3 - The 'Shadow Carceral State' of Decriminalization .......................................................106

Chapter 7: Conclusion: The Genealogy of the POA and the Unexamined Branches .........122

7.1 - The Tensions of Punishment, Justice, and Money within Decriminalization and

Administrative Sanctions

7.2 - The Limitations of this Study, Where Research Must Go Next, and Policy

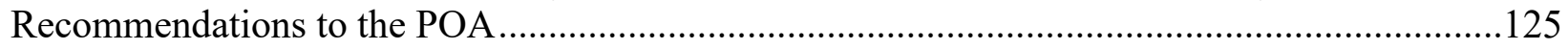

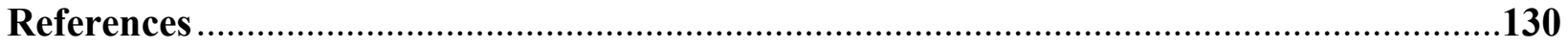

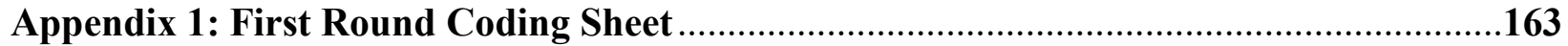

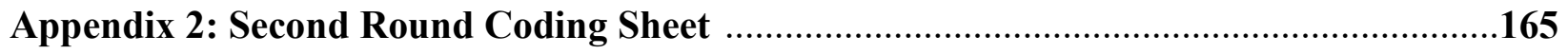

Appendix 3: Example of a POA Ticket (i.e., Certificate of Offence) ................................168

Appendix 4: Number of POA Charges with a Jail Sentence between 2004 to 2017 ..........169

Appendix 5a: Number of POA Charges with Jail Sentence (in relation to specific statutes)

Appendix 5b: Top Five POA Charges with Jail Sentences in 2017...............................170

Appendix 6: Number of POA Tickets Issued from 1995 to 2017 ....................................171

Appendix 7: Defaulted Fines Added and the POA Collection Rates from 2010 to 2018 ....172

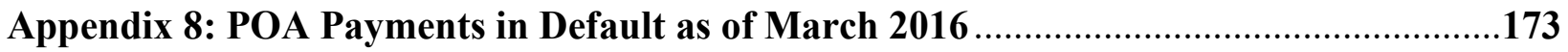

Appendix 9: Annual Number of Driver Licence Suspensions Issued for Defaulting on a

Fine from 1995 to 2016 


\section{Preface - Reflections About My Experiences at the POA}

To begin this thesis, the exploration of the Provincial Offences Administration (POA), and its model of decriminalization, punishment, and social control, I believe it important to acknowledge and situate my work in relation to my own experiences as a former POA employee.

Given both the role and responsibility of a POA City Clerk and First Attendant Facilitator (FAF) for the City of Ottawa during my seven years (2009-2016), I was exposed to many aspects of the system's operation. Considered a 'street-level bureaucrat', as Harris (2016: 124-127) frames such a position, my experiences saw me work on the front counter, the phones, and/or in close quarters, guiding persons fined through the process whether in relation to applying for court, mediation, payment plans, re-opening cases, appeals, or review parking matters. During my time, I was not only able to see the law in action, the potential cultural values imposed in its spaces, as well as the "discretionary power" (124) bureaucrats possessed, but also the latter's limitations. Coming from a critical criminology background, I saw how this system and its model, through the experiences of those being the object of the POA and its employees' judgement and scrutiny, was potentially failing to serve them. Whether through rigidity in our sanctions, in extensions or reopening applications, in employees' perceptions of sanctioned people and their cases, and/or in other policies and practices, it seemed clear to me that the POA system was neglecting them and that my ability to aid people within its structures would be limited by various forces and factors.

Yearning to discern more intimately what some of these factors and forces were, I turn to writing this thesis. Aware that not all of them could be studied, my research focuses on connecting my time at the POA with the macro social structures and genealogy shaping its model and practices. That said, this research and its interpretation is only one part of the story, greater focus is needed if we are to gain greater insight and comprehension into outcomes of punishment within 
decriminalization. As Garland (1990) once said, in creating and implementing penal policies we are not solely determining how we deal with marginalized individuals, but also "defining ourselves" (276), including the form and type of social relations we have with one another (271). Taking inspiration from this apprehension of punishment, I now turn to this thesis's body of work.

\section{Chapter 1 - Introduction: Locating the Roots of Decriminalization}

"[11] Mr. Jaques is not the first person in such a situation to come to this court in order, as he put it, to "beg for mercy". He plainly deserves it, but I cannot grant it. The legislative scheme offers no way out for people who are impoverished, dealing with health issues or other difficulties, and who bear the burdens of these enormous fines for many years. It is most unfortunate that there is no process in the system for commuting old and backbreaking fines for people who have little prospect of paying them, and whose lives are being ruined. Perhaps it is time to consider a quasi-bankruptcy scheme for people in Mr. Jaques' unfortunate position."

- Written decision by Justice Peter Lauwers after defendant appeals for aid on driving offences in Ontario (R. v. Jaques [2015])

By employing a sociological imagination, where the objective is to connect people's

personal troubles to the social structures around them, including the unveiling of their plights as wider 'public issues' (see Mills 1959/2000), Mr. Jaques's personal story (and personal troubles) provides a plethora of dimensions to deconstruct, sketch, and define.

To begin, Mr. Jaques's cases, which comprise mainly of driving-related offences, fall under the Provincial Offences Administration of Ontario (POA). Offences covered under the POA include those outlined in the Highway Traffic Act (HTA), Compulsory Automobile Insurance Act (CAIA), Liquor Licence Act, Safe Streets Act (SSA), municipal bylaws (e.g., noise complaints, parking tickets), and also those largely regulating corporations, such as the Occupational Health and Safety Act, the Environmental Protection Act, and the Employment Standards Act. 
Created in 1979 under the Provincial Offences Act (referred to as the Act going forward), the POA was (and continues to be) envisioned and constituted as a "less rigid and formal" administrative process than the Criminal Code of Canada, one that removes "assumptions about crimes and persons who commit them", as the stigma was deemed inappropriate for " $90 \%$ of the provincial offences"; provincial offences under the Act, proscribed in many cases as "public welfare offences", govern activities that are mostly considered "legal...[and] useful to society", such as driving, and thus merely needing to be regulated (McMurtry as cited in Ministry of Attorney General of Ontario [MAG] 1978a: 1).

A regulatory model that exemplifies a form of decriminalization ${ }^{1}$, the POA's main tool to 'regulate' these activities is an "out-of-court fine" (Ontario Association of Police Services Board [OAPSB] 2011: 6), with the option when consider warranted (due to the serious nature ascribed to an action and/or failure to comply under the Act) of imprisonment or a summary notice for a mandatory court appearance (Law Commission of Ontario [LCO] 2011: 2). The POA's out-ofcourt-fine embodies Bottoms's (1983) concept of the "modern fine" (see also O'Malley 2009a, 2009b, 2010a, 2011, 2013), which refers to systems of penality that shift away from imprisonment as the "default mechanis[m]" when fines go unpaid as occurred in the $19^{\text {th }}$ and $20^{\text {th }}$ centuries (see Bottoms 1983: 201, footnote [fn.] 7; Rusche \& Kirchheimer 1939/2003: 169).

In fact, prior to the POA's creation, fines were processed under the Summary Conviction Act (SCA), which commonly saw people jailed for defaulting on a fine. According to data obtained, as late as $1977-78$ and $1978-79$, there was between 16,000 to 19,000 annual fine-default admissions to Ontario jails (see Ministry of Correctional Services [MCS] n.d. as cited in McMahon

\footnotetext{
${ }^{1}$ As one record explicitly states: "The POA was enacted in 1979 to decriminalize minor regulatory offences by replacing the Summary Convictions Act procedure" (Elliot 1996: 4, emphasis added).
} 
1992: 135 and Smith, McGuire, O'Gorman \& Walker 1978: 10). Described in the province's own records as "a symbolic relic of [the] debtor's prison" (Summary Conviction Review Committee [SCRC] 1977a: 19) and "the cause of many an administrative headache" (Smith et al. 1978: 2), including the price tag that came with it (SCRC 1977a: 19), the purported "desire" behind the POA, according to Ontario's Attorney General upon introducing its legislation, was the "recognition" and "reroute[ing]" of the former approach (i.e., SCA) by putting forward "bold" and "imaginative measures" for a system in "urgen[t] nee[d] [of] reform" (McMurtry 1978a).

More specifically, outlined under the POA's "basic thrust", the goal became to both prevent fines from going into default (MAG 1979: 127) as well as eradicating "the taint of the debtor's prison" (MAG 1978a: 14). To do so, the POA established (and continues to add) a diverse set of fine enforcement tools and strategies including: suspension of license, revoking the ability to renew one's license plates, lower credit rating, additional fees and costs (e.g., default fee, court costs, collection agency costs, reinstatement fee $^{2}$ ), garnishment of wages, collection through municipal tax rolls or collections agencies, as well as other sanctions such as demerit points and a hike to one's car insurance. In the case of Mr. Jaques, many of these tools were imposed, including the inability to get a "record suspension for unrelated charges" until the payment of approximately $\$ 10,000$ in fines was completed (R. v. Jaques 2015).

As the Justice points out, the story of people like Mr. Jaques who 'plead for mercy or leniency' to the court as a result of the burden placed by 'enormous fines' is hardly uncommon. In fact there are over 3 million cases currently in default (Ontario Court of Justice [OCJ] 2018a) totalling close to $\$ 1.4$ billion ['B'] (MAG 2016a), a total that accounts for several mandatory fees

\footnotetext{
${ }^{2}$ To give the reader an example of such a fee, when your driver's licence is suspended, to reinstate it, you have to pay a fee of $\$ 198$ (see MAG 2017a); an amount that recently increased within the last couple of years from $\$ 150$ where it mainly stood when I was working there.
} 
an offender must pay (i.e., default fee, court cost, victim fine surcharge, and collection agency cost) while also omitting other costs (e.g., insurance and credit ratings, licence suspension and reinstatement fee, to name a few). Digging further, "recent data" shows that over $75 \%$ percent of these defaulted payments have largely come about within the last decade (Bovdis 2017) and are almost exclusively attributed to Ontario residents (91\% according to OASPB 2011: 9). Referred to by the OASPB (2011) as the 'Billion Dollar Problem', a situation now commonly discussed in municipal and provincial governments (e.g., Greater Sudbury ['Sudbury'] 2017; MAG 2016a) and news articles (e.g., Jones 2017a; Pelley 2018), the illustration first coloured by Mr. Jaques's 'personal troubles' is now gradually being traced to a larger 'public issue'.

By placing this illustration and 'public issue' within its greater setting, sociologists and criminologists alike have only begun to delve deeper into spaces such as the POA, particularly as they relate to monetary sanctions as well as alternative forms of punishment (e.g., Chesnay, Bellot, \& Sylvestre 2013; Harris 2016; Zedner 2016), the 'regulatory state' (e.g., Braithwaite 2003; O'Malley 2013), and systems of decriminalization (e.g., Natapoff 2015a, 2015b). From this research, a complex picture is emerging that is beginning to destabilize the fixed essence of decriminalization as a "progressive penal reform" (Natapoff 2015a: 1060), succeeding in mitigating the "punitive logics" (Velloso 2013a: 167) that continue to trouble criminologists in familiar spaces such as carceral institutions and the criminal justice system (CJS) more broadly.

Having said that, the sketch and public issue that has arisen in the POA, with Mr. Jaques as one of its many branches, has only started to be fully explained and/or understood. An issue caused in part due to neglect of this field going back decades (i.e., fines, but also decriminalized systems) (see Bottoms 1983; Velloso 2013a; Young 1987), and research focusing on specific aspects of these spaces, whether corporate crime (e.g., Bittle \& Snider 2015; Glasbeek 2002; 
Snider 1993), homelessness (e.g., Chesnay, et al. 2013; O'Grady, Gaetz, \& Buccieri 2013; Valverde 2012a), or monetary fines in the CJS (e.g., Hampson 2016; Harris 2016; Harris, Evans, $\&$ Beckett 2010, 2011), this thesis takes up this endeavour of examining the 'public issue' of the POA, while also situating and connecting its findings to these other important studies.

To trace the lineage of the POA's decriminalized model, its use of the modern fine, and the 'Billion Dollar Problem' (i.e., public issue), my study 'descends' upon the roots of the POA through a genealogy. Locating 'emergences' that shape(d) and form(ed) its approach to punishment and justice, thus producing "a history of the present" (Foucault 1977: 31) of the POA, this thesis poses the following question:

To what problems is the POA a response? How have these problems emerged and been constituted within the provincial government of Ontario?

Subsequently, to address my main research question, I ask the following sub-questions:

What role does these configurations contribute to the regime of punishment and justice established within the POA? What subsequent outcomes does this system and its approach produce?

Coloured by a sociology of punishment (see Garland 1990) and study of problematization (see Bacchi 2009, 2012), my questions and study discern the knowledges and discourses embedded into the policies and practices of the POA. The larger objective of this research is to discern how the public issue of the Billion Dollar problem came to be, how social structures have shaped the functions and purposes of punishment, decriminalization, and justice, and lastly, how decriminalized models of penality such as the POA are fairing (or failing) in transforming justice and punishment into "anti-penal" (Velloso 2013a) or "progressive" (Natapoff 2015a) systems regulating society as many argue or believe to be currently the case.

To commence this voyage, I begin in Chapter Two by exploring the existing boundaries constructed by various bodies of literature on the subjects of social control, punishment, the fine, 
and regulatory systems, while also showing gaps that remain to be addressed, including those in relation to the POA and its system of punishment. Following that, I turn to my theoretical framework (in Chapter Three) and methodological approach (in Chapter Four), to illuminate my adoption of a critical criminological framework and post-positivist methodology that continues the 'radical' traditions of critical criminology (see Doyle \& Moore 2011). This thesis extends critical criminology's margins by exploring and (de)constructing knowledges and discourses about punitive spaces and systems that are yet to be fully understood (i.e., the POA and its version of the 'modern fine').

Starting off my analysis section in Chapter Five: The Sociology of the POA, Decriminalization, and its Problematizations, my study first explores the problematizations at the center of the POA. Reviewing records from its creation in 1979, its transfer to municipalities in the late-1990s, and its 'modernization' era today (i.e., 2014-2017), this chapter examines the central problems found in POA's discourses and policies that contributed to the construction of its knowledges, rationalities, and practices. I illustrate how the POA is largely shaped by economic problematizations and reveal how the phenomenon of decriminalization is principally "a kind of regressive economic policy masquerading as progressive penal reform" (Natapoff 2015a: 1060), which in turn shapes the purposes and objectives of the POA, including its model of punishment and social control. In the end, this chapter concludes by juxtaposing the "master changes [i.e. patterns]" (see Cohen 1985) of the POA with the various social structures (e.g., neoliberal political economy, biopolitical system of governance) and other social forces (e.g., rise of the automobile, issue of circulation) to have influenced the form the POA and the modern fine have taken. Understanding punishment and its systems to be both a shaper and shaped by its social environment (Garland 1990: 22), this chapter also illustrates and argues that the POA and modern 
fine have played an active role in perpetuating, preserving, and helping to create those very same structures that contribute to their definitions.

My final analysis chapter, Chapter Six: The New 'Debtor Prison' of the POA, examines both the discourses shaping the "polysemy of punishment" (see Walby \& Piche 2011) and construction of the notion of 'simple' and 'local' justice found within the POA's model of decriminalization. Taking from previous chapters, this one discerns their roles as primarily shaped by a "revenue trap" (Natapoff 2015a: 1098), with punishment reduced to its redistributive feature, while the end, justice, is centered on establishing a 'cost-effective' model for its administrators, not sanctioned individuals themselves. Following that, this chapter then examines how the "values, meanings, and conceptions" (Garland 1990: 225) within discursive practices are realized (or not) in the POA's outcomes. In the end, it concludes that the POA's decriminalization model, which was constructed with the objective of eliminating its debtor prison and preventing fines from going into default, is largely failing to achieve these goals. Instead, guided by the economic problematizations, master patterns of the POA (examined in Chapter 5), and its conceptualization of punishment and justice (examined in Chapter 6), the POA is creating its own form of a "shadow carceral state" and "subterranean politics" (Beckett and Murakawa 2012), as its approach to penalization ${ }^{3}$ leads to a higher number of people entrapped into the POA's "tentacles of penal power" (222) through various forms of incapacitation (e.g., driver licence's suspension, lost of insurance due to increase, lower credit rating, to name a few).

\footnotetext{
${ }^{3}$ To define this concept, the term itself is taken from Chesnay et al. (2013) work, who utilize it to discuss the current trend happening in public spaces in Canada, where regulatory systems of law - municipal bylaws, provincial and federal statutes - are becoming the "primary normative punitive system in the resolution of conflicts" in place of the CJS (163). As they explain, these systems and their sanctions may not necessarily result in incarceration, but still can be equally punitive for many (ibid.). In the end, as Velloso (2013a) adds, the phenomenon of "criminalization...[is] too attached to crime-related references" (178); thus, to discern the unique processes and 'punitive logics' at work in regulatory systems, such as the POA, the term penalization is used throughout this thesis.
} 
Exploring Young's (1987) notion of a "state of permanent tension" between money, punishment, and justice, this thesis concludes by considering the potential "disenchantment" and "estrange[ment]" of justice and punishment found within the POA due to its central focus on monetization, mainly critiquing its inability to meet or fulfill a "regulatory cycle" (Libman 2012a; Verhulst 2008) or "simple justice" model it visualized for itself (see Cohl et al. 2015: 148). Furthermore, in the end, this thesis argues and paints decriminalization as a "complex and conflicted regulatory strategy" (Natapoff 2015a: 1107) that has many limitations yet to be adequately addressed or studied. Consequently, this thesis outlines where research must (and can) go next, provides policy recommendations, while also addressing limitations to its study.

Overall, with these forms of penalization or decriminalization becoming ever more common, whether in relation to regulating marijuana (Cain 2017a; Jones 2017b), the behaviour of 'distracted pedestrians' (CBC 2017), or a move away from the "overly punitive and costly" mass incarceration schemes of the past or present (Natapoff 2015a: 1104), systems such as the POA must be further studied and better understood. As one op-ed states about the POA: "[i]t's time for a public conversation" (Mukherjee 2018), this thesis contributes to that conversation.

\section{Chapter 2 - Contextualizing the Spaces of the POA}

To better comprehend the POA system, along with the potential negative consequences faced by people within it, it is imperative to analyze the literature discussing the main fields related to systems such as the POA. For that reason, in this first section of this chapter, I examine the literature on the concept and theories of social control while situating these discussions within current debates as to where and how social control is constructed and the components - risk, danger, and law - that produce its 'order' within contemporary society. Following this section, I 
then explore the literature on punishment, the fine, and the regulatory system, locating the role these components play in shaping legal administrative systems like the POA.

\section{1 - Visions of Social Control and Punishment in the Post-Industrial Society}

A concept used in "diverse ways" (Horwitz 1990) with a "rather mixed lineage" (Blomberg \& Cohen 2003: 1), the study of social control has consisted of various discussions, theories, and debates over the establishment and "creation of norms, processes of adjudication and sanctioning" along with the pursuit of "broader societal guidance, integration and ordering" (Marx 2007: 347)". While many thinkers have focused on the 'consensus' role social control plays in either protecting society's moral order (see Durkheim 1893/1984), how forms of rationalization help to legitimate the state's authority over its citizens (see Weber 1920/1978), or its evolution from a "norm[ative] structure" to a legal system that implements "continuity" and "security" in social interactions (see Ziegert 1980), other critical theories have focused on other facets of the role and function of these systems.

In the latter theories, formed by Marxists, sociologists, criminologists, and sociologists of deviance alike, they observe social control systems in many cases to be inherently coercive or oppressive in the order they help preserve and/or establish. Described also as conflict theories, they analyze the institutions, processes, and various social forces - economic, political, and cultural - that construct the ontologies of deviance, stigma, crime, and illegalities at the center of social control systems (see Becker 1963; Blomberg \& Cohen 2003: 4-7; Matza 1969). In the end,

\footnotetext{
${ }^{4}$ There is a wide-range of existing literature about the concept of social control. Research in this field includes studies about: formal social control systems (e.g., medical institutions, schools, welfare system, legal and regulatory institutions), informal social control systems (e.g., family, community, transportation systems), their relationship(s) to informal regulations (e.g., shaming, staring, avoiding), formal regulations (e.g., law, fines, incarceration), as well as the role of technology in their realization (Byrne \& Rebovich 2007). Due to the vast diversity in this area of study, the review of the literature for this thesis focuses largely on the concerns related to its research project: the administrative system of the POA. For those wishing to examine some of these different areas more widely, please refer to Bereska (2014), Chriss (2007), or Edwards (1988).
} 
their studies conclude that deviance did not lead to nor create social control, but rather, they assert that it is social control itself that creates deviance (Blomberg \& Cohen 2003: 4; Pfolh 1994)5.

Although these social control theories were vital in countering and deconstructing some of myopic analyses provided by 'consensus' theorists, the complexity of modern Western democracies and their dichotomies "of force and authority, of regulation and liberties, of coercive habit and legitimate consent" (Hall \& Scraton 1981/2005: 393) were only beginning to be analyzed more rigorously. While this thesis contributes to the literature developed from conflict theories, it first turns to two theorists who pursued these issues and revolutionized our understanding of the “ideologies, master patterns, strategies, tactics, [and] alliances” (Blomberg \& Cohen 2003: 6) still relevant to studies of social control today: Stanley Cohen and Michel Foucault.

\subsection{1 - The Expanding 'Soft Machine' of Social Control - A Story of Inclusion and Exclusion}

Exploring the "fragmented, abstracted" micro-studies of various systems of social control (i.e. prisons, police department, mental hospitals) existing in "the density of urban life" during the 1960s and 1970s, Cohen (1979) sought to locate the similarities found within their emergence and establishment (340). Providing such a macro analysis to the ethnographic studies, his research placed the social control systems within the "overall social space", comprised of locating the "master patterns" (340) that shape, produce, and create them, as well as giving insight into how deviant categories are constructed, established, and implemented.

In examining the "master changes in deviancy control", Cohen (1985: 16-17) argues that the "original [master] patterns" of the $19^{\text {th }}$ century - rationalization, centralization, segregation, classification - were in many cases simply extended, intensified, and further enmeshed in the

\footnotetext{
${ }^{5}$ Many criminologists attribute these forms of inquiry as the starting point for where the "New Criminology" wave (see Taylor, Walton, \& Young 1973) was established as well as the starting point for the field of critical criminology (see Hall \& Scraton 1981/2005; Young 2011: 212-218).
} 
1960s (37). Proscribed as the "dispersal of social control" (Cohen 1977: 227) or the emergence of a "punitive city" (Cohen 1979), these new patterns consisted of a dispersal of social control systems that penetrated, blurred, and became absorbed into the "carceral archipelago" (360). Observing these patterns as creating a form of "net-widening" or "thinning of the mesh", arising also in various diversion or community-based programs, Cohen believed these social control models to be masking and blurring "their most coercive intentions and consequences" as the "principle of "indefinite discipline" became the "new mode of control" (350-360). In short, the decarceration movement of the 1960s appealed more to the "soft ideology of community absorption" while preserving the system's "more punitive objective of restitution and compensation" (357); thus, instead of people exiting the 'machine' governing our systems of social control, the latter simply expanded, entangling more individuals in its net.

Since Visions of Social Control (1985), other criminologists have attempted to situate Cohen's work within currents trends and systems of social control. Some scholars, including Pratt (2002) and Lianos $(2000,2003)$, have pointed out that contemporary social control systems within Western post-industrial societies have largely been internalized and accepted by citizens, despite their growing expansion and intrusion in their everyday lives. As Pratt (2002) argues, "the electrification and computerization of increasing areas of everyday life" (173), including its growing role in surveillance and security, has been of relatively little concern to most citizens, and in many cases, is even desired.

Moreover, as Lianos (2000) points out, the evolution in systems of social control is not initiated by the CJS, but is produced and promoted by the economy and state as a "means of perpetuating existing social structures [i.e. a competitive and limitless consumer capitalist system] and the supremacy of the First World" (264). In other words, the systems of social control that 
establish social order in society are driven by the needs in a capitalist society, and therefore subsequently by the state and its citizens, to eliminate all potential risks and danger within it. Overall, explanations of social control as a dark sinister force imposed by the state and the criminal justice apparatus have been "overrated and overestimated" (Pratt 2002: 173), which in case of Cohen's work, still paints an incomplete picture of the relationship(s) between systems of social control to the general public in Western societies.

Notwithstanding its limitations, Cohen's analyses are still widely used to discuss the concerns facing our contemporary systems of social control and punishment. This includes, but is not limited to: the potential 'net-widening' rather than reduction of the 'soft machine' of social control (see Cohen 1979: 350), the masking or concealing of "new forms of punishment" and social control (see Moore \& Hannah-Moffat 2005), as well as the labeling of deviants, risks, and danger to society and the order social control systems supposedly establish. Studies by Velloso (2013a, 2013b), Harris, et al. (2010, 2011), Beckett and Murakawa (2012), Hermer and Mosher (2002), Chesnay, et. al (2013), and Moore and Hannah-Moffat (2005) all explore how current systems of social control and punishment materialize in various ways, effects, or 'patterns' mirroring what Cohen was concerned with. Thus, although the critiques raised by Pratt (2002) and Lianos $(2000,2003)$ contain nuances to consider in analyzing the drivers of systems of social control, Cohen's work remains relevant in examining the forces shaping them today ${ }^{6}$.

Keeping these various factors in mind, this research explores one component of the 'soft machine' of social control: the regulatory administration the POA and its 'hybrid' punishments, including monetary fine(s), demerit point(s), lower credit rating, garnishment of wages, license

\footnotetext{
${ }^{6}$ In fact, Pratt (2002) acknowledges this point in his critique of Cohen's work saying: "even the most administrative of administrative criminologists overseeing penal policy development is almost certainly going to be conscious of the way in which their careful planning is likely to be subverted by the 'net-widening' tendencies" (168)
} 
plate denial(s), license suspension(s), and increases in car insurance premiums. Troubled by the POA's potentially 'net-widening' features, this thesis explores this regulatory system's emergence, exploring its distinct 'forms' of punishment and the potential rationalities or logics governing their existence. Unlike Cohen's Vision of Social Control (1985), I divert from examining social control in the context of the prison and the "criminocentric dogmatism" (see Velloso 2013a, as discussed in the next chapter) argument that it is "the paradigm for understanding the whole picture" (Cohen 1985: 15), instead shifting its 'vision' towards another penal system yet to be adequately studied'. To further discern and delineate the 'master patterns' operating within the POA's system of social control, I now turn to work of Michel Foucault to grasp the various knowledges and power relations that have underlined the systems of governance, social control, and punishment in Western societies.

\subsection{2 - The Capillaries of Power-Knowledges within Systems of Social Control}

Importantly, Cohen's work takes inspiration from Michel Foucault, whose contributions revolutionized the fields of criminology, justice, and governance studies through his analysis of power, knowledge, subjectification, and social control (for contemporary examples see Lyon 2006; McNay 2009; Staples 2014). Foucault's (1991) object of research focuses on how society is governed through a "production of truth" that formulates a binary of what is considered 'false' and 'true' (79). These truth regimes subsequently establish forms of rationalities and knowledges that themselves produce forms of power relations that govern and shape individuals. Power, in this case, is productive not repressive, wielded through knowledge to form power-knowledges, which

\footnotetext{
${ }^{7}$ To be fair, Cohen does acknowledge this point in part in later work with Blomberg (2003). In it, they argue that the notion of 'alternatives' punishments and/or systems of social control is largely a misnomer that conceives the criminal law as "the normal method of social control" when in actuality the latter's model and approach is the true 'alternative' model (7).
} 
shape our social order and thus possibilities for ways of being, thinking, and acting in it; this configuration is referred to as the process of subjectification in which we as subjects are formed.

While a lot of attention and focus is spent on Foucault's (1977) work in Discipline and Punish, which examines the construction of a "micro-physics of power" (26) (i.e., disciplinary power) found in various systems of social control (e.g., prison, bureaucracies) along with the dividing practices (e.g., mad/sane, deviant/law-abiding) and internalization by subjects they help establish, his later works provide critical nuances and expansion to this initial study. As Foucault (2007) clarifies in Security, Territory, Population, one should not assume that power relations remain static, nor do societies cleanly shift from an age of sovereignty to a disciplinary age and into another one ${ }^{8}(8)$. With new knowledges, problematizations (see Bacchi 2012, as explored in the next chapter), forms of classification, agencies, and institutions emerging, they concurrently establish a different regime of governance that sees practices, techniques, and power relations simultaneously change, transform, and maintain themselves through a "series of complex edifices" (Foucault 2007: 8).

Best exemplified in his later works, Foucault $(2007,2008)$ addresses the relationship between the state and its citizens, characterized by Gordon (1991) as the "macrophysics of power" (4). These works examine power-knowledges that are both interrelated and go beyond the "microphysics" or disciplinary mechanisms in Discipline and Punish (1977). To do so, Foucault (2007) focuses on a new "art of government" (100) that relates to the "emergence of the problem of population" (104). With this emergence, new categories and forms of statistics arise, including the birth of "political economy", as the focus of governance shifts from the family to the "multiple

\footnotetext{
${ }^{8}$ To clarify, what is meant here is simply that civilizations do not completely transition from one form of governance to another. Disciplinary practices and power relations cannot and do not completely replace sovereign ones, nor has either been completely removed. Instead, powerrelations in society, whether disciplinary, sovereign, or combinations of the two with potential others, have and are constantly changing.

${ }^{9}$ According to Foucault (1991), the notion of 'political economy' is a technique of intervention that sought to establish "an economy at the level of the entire state" (92). Seen as an "essential issue in the establishment of the art of government", this meant creating a production apparatus that
} 
network of relationships [existing] between the population, the territory, and wealth" (106). As a result, new knowledges and power relations form a "regime of multiple governmentalities" within the state (Foucault 2008: 77), encompassing a range of political and economic problems that become the "first objects of knowledge" regimes target to obtain control of the population (Foucault 2003: 243).

For Foucault (1991), governmentality is defined as an "ensemble formed by institutions, procedures, analyses and reflections, the calculations and tactics, that allow the exercise of this specific albeit complex form of power" (102). It includes various "mentalities" or technologies of powers that emerge, including the rise of "biopolitics" in society. With an aim that is regulatory rather than disciplinary, a biopolitical government sees the population as "the end and instrument of government rather than as the sovereign's strength" (Foucault 2007: 105). This manipulated population, aware of its desires and wants, is simultaneously unaware "of what is being done to it" (105). Overall, biopolitics is best described as the "politics of life" (Valverde 2007: 175), where the objective is to maximize or extract as much from the population (e.g., maximize birth rates, lower mortality rates); consequently, a state of "regularity" becomes established, creating a form "homeostasis" for the optimization of life (Foucault 2003: 246).

Alongside biopolitics, is the emergence of the 'mentality' of "security", specifically "security of population" (Collier 2009: 88), a key technology of power in the $19^{\text {th }}$ century. As Valverde (2007) states, cities under this security model are "less concerned to establish visually appealing grids of authority and instead work with probabilities, rates and risks" (174; Foucault 2007: 19). Thus, institutions such as the police are to govern themselves and their subjects based

would also serve as "a form of surveillance and control" (92) in which "the human body [is conceived] as a resource to be exploited in the process of production" (De Giorgi 2013: 42) to establish order within the sovereign state. 
on the "regulatory principle" (Foucault 2008: 147), one that bridges and transforms older sovereign and disciplinary practices within these "newer practices of (state) risk governance - including biopolitics" (Valverde 2007: 164) ${ }^{10}$. The result of these evolutions in power relations and governmentalities is not only the merger of technologies of discipline, regulation, and security that comprises the entire space between "[the] body and population" (Foucault 2003: 253), but also tactics (i.e. mentalities) which the continuity of the state relies and exists upon (Foucault 2007: $109)^{11}$.

Overall, Foucault's body of work is one that paints a complex and nuanced picture of how systems of governance and social control, through both state and non-state apparatuses, emerge, evolve, and establish themselves in our societies. Describing Foucault later work as a "history of technologies" or "form of topological analysis", Collier (2009) observes its approach as one that examines how old and new forms of reasoning, practices, or techniques (re)combine and become deployed within a specific sector (e.g., transportation) to "historically situated problems" (89-91, 99). With this in mind, this study analyzes the POA as a 'history of technologies' locating and discerning the various 'political rationalities' and other 'mentalities' (99) that coalesce and configure within this administration and its mode(s) of social control and punishment. Before delving into the literature on punishment, I briefly examine the more contemporary literature exploring systems of social control that goes beyond the work of Michel Foucault and considers the composition of these systems within a post-industrial society.

\footnotetext{
${ }^{10}$ As explored in the work of other sociologists, whether in relation to techniques of hierarchical observation (Packer 2003), normative judgements or forms of normalization (Valverde 2007), or micro-penalties (Hunt 2006), each study is able to locate practices and systems which still possess certain forms of disciplinary knowledges. As Foucault himself explains (1977), while such models and approaches may be different they are not "incompatible" (199).

${ }^{11}$ One example from criminology that discusses many of the trends Foucault refers to is in Garland's (1996) The Limits of the Sovereign State. Garland observes how the state, to maintain its legitimacy and sovereign power over its territory, is forced to adjust its crime or social control strategies and practices (i.e. governmentalities) which take on a schizophrenic character that responsibilizes citizens on the one hand while also severely punishing those apprehended. This demonstrates an interaction between disciplinary, security, and sovereign power relations take place in order for the state to preserve its role and place in society.
} 


\subsection{3 - Beyond Foucault - Social Control in the Post-Industrial City}

With Foucault's work looming large over social control research even today, many academics have since attempted to either expand his ideas (e.g., Hunt 2006; Packer 2003; Staples 2014), go beyond them (e.g., Lianos 2003), or do a little of both (e.g., Boyne 2000; Lyon 2006) in order to understand how contemporary systems are instituted and arranged.

With factors that include the rise of technologies (see Lianos 2000, 2003, 2010, 2012), emergence of new political regimes and/or bureaucracies (see Bottoms 1983), and the "cultural face" of Western society (Staples 2014: 35), the configuration of social control in our contemporary societies is becoming increasingly dispersed, technological, automatic, local, and impersonal. Whether creating "microtechniques of discipline" through biometrics or CCTV (Staples 2014) or establishing a "hyper regular" form of biopower (Lianos 2012: 37) through automated socio-technical environments (e.g., ATMs, turnstiles, access cards) (21-22), these emerging social control tools are largely being guided by institutional systems of management, efficiency, and administration (Lianos 2013: 72; Staples 2014: 35).

Taking up Cohen's (1985) "different theoretical agenda" at the end of Vision of Social Control of seeing the "real force of social control" as lying outside the state (272), Lianos (2013) observes its source as lying within the "socioeconomic dynamics of contemporary capitalism and the individualistic tactics that this dynamic generates" (2). With the state's influence continuing to wither through a neoliberal capitalist model, this produces not only a void in security, but also a growing fear of danger as citizens must find ways to 'self-regulate'. From this fear, control is sought and a mutual reinforcing relationship established, as social control techniques in turn become focused on eliminating danger (Lianos 2000, 2003) and/or preventing deviance (Staples 2014: 199) before it arrives. Proliferated through privatization (Lianos 2012) and the growing 
rationalization of society through bureaucracies (Staples 2014; see also Bottoms 1983), social control today is a highly fragmented, yet organized system defined by "the structures of late capitalism" to create a normativity that preserves and perpetuates the latter (Lianos 2010: 80).

Formed under these conditions, social control research today must focus on the outcomes of these systems rather than continue to always search for motives, as these technologies are largely devoid of any such moral or value-laden features (Lianos 2003: 422-424). Simultaneously however, as Lyon (2003) importantly adds, research must also consider how contemporary social control systems may be supporting the process of "social sorting", where inequalities are potentially being reinforced by surveillance practices and the construction of danger or deviance.

Taking up these ideas while delving further, questions also arise as to the impact these contemporary transformations (i.e., from social control systems and the social structures that established them) have on current systems of punishment, including administrative ones. For starters, how do the structures of 'late capitalism' as well as the forces of managerialism and efficiency effect the form punishment takes, including the 'political rationalities' that emerge within an administrative model (e.g., the POA)? It is under and with this inquiry that I now turn to the literature on punishment and the fine.

\section{2 - Exploring the Boundaries of Punishment in the Administrative World}

To further examine some of the gaps located in the social control literature, I now turn to a discussion on the role of penality ${ }^{12}$ within our contemporary systems of social control. As Canton (2017) argues, sociological inquiries ought to ask: "why punishments take the form that they do" (9). This study pursues these lines of inquiry, understanding as others have (see Garland 1990;

\footnotetext{
${ }^{12}$ Throughout this chapter, the use of the term 'penality' and 'punishment' will be used interchangeably.
} 
Sparks 2003) that these institutions of punishment and social control are "exemplary sites" (Blomberg \& Cohen 2003: 7) to examine macro-trends and their influences on society.

As Zedner (2016) points out, the definition of punishment is one that is widely contested. This is due in part to the multiplicity of meanings and purposes that can be attributed to the concept and the various processes - law-making, administering penalties, conviction, sentencing symbols, images, rituals, and discourses that comprise it $^{13}$. This however has not prevented scholars from attempting to define the boundaries, core, and scope of punishment and its social, political, cultural, and economic processes (see Canton 2017; Hannah-Moffat \& Lynch 2012; Valverde 2012b; Zedner 2016). For Sparks (2003), punishment at its core is: "both a severely practical matter and a thoroughly expressive one" (21, emphasis added). Put differently, referred to also as the "two faces of punishment" (Sparks, 2003: 22) punishment and the systems that govern its direction are a negotiation between governments' task of regulating and ordering both society and the passions as well as emotions of subjects within it that might mobilize in response to unwanted acts and behaviours (22). These observations are also similarly located in the work of other scholars, who define and describe punishment or its "fundamental elements" (Zedner 2016: 6) as: an expression of censure and "imposition of hard treatment on the offender" (Ashworth \& Zedner 2014: 14), a mechanism to establish authority by the state (Canton 2017: 31), and/or a form of sanction that is "intended to be burdensome and painful" (Duff 2001: xvi-xv).

This dialectic of punishment, as an expression of moral emotions (Canton 2015; Haidt 2003,2012 ) and a practice managed, rationalized, and administered by the state, is one that is also explored in macro-theories of Garland's "culture of control" $(2001,2003)$ and Simon and Feeley's

\footnotetext{
${ }^{13}$ As Brown (2009) points out: "penal meanings will always be plural and tricky to harness" (212), a challenge criminologists and sociologists are left to grapple with. For an example exploring the "polysemy of punishment", please refer to Walby and Piche (2011).
} 
"new penology" $(1992,2003)$. Similar to theories of social control discussed in the previous section, each analysis seeks to situate the transformations of punishment within the economic, social, cultural, political, and historical forces of the periods of modernity (late $19^{\text {th }}$ century to the end of the $20^{\text {th }}$ century) and postmodernity (mid- $20^{\text {th }}$ century to present).

For Garland (2001), the transformation of punishment into its contemporary form revolves around the "crisis of penal modernity" that emerged in the mid-1970s from the decomposition of "the "penal-welfare structure" (27), a system guided by the welfare state whose central objective was to 'correct' and 'rehabilitate' offenders. According to Garland (2001), the establishment of a market and moral discipline emerges around the 1980s from various neo-liberal and neoconservative policies, helping to form a new "culture of control" that is retributive, risk-oriented, and responsibilizes individuals to protect themselves (196-199).

In contrast, Simon and Feeley $(1992,2003)$ describe many of the shifts explored by Garland as a part of "new penology". Rather than changes being rooted in the morality of the old penology or within 'modernity', they contend that the character of modern punishment and its 'new penology' materializes as a result of its growing managerial features. This sees punishment's objective(s) or purpose(s) move away from "transforming individuals" (2003: 79) towards an emphasis on "systemic rationality and efficiency" (1992: 452), as new categories, practices, and classification of risk and dangerousness are introduced to better manage the system $(452)^{14}$.

All in all, whether we are now in a 'new penology' as Simon and Feeley (2003) argue or simply continuing within changes located in modernity as Garland (2003: 61) observes is not the focus of this study nor the purpose for raising this discussion here. In fact, both authors

\footnotetext{
${ }^{14}$ The themes located by Simon and Feeley $(1992,2003)$ in the CJS can arguably be seen as examples to similar trends found and discussed by Lianos $(2012,2013)$ in relation to systems of social control.
} 
acknowledge the existence of the other's trends (Simon \& Feeley 2003: 76-78, 108; Garland 2003: 54-55, 59). Instead, it is meant to demonstrate that the "social process of punish[ment]" continues to include, at minimum, of a composition between "the passionate, morally toned desire to punish and the administrative, rationalistic, normalizing concern to manage" (Garland 1990: 180).

While one must be reflexive of the potential "reductive gaze" (Carrier 2010) totalizing theories of punishment - as raised by Garland and Simon and Feeley - can provide (see also Moore \& Hannah-Moffat 2005), this thesis does endeavour to explore such theories and the purported "fundamental elements" of punishment (Zedner 2016: 6) outside of the realm they and many others almost exclusively study: prisons and the CJS. Attempting to delineate new branches in relation to other systems of punishment, such the POA, my research investigates how these notions of punishment may exist, operate, or be contradicted in the world of administrative sanctions, models of decriminalization, and/or regulatory systems.

When examining literature that does touch upon the subject of administrative sanctions, such as those found in the POA, studies have only more recently been emerging. In Zedner's (2016) study to locate the boundaries, justifications, and definition of punishment, she observes that the need to impose a sanction that is harsh or repressive is less "self-evident" for strict liability ${ }^{15}$ and regulatory offences (7). Examining these forms of civil or "administrative penalties" (9), Zedner emphasizes the "economic rationality" (8) of their configuration. Described as fixed penalties, which consist mainly of fines and prohibition orders, they are seen by governments as swifter, quicker, and presumably a "more 'effective' intervention than the criminal process" (9). Countries such as Germany in 1968, Canada in 1979, and the UK amidst recent changes in 2005

\footnotetext{
${ }^{15}$ A legal threshold affirmed in the Supreme Court of Canada decision of R. v. Sault Ste. Marie (1978), the notion of "strict liability" (Libman 2012b: 374) refers to the barometer or threshold of culpability deemed necessary in regulatory offences. Instead of the need to establish the mens rea of the offender, "strict liability" simply requires the demonstration of proving the "negligent violation of [the POA and other regulatory] statutes" (Swaigen 1992: xxxvi)
} 
are just some of the governments that have "re-designat[ed]" matters previously under criminal law to administrative regulations. This is done in part to cut costs, reduce criminal courts case loads, and distinguish the types of offences regulated under these laws from more serious ones; accordingly, sanctions are issued in pre-trial and evidentiary requirements are much lower than in criminal proceedings, making cases presumably less onerous to process and administer (8-9).

From Zedner's (2016) findings, one can easily discern the managerialist component in the form punishment takes when transferred to these administrative sectors, as Simon and Feely argue $(1992,2003)$. In spite of this, queries arise and still remain as to the existence, or lack thereof, of any moral, punitive, or repressive elements in administrative penalties. Exploring the existing academic literature on punishment as it pertains to these questions and their systems of social control and punishment (e.g., Beckett \& Herbert 2010; Harris 2016, to name a couple), research suggest that many of these elements of punishment do exist in these institutions. Investigations that span various institutions and forms of punishment (e.g., non-custodial, regulatory, and/or municipal measures), their work locates different sets of "punitive logics" (Velloso 2013a: 167) that exist in the system or area being examined, whether a part of the CJS or entirely outside of it.

Exploring a diverse set of research objects (e.g., homelessness, public order policy, migration/terrorism), each study observes a "mentality of exclusion" (Hermer \& Mosher 2002: 16) instilled in their administrative systems. For many, the latter is accomplished through tools or techniques that are largely based on retributive and deterrence-based schemes and view individuals as market-oriented actors that are responsible for their (non)compliance with the established order (Hornquist 2004: 48-49; Moore \& Hannah-Moffat 2005: 92-94). In turn, objectives of governance, whether a form of advanced liberalism (see Rose, O’Malley, \& Valverde 2006) or neoliberalism (see Lippert \& Sleiman 2012), become primarily concerned with making cities conducive for 
“consumption, leisure and luxury" (Chesnay et al. 2013: 164), as a "logic of 'security" (Hornqvist 2004: 31) is initiated to eliminate risk and any form of perceived 'danger' to this model. Consequently, a dialectic form of punishment still exists within these administrative systems, albeit with some alterations, as the need to punish firmly to preserve a social order alongside the need to manage and govern efficiently though these institutions, is a balance located in regulatory or non-custodial types of punishment and the systems utilizing them.

Taking these analyses into consideration, more studies are acknowledging the importance of investigating systems of punishment outside of the carceral and CJS (see Kohler-Hausmann 2013; O’Sullivan 2012: 75; Valverde 2012a; Velloso 2013a), including raising critical questions about the potential expansion of "punitive power through ostensibly non-punitive means" (Hannah Moffat \& Lynch 2012: 119). For Beckett and Murakawa (2012), the above-mentioned cases exemplify the growing imposition of a "shadow carceral state". They argue that "legally hybrid pathways" between the civil or administrative law and the CJS have and continue to expand with “civil 'alternatives"” (e.g., financial penalties, immigration detention) entrapping individuals in an "institutional enmeshment" of state surveillance, incarceration and/or "inescapable debt" $(222)^{16}$. Through these changes, distinct "legal logics" are formed in the courts as administrative tools ${ }^{17}$ are construed as forms of "non-punishment[s]" solely based on their 'supposed' legislative intentions and the venue where they are processed: the administrative realm. A process that reinforces the notion of administrative forms of punishment as 'minor' transgression with nominal

\footnotetext{
${ }^{16}$ According to Beckett and Murakawa (2012), the establishment of the 'shadow carceral state' in "many ways" (222) resembles Cohen's 'punitive city' (1979) and his concerns about the net-widening features to the "new mode of social control" (360) observed at the time. In fact, taking Cohen's argument then, one can suggest that the "logic $[\mathrm{s}]$ of the master patterns" to the shadow carceral state "is not at all new" (359) but a mere transformation from practices Cohen's work explores.

${ }^{17}$ In the US, these tools can be defined as administrative (see Morrissey v. Brewer [1972]) or as a "civil penality" (see United States v. Ward [1980]). In Canada's system of "administrative law" (see Re B.C. Motor Vehicle Act [1985]; R. v. Charles [2017]), these sanctions are commonly described as "public welfare offences" (see R. v. Sault Ste. Marie [1978]) or also as "regulatory offences" (see R. v. Pellegrini [2006]). For examples in provincial courts today, see R. Ellis (2018) in Ontario, R. v. Houle and Tardy (2018) in Manitoba, R. v. Griffin (2018) in PEI.
} 
consequences and therefore not punitive, this conception (arrived at by the courts and governments) blatantly ignores, as Beckett and Murakawa (2012) argue, the "painful and punitive" (232) experience felt by largely vulnerable and marginalized groups, who become entrapped in the system with less legal protections yet encounter similar punishments as those found in the CJS.

Nevertheless, as these studies are only beginning to emerge, there are still some gaps left to be explored. In the case of Beckett and Murakawa's (2012) work, their analysis almost exclusively focuses on how administrative sanctions are pathways to the CJS or forms of criminalization. Though these neglected tools certainly serve the "analytical purpose" (223) of their study in demonstrating an important oversight in crime and punishment studies, how the findings and legal construction of 'non-punishments' relate to other administrative sanctions, such as driving and other regulatory offences, need to also be examined and considered. Furthermore, this also includes an examination of how these forms of penality can be equally punitive without them leading to criminal repercussions (i.e., prison, criminal record). Exemplified in Chesnay, et al.'s (2013) study, they observe how public spaces in Canada through regulatory law - municipal bylaws, provincial and federal statutes - are becoming the "primary normative punitive system in the resolution of conflicts" in place of the CJS (163). Referred to as a method of penalization rather than criminalization, their research focuses on sanctions that may not necessarily result in incarceration yet are equally punitive to those that receive them. Thus, although Beckett and Murakawa (2012) briefly explore civilian penalties and their ability to "regulat[e] and restric[t] mobility, impos[e] debt, and sanctio[n] nonpayment" (238), further investigation is required to understand how forms of penalization may negatively impact individuals who become the object of their enforcement. This thesis undertakes this work. 
Notably also, many of these studies examine the administrative and CJSs within the United States (US), which has different processes from its European (Zedner 2016) and Canadian counterparts (Chesnay et al. 2013). Taking this into account, criminologists are becoming more cognizant about the importance of providing locally-nuanced studies, not just as they vary from country-to-country, state-by-state, or province-by-province (Canton 2017: 42; Garland 2018), but also the different ways they operate within each of these spaces ${ }^{18}$. Furthermore, as Velloso (2013a) and Valverde (2012b) point out, administrative and civil forms of penalization (e.g., bylaws, Poor Law, asylums) have been used in Western societies for centuries as alternatives to punishing subjects. Thus, studies of this subject today must concentrate not on the novelty of such approaches (since they are not new) but instead on how "forms of punitive social reaction [may be] present" (Velloso 2013a: 170) in administrative systems. Focusing on the regulatory system of punishment in Ontario, this thesis infuses not just an exploration of a still understudy subject like provincial offences, their history, and the sanctions formed to enforce them, it also aligns itself with the contemporary outlook on studies of punishment by providing a nuanced local case example.

In the end, the studies examining the complexities of punishment explored in this section are critical to better understanding the different forms or characteristics that contemporary systems of punishment take. As Moore and Hannah-Moffat (2005) argue, the "complexity and diversity of Canadian penality" is much more varied than the narrow definition provided by the "penal-turn" literature (85). This has not changed today, with studies locating "distinct legal logics, practices, and intervention institutions" that produce "different penal configurations" (Velloso 2013a: 173) outside the CJS. As Wacquant (2012) states: "penalization takes many forms and is not reducible

\footnotetext{
${ }^{18}$ A great example of this type of research, and one relevant to this thesis (examined later in this section) is the study of monetary sanctions done by Harris (2016) in A Pound of Flesh. In her work, Harris observes what she describes as a "punitive continuum" (see 99-123), where "counties develop policies and practices that reveal their own county-level punishment "culture"” (133) when it comes to monetary fines.
} 
to incarceration" (246-247). Therefore, if the study of punishment is to do "descriptive, analytical, and normative work" as some criminologists suggest it must (Garland 1990; Simon \& Sparks 2013; Zedner 2016), how the dialectic of punishment - its managerial and expressive features influences or emerges in relation to administrative systems and forms of sanctions must be analyzed on its own merits. This thesis addresses this gap in relation to the POA system in Ontario.

\subsection{1 - The Penology of the Fine}

Similar to the some of the gaps located in the punishment studies above, the fine within criminological studies and debates has, until recently, been examined sparingly. Back in the 1980s, criminologists who studied fines as their object of research describe this shortcoming as a neglected feature of the penal system in criminology (Bottoms 1983), and one that remained "beyond the conceptual and empirical scope of its disciplin[e]" including the larger social sciences (i.e. law, sociology, history) (Young 1987: 3). Young (1987) going further proscribed this phenomenon as the "cultural estrangement of punishment from money", a process where monetary sanctions are deemed a culturally insufficient form of punishment and thus categorized as a "nonpunishment", due in large part to an "unspoken assumption that [a] 'proper punishment' consists [only] of imprisonment" (12-15). Simply put, this societal assumption was in part produced from the lack of attention given to the fine by academia (e.g., criminology), which in turn only continued to uphold and preserve the traditional cultural notions of punishment in civil society.

A dynamic arguably still found today (see Becket \& Murakawa 2012; Zedner 2016), the irony is that the fine, as found back then (see Bottoms 1983; Young 1987), is still predominantly and/or widely used in both the CJS (Harris et al. 2010) and regulatory ones (Chesnay et al. 2013; O'Grady et al. 2013; O' Malley 2009a, 2010). According to recent figures, fines were issued in 74\% of summary cases in the UK in 2013 (Zedner 2016: 15, fn. 2), around 20\% of misdemeanor 
or felony cases in the US in 2016 (Martin, Sykes, Shannon, Edwards, \& Harris 2018) and 31\% of summary cases in Canada in 2014 and 2015 (Statistics Canada [StatCan] 2015a). This pales in comparison to the number of fines issued for traffic-related or regulatory offences in Canada during those same years; for example, in the province of Ontario alone, just over 3.3 million provincial fines were issued in 2014 and 2015 (OCJ 2015a) ${ }^{19}$ in contrast to the 328,000 criminal matters processed in all of Canada during those same years (StatCan 2015a).

Taking note of the fine's important role in systems of punishment and social control throughout the centuries, particularly in Western societies, sociologists and criminologists, albeit only a few, began to examine how this phenomenon came to $b^{20}$. One such group of Marxists who examined this question were Rusche and Kirchheimer (1939/2003). In their foundational text, Rusche and Kirchheimer note that punishment is a "social phenomenon", which continuously morphs into specific yet different forms not just because of its "social ends" of sanctioning crimes, but also due to shifts in social structures and relations of a society $(5-7)^{21}$. As they argue, "[e]very system of production tends to discover punishments which correspond to its productive relationships" (5); in the case of monetary sanctions, this was directly related to the rise of capitalism, improved living conditions for more individuals in the second half of the $19^{\text {th }}$ century, and money becoming "the measure of all things" (168).

Under these structural changes, a fine system became a central feature of the state's judicial administration, contributing to its rationalization (e.g., emptying of prisons, reduced cost, creation

\footnotetext{
${ }^{19}$ This does not include the thousands of parking tickets many of municipalities issue in a year. With no publicly available data for these figures, the most recent statistics found were from the LCO report of 2011, which provided by the two POA municipal managers, showed that the City of Ottawa issued 343,719 parking tickets and the city of Brampton issued 89,285 in 2009 alone (25).

${ }^{20}$ Unfortunately, most of the studies examined for this thesis review systems of punishment from Western Europe and North America. It is unclear how such systems are organized in other regions of the world, an important aspect to study, but outside the scope of this thesis.

${ }^{21}$ Important to note, Rusche himself years earlier wrote "Arbeitsmarkt und Strafvolzug" (1933/2014) that introduced many of the ideas explored in his later work with Kirchheimer, including the central importance of social structures in shaping systems of punishment. Of course, his focus was on how "economic-historical analysis" (Rusche 1933/2014: 254) shaped punishment; however, he did acknowledge that other "forces" played a role as well, including cultural ones (254).
} 
of 'administrative work') with various 'unwanted behaviours', including those in labour laws, vagrancy, prostitutions laws, and what the authors defined as "technical offences" $(173)^{22}$. That said, Rusche and Kirchheimer (1939/2003) contend that fines do have "a serious burden [and] real penal character" for those unable to pay, and that the state's reliance on this technique of punishment resulted from a lack of initiative to fully eradicate the sanctioned behaviour (175-176).

Since the late 1930s, other researchers (Bottoms 1983; O’Malley 2009a, 2013; Young 1987, 1989) have sought to expand on Rusche and Kirchheimer's work on the fine and situate it within emerging social trends and changes. Bottoms (1983) observes the continuing rise of the fine from 1930s well into the 1980s as a direct result of the rise of technology, bureaucracies, and corporatism in our Western societies, all helping to establish new "preventative social-control systems" - a transformed role for punishment - and a new consciousness in all subjects. Similar to arguments made by Lianos (2012) and Simon and Feeley (1992, 2003), Bottoms (1983) sees these shifts resulting in the elimination of "disciplinary punishment...to achieve control" (187, emphasis in original), as a "bureaucratic administrative law" develops with a focus less on the carceral individual and more on "control of whole groups and categories" (191).

These institutions, Bottoms contends, are less concerned with prosecution and more with prevention and the "non-human abstracted ruling interest, public policy or on-going activity, of which human are subordinates, functionaries, or carriers" (Kamenka \& Tay 1975: 138 as cited in Bottoms 1983: 168). In other words, for the state, the main object of concern is not the citizens or individuals themselves, but their ability to efficiently and safely navigate spaces in order to fulfil the objectives and/or norms set by the community, or bureaucracies as their representatives.

\footnotetext{
${ }^{22}$ Problematically, little explanation is provided as to what actions or behaviours constitute a 'technical offence'; yet based on their criteria of the absence of "any feeling of guilt or wrongdoing", one could argue they are referring to driving-related, jaywalking, or other such regulatory offences.
} 
Therefore, these agencies, according to Bottoms, have a "limited competence" (185) with an 'expert knowledge' that is more akin to a biopolitics power relation indifferent to other "aspect[s] of the offender's life" (189) outside of the realm the institution governs ${ }^{23}$. Within these changes, for Bottoms the fine transforms into the "modern fine", whose role becomes secondary as the programmed environment (e.g., street lights and signs, schools, factories, the welfare system) primarily governs society. Consequently, Bottoms defines the contemporary sanction as 'the modern fine' in order to delineate this change along with its shift in "default mechanisms" away from the practice of imprisonment, a common attribution and occurrence in the $19^{\text {th }}$ and early $20^{\text {th }}$ century (201, fn. 7; see also Rusche \& Kirchheimer 1939/2003: 169).

That said, Bottoms (1983) also takes a political economic position by suggesting that compliance became established through a "new relationship" between the factory and the market, as the increase in wages and productivity also saw social relations change in civil society (190191). This discussion is picked up by O'Malley (2009b), who argues that although the modern fine may have been influenced by the penal-welfare complex of the $1980 \mathrm{~s}^{24}$, the central component that results in its continuing expansion into the $21^{\text {st }}$ century must lie elsewhere. Moving beyond Bottoms, O'Malley (2009a, 2009b, 2010a, 2013) observes the use of fine as growing even before production relations shifted to a post-Fordist model ${ }^{25}$. Instead, O'Malley sees the emergence of a consumer society as the source, as the "proliferation of motor vehicles and traffic regulation" (92)

\footnotetext{
${ }^{23}$ For example, in the case of traffic tickets, the institution administrating these punishments would only be concerned with issues that pertain to the infraction, viewing the person largely as a just a 'driver'. This includes concerns about the driver's driving record, level of culpability or fault, and if the individual is properly insured and licensed to drive. The gaps of this rationale are addressed later in section and in my analysis section. ${ }^{24}$ As Garland (1981) explains, the penal-welfare complex was established through a mutual relationship between the "ideology" of the Welfare State and the "realm of penality" (29-30). Although for Garland (1981), the focus was on the establishment of the welfare sanction; Bottoms (1983) argues that the modern fine was in part established by various welfare systems - "social security, public housing, socialized medicine, and so forth" (192) - that allowed for this type of monetary penality to also emerge.

${ }^{25}$ For the purpose of post-Fordism use above, I refer to De Giorgio's (2006) definition, who focused on the shift in work and our production system from an industrial model (as found under the Fordist model) to one that centers around technology and the "virtual territories where fluxes of information, images, finance and symbols circulate along [its] decentered networks", establishing "new relations of productions" for the working class in contemporary society (44).
} 
and formation of individuals as consumers arises in parallel with the modern fine, while the "surplus income of the [established] consuming class" (108-110) remains a vital component.

In this contemporary consumer society, which contrast with Simmel's (1978/2004) notion of money as meaningless, O’Malley (2009b) sees money take on a new meaning as it becomes the "means by which we invest in, express, love and display our selves" (78). For governments, the characteristics of money - ubiquitous, flexible, redistributive, and undifferentiated (the latter referring to the lack of concern over who pays) - provides an adequate tool to manage its system of punishment and social control. Ultimately O'Malley argues that the "monetization of the working class" (Lea 1979), a point explored by Bottoms (1983), has officially expanded into the “complete monetization of justice”, risk, and civil society (O’Malley 2013: 387, emphasis in original). To arrive at this point, O’Malley observes “[a]n economic rationality” pervading the "legal regulation of everyday life" (387), with money as the main "currency of justice" (2009a: 24). Thus, borne is a "reformulated vision of individual responsibility" (25) and a change in "what we imagine to be "justice"" (x); individuals who fail to comply with the use of the fine are viewed as "failed consumers" who become 'ineligible' to this 'gentle' approach to punishment (2013: $389)^{26}$.

Although Young (1987) draws similar conclusions as Bottoms and O’Malley, describing individuals as 'disciplined' by the "medium of money" (315), he more explicitly problematizes the "state of permanent tension" that exists between punishment, justice, and money (1989: 64). His analyses (Young 1987, 1989) focus on money's cultural significance in the CJS, including the

\footnotetext{
${ }^{26}$ An important aspect of O'Malley (2013) more recent work on fines and systems of social control and punishment constructed to operate them (e.g., administrative system such as the POA) is the rise of "simulated justice" models within its spaces. Defined by O'Malley (2013), this model of justice is the establishment of an "automated policing system" that creates "[a]n electronic calculable morality of risk", which itself is based on a "cost-benefit model of distribution of abstract universal rational choice subjects" that nearly eliminates the ability to contest offences (384-388). One example of this form of simulated justice is the growing use of red-light camera tickets. Overall, while this thesis touches on this subject matter, it is not its central focus. Having said that, examining this issue going forward will be an important task for academia to take on.
} 
different "cultural resonances and connotations" (1989: 64) between money, a commodity and medium of exchange, punishment, typically an emotive response to a perceived wrong, and attaining 'justice'. That said, in his early study interviewing Scottish sheriffs, Young (1987) shows that fines do hold for some of its issuers the classical notions of retribution and deterrence (see 209-258, 1989: 48-60 $)^{27}$. Nevertheless, the "inherent potential to corrode" or "disenchantment" (1989: 64) that placing a price on punishment may end up having on society still remains; as a result, for Young, this is not only a reference to the constant tension of money being used as a form of punishment in the name of 'justice', but more importantly, a call to sociologists to explore the "broader questions" (64) raised by its relationship (i.e., money, punishment, and justice). This call is one this thesis contributes to, specifically in relation to regulatory and minor offences.

Yet beyond Young's (1987) interviews and the limited statistical analyses by Bottoms (1983) and O'Malley (2009a, 2009b, 2010a, 2011, 2013), these sociology of punishment studies are limited to very macro theoretical assessments of the environment that has produced the fine as a predominant tool of administrative legal systems impact(s); as a result, these studies largely fail to closely locate the unforeseen consequences of such systems of punishment, and/or the limitations or gaps in their theories when looked at through a specific and local fine system. To address this, my thesis examines this very dynamic in Ontario, studying both the emergence of the POA, the modern fine, and its discursive practices within the social structures, but also their possible effects on the outcomes located in their non-discursive practices.

Moreover, recent US studies (Beckett \& Harris 2010, 2011; Harris, et al. 2011; Harris, Huebner, Martin, Pattillio, Pettit, Shannon, Sykes, Uggen, \& Fernandes 2017, to name a few) have

\footnotetext{
${ }^{27}$ One area that this thesis does not explore, but is important to investigate, is the cultural perceptions and meaning that law enforcement agents, the courts, and even the public have when it comes to use of the fine in our criminal and non-criminal systems of punishment today. This is to question if similar sentiments can be found to those Young located in his study in 1987.
} 
explored the practical consequences of the monetization of the CJS, which in the US includes traffic offences, as 'offenders' bear more of the administrative costs of these systems through fines and fees that states depend on as a source of revenue ${ }^{28}$. In many cases these changes establish a "new debtor prison" (Hampson 2016), as people are imprisoned or severely punished for their inability to pay (see Benns \& Strode 2016; Regoeczi \& Kent 2014; Robertson 2015; Sanchez \& Kambhampati 2018). As Natapoff (2015a) observes, for all the positives of decriminalization, there is a "dark-side" too, finding its creation to potentially be a "kind of regressive economic policy masquerading as progressive penal reform" (1060) ${ }^{29}$. Consequently, such means of sanctioning individuals under these models commonly leads to what Harris et. al. (2010) refer to as the "widespread imposition of 'collateral' or 'invisible' sanctions"”, where what is meant to be “a temporally limited experience" turns into one of "a long-term status" $(1755)^{30}$.

The examples above demonstrate the dark figure of the 'the shadow carceral state' (Beckett \& Murakawa 2012) existing in part due to political circumstances in circumventing arduous legal procedures, as Zedner (2016) and others have raised (see also Beckett \& Harris 2010; Sylvestre 2010), but also for the economic purposes of reducing cost to the judicial system and generating revenue for states and municipalities. Thus, the recent "adaptatio[n]" to the "social control tool" of the fine through the processes of decriminalization has resulted not only in the ability to incarcerate individuals through new legal hybrid paths, but also in the system's power to "curtail

\footnotetext{
${ }^{28}$ In New York for example, fines are said to generate $47 \%$ of the criminal court revenue, with New York City and New York State receiving \$14 million dollars each (Martin et. al. 2017: 476).

${ }^{29}$ On another note, many studies have shown these type of offences, criminal or regulatory ones, to carry other socio-cultural consequences, including a "courtesy stigma" (Harris et. al. 2011) or more generally a "cumulative disadvantage" based on race, ethnicity, and class (Harris et. al. 2010; see also Kent \& Regoeczi 2014; Langton \& Dunrose 2013; Natapoff 2015a; Zats 2016). Another study examines the unrestraint police discretion provided in administrative systems, such as those for traffic regulations, which has had a disproportionate impact on subjugated communities (Blair 2015). Although this thesis touches upon aspects and questions located in these studies, a more focused examination is required when it comes to the impacts of traffic fines here in Canada and whenever these administrative tools are being used unreasonably and disproportionately by the police against racial and ethnic minorities.

${ }^{30}$ For other case studies in America, particularly as they relate to traffic offences, see the Western Center on Law and Poverty report from 2015, the Legal Aid Justice Center report from 2017 (see Salas \& Ciolfi 2017), or from the ArchCity Defenders in Missouri in 2014 . For a detailed report on the fines, fees and other cost associated with the US CJS see Bannon, Nagrecha, and Dillier (2010).
} 
the liberty and mobility of subjects" (Beckett \& Murakawa 2012: 232) with a cheaper tool whose impact can be just as debilitating. With the state and courts construing many of these sanctions as 'non-punishments' or simply as civil or administrative in nature, researchers have expressed a serious concern as to the reasoning behind these adaptions to systems of punishment, their tools, and what these changes may conceal or ignore. This thesis contributes to this discussion by contrasting state discourses of punishment in relation to the POA and its main tool (i.e., the modern fine) to their actual outcomes, while also in the end, "developing a scholarly conception of the penal state" that is outside of "official claims" (224).

In the end, as Young (1987) argues, to "explain the fine", it is necessary to understand the “complex and changing connections between punishment, money and [the] legal order" that allows for "money [to] ente[r] into the equation as a force in its own right" (9). This thesis pursues this line of inquiry in relation to the POA - the relationship(s) between punishment, money, and legal order in the system. In addition, it adds to Young's equation by examining how this relationship unfolds and constructs the administration at the centre of its processes. In other words, it investigates the rationales that emerge in the POA due to the establishment of the fine as a form of punishment within a 'strict-liability' legal order, as well as the limitations and consequences of this sanction. Importantly, the examples explored in the US administrative legal systems and the US CJSs for that matter may not be identically reproduced within administrations such as the POA; as such, this thesis investigates the similarities to and divergences from the findings of the studies mentioned here and in previous sections, including those by Beckett and Murakawa (2012).

\section{3 - Situating Social Control and Punishment within the Regulatory Field of Canada}

In Canada, studies of regulatory systems of punishment and social control have mainly focused on the implementation of the SSA (Chesnay et al. 2013; O'Grady et al. 2013) and the 
regulation of corporate bodies (Bittle \& Snider 2015; Snider 1993; Glasbeek 2002). Studies of Canada's regulatory systems more generally (Libman 2011, 2012a, 2012b; Rankin 2014; Verhulst 2008), mainly examinations of the British Columbia and Ontario model, see their purpose and characteristics in similar terms. In each, the regulatory system is understood as one attempting to persuade rather than punish, to attain compliance it seeks to be less adversarial, and in many cases, regulators see themselves as "expert advisers rather than [an] industrial police [force]" (Gobert 1994: 725 as cited in Libman 2012a: 134).

This is partially because many of the acts sanctioned under these systems are conceived by both the literature and regulatory administrations as "public welfare offences" in contrast to criminal ones. Taking the landmark decision in R. v. Sault Ste Marie (1978), public welfare offences, which include traffic infractions, are considered acts and behaviour that involve "a shift of emphasis from the protection of individual interests to the protection of public and social interests" (1312). This in turn establishes a "branch of administrative law" (1303), similar to the “bureaucratic-administrative law” Bottoms (1983) discusses.

Some of these studies touch on the issue of punishment in regulatory systems. As Libman (2011) points out in R. v. Hughes (2004) case, traffic offences, which include steep fines and demerit points that may lead to a license suspension, can be "very much penal in nature in many cases" (as cited in Libman 2011: 32). Similarly, in R. v. Welcher (2007), concerns are raised about the "adverse effects" such punishments have on insurance premiums, especially on young people and those within lower socio-economic strata (as cited in Libman 2011: 32). These examples raise concerns about these regulatory systems, such as those for administering traffic tickets in Canada, unjustifiable or unwanted excess to punishments (see also Libman 2011: 31-33, 2012a: 382). 
To address some of these concerns, Libman (2011, 2012a 2012b), Rankin (2014), and Verhulst (2008) explore the need to modify the regulatory system by having a "set of sentencing principles" for all cases within its purview. For Rankin (2014) these "sentencing rationales" (808) mainly center on the notion of "general deterrence over rehabilitation" (809). In the case of Libman (2011, 2012b) and Verhulst (2008) this includes four criteria: an infraction that: "remedies the violation"; "rehabilitate[s] the offender" to promote change in conduct; general deterrence as an attempt to prevent others for doing the same thing; and denounces or censures the behaviour. Subsequently, Libman (2012a) and Verhulst (2008) also explore the notion and importance of establishing a "regulatory cycle", where the sentencing of regulatory offences is not the 'end' of a case, but instead part of a 'cycle' where the offender can return to partaking in the sanctioned activity (Libman 2012a: 139; Verhulst 2008: 283).

Having said that, major gaps exist in these studies. For one, they largely examine the regulatory system from a socio-legal position that accepts certain premises without challenging the role social structures (i.e., political, economic, cultural) play in shaping them, limiting their object of study also to the practice of sentencing. By taking a critical perspective, I re-orient the gaze to many of these unexplored areas. In doing so, I contribute to the goals laid out by these studies above, locating further causes or areas that may prevent the POA from living up to regulatory models these writers claim it should.

\section{Conclusion: A Contemporary Map of Punishment, 'Monetized Justice' and Social Control within a Decriminalized System}

To make visible the map that lays before this research project, delineating routes taken and those yet to be fully explored, I have reviewed the existing literature on the foundational fields of the POA: social control, punishment, the fine, and the roles of each within a legal administrative regulatory system. Starting with the literature on social control, this section explored its analyses 
in attempting to address the complexity of how order is constructed and preserved in Western societies. Exploring and taking largely from Cohen (1977, 1979, 1985), Foucault (1977, 2007, 2008), and Lianos (2000, 2003, 2010, 2012, 2013) works, this thesis explores and discerns the master patterns and power-knowledges shaping the soft machine of the POA and other legal administrative systems like it within the post-industrial city.

Whether under the "great regularization" (Lianos 2012: 2) or a "culture of surveillance" (Staples 2014), this literature review then examined the role of punishment within such societies. In this vein, studies within the punishment literature, most notably by Bottoms (1983), O'Malley (2009a, 2009b, 2010a, 2010b, 2013), and Simon and Feeley (1992, 2003), have explored the establishment of a "bureaucratic-administrative law" (Bottoms 1983: 191) employing a managerial (Simon \& Feeley 1992, 2003) and/or cost-benefit (O’Malley 2013: 387) logic within various administrations. As others indicate (e.g., Chesnay et. al 2013; Valverde 2012b; Velloso 2013a; Zedner 2016), configurations in punishment, including here in Canada, continue to be re-classified from the CJS into the administrative realm, leading to a widening of systems of penalization to resolve conflicts and social issues. Noting the concerns raised about the impacts of distinct "legal logics" (Beckett \& Murakawa 2012: 235; Velloso 2013a: 173) and "punitive logics" (Velloso 2013a: 167) in these non-CJSs, this thesis explores these impacts as they relate to the POA.

For Bottoms and O'Malley, the main tool of punishment that emerges to regulate many of these systems is the modern fine. With money becoming "a force in its own right" (Young 1987: 9) within various systems of punishment, O’Malley (2013) observes this transition as the “complete monetization of justice" (387). Correspondingly, US studies (Harris, et al. 2011; Harris et. al. 2017, Martin, et al. 2018, to name a few) have explored the emerging limitations and consequences as a result of the growing use of monetary sanctions within the judicial realm. This 
has led some to proscribe these changes as the "dark-side" of decriminalization (Natapoff 2015a), the creation of a "new debtor prison" (Hampson 2016), or the pernicious imposition of a "shadow carceral state" (Beckett \& Murakawa 2012). On that note, this thesis investigates the existence and role such a system of 'monetized justice' or 'monetized risk' (O'Malley 2013: 388) may have on the operational side of the POA in Ontario.

With few studies done of Canadian regulatory systems, especially from a macroperspective that ties together areas already examined (i.e., homeless, corporate crime, and sentencing principles), I thus endeavour into a new area of examination to provide greater understanding and nuance to the existing literature. Drawing from the work described in this chapter, I explore the social construction of both the system of control and the character and forms that punishment take within the model of decriminalization found in POA. In investigating an administration whose search for control is both rigid yet flexible, or at the very least cost effective, this research study investigates the rationales governing such a regulatory system in the potential arrival to "the era of "involuntary' social regulation" (Lianos 2012: 36). Lastly, with discussions and debates being had about the role of the fine within judicial systems almost exclusively in the US (see Martin et al. 2018; Harris et al. 2017; Beckett \& Harris 2011; O’Malley 2011, 2013), I inject a Canadian perspective into the conversation of a field still very much "understudied and undertheorized in criminology" (Martin et al. 2018: 472).

\section{Chapter 3: Re-Orienting the Criminological Gaze into Unchartered Waters}

Following the previous chapter, one that situated my thesis within the body of literature exploring the various objects at its center - social control, punishment, the fine, and regulatory systems - this chapter outlines the theoretical framework guiding my research. Much like a driver using a map to help navigate their course, theory is a tool used by researchers not only to locate 
the puzzle, but to also provide meaning and context to it. As Berg and Lune (2012) observe, "[t]heories are explanations" that attempt to make sense of a puzzle or event through "coherent narratives" (20), but as McCotter (2001) adds, theories do not "direct [us] to one particular place, but giv[e] a variety of choices and directions" (3). In other words, theories provide "situational" or "particular" contexts to a puzzle while always remaining open to "new and better routes", and while they help to inform us about our social worlds, they by no means wholly define them (3).

Taking inspiration from these perspectives and maintaining an interpretive methodology (see next chapter), I draw my own theoretical 'map'. Understanding theory to be a "deliberate attempt to go beyond what we know" (Sarason 1990 in McCotter 2001: 4), in this chapter, I examine and adopt a critical criminological and "sociology of punishment" (Garland 1990) theoretical framework, while contributing to the literature that has sought to move away from “criminocentric dogmatism" (Velloso 2013a) that has plagued criminology and justice studies of the past. By applying these theories and their respective concepts (i.e., criminological imagination), while also combining them with others that relate to my research questions and object (i.e., the study of problematization), I subsequently take these basic building blocks and venture into unchartered waters; by employing this approach, I hope to highlight as well as gain a better understanding of how systems of social control and punishment, such as the POA, are implicated in our social world and shape society's ideas of justice, fairness, and punishment.

\section{1 - Adopting a Critical Criminological Framework and Pushing the Boundaries of our 'Criminological Imagination'}

In an attempt to distinguish the main "purpose" of various paradigms a researcher might apply to their study, Lather (1994) categorized them as follows: for positivism, it is prediction; for constructivist and interpretive research, it is understanding; for critical and feminist research, it is 
emancipation; and lastly for post-structural and post-modern frameworks, it is to deconstruct (105). Although she does acknowledge that "each paradigm offers a different but not exclusive approach to generating and legitimating knowledge" (105), many theoretical approaches have multiple purposes at their core. One such paradigm in criminology is its critical strain. Bringing understanding by deconstructing our traditionally held perceptions on various issues including crime, deviance, and punishment, its framework seeks to emancipate the subjugated from the forms of domination and oppression that arise from these hegemonic knowledges.

Labelled a "form of intellectual resistance" (Carrington \& Hogg 2002: 5), the "countervoice to neoliberalism and conservatism" (Young 2011: 217), or a framework that confronts "predatory and punitive ideologies" (Currie 2002: viii), critical criminology as a theoretical framework has historically pushed boundaries in challenging individualistic or traditional notions of crime, 'criminals', social control, and punishment. Where the positivist, correctionalist, managerialist, establishment and/or mainstream criminologies place emphasis on the “"maladjusted' individual", rational choice and situational control theories, or other forms of “individual positivism" (Young 2002: 253), critical criminology largely centers its attention on the "social, economic, and political contexts that produce crime itself and state responses to crime" (Barton, Corteen, Scott, \& Whyte 2007: 5). This endeavour is conceived by critical criminologists as a necessary escape from "the criminological straitjacket" (5) or the reorientation of the “criminological gaze" (Young 2011) of individualize conceptions of crime and punishment towards more structural questions and their influence in producing deviancy, crime, and systems of social control and punishment (see Cohen 1998).

Now, one may be wondering what does or can critical criminology provide to an analysis of an administrative provincial system operated by local municipalities. That said, the orientation 
of critical criminology is one that continuously develops and advances "alternative theories" (DeKeseredy 2011: 26) capturing a "radical heterogeneity" to be celebrated (Doyle \& Moore 2011; see also Martel, Hogeveen \& Woolford 2006; Sumner 2004). Theories under this framework may have neo-Marxists foundations, but as Moore and Doyle (2011) point out, twenty-first century critical criminologists have sought to expand its scope into more "varicoloured power relations... as well as complex matrices of governance" (4). Importantly, the reflexivity of critical criminology demands that its users be "actively conscious of its own margins and exclusions" and to "continually interrogate silences, omissions, and exclusions both from its research and theoretical approaches and from its politics and policy agendas" (4). This is one of the strengths of critical criminology, as it attempts to rethink and reimagine not just crime and punishment, but also ideas about "safety, security and harm in broader social contexts" (Barton et al. 2007: 8).

It is within these broader social contexts, while applying a critical criminological framework that continues a tradition of radical heterogeneity, that I venture into a neglected area of research within criminology and justice studies: administrative penalties and the systems created to operate them. Before doing so however, it is imperative to further bridge this divide and explore why critical criminology not only has the tools to deconstruct and emancipate a system of social control outside of the traditional boundaries of criminal justice, but why it should.

One such tool that guides critical criminology as well as other paradigms (e.g. cultural criminology) is the concept of criminological imagination. Derived from C. Wright Mills's (1959/2000) concept of "sociological imagination", a researcher applying a criminological imagination focuses on "the fundamental triangle" - human biography, social structures, and their historical contexts - that Mills argues is faced by individuals within society (Young 2011: 2). In doing research that actively applies this triangulation, Mills (1959/2000) contends that many 
"personal troubles" faced by humans are in fact, unveiled as "public issues". Thus, criminological imagination requires criminologists to be "able and willing to break free of old constraints and look at the problem of crime and punishment with fresh eyes" (Currie 2002: viii). It further implores us to both challenge and expand beyond "the conventional wisdom on what constitutes the legitimate domains, subject matter, and approaches to criminology" (Frauley 2010: 75), including its "domain of objects" (91) or "master category" (Frauley 2015: 619) of crime.

To operationalize such a concept and prevent it from being merely used descriptively in critical criminology, as Frauley (2010) observes, criminological imagination must also include a more rigorous analytical framework. To achieve this, studies operationalizing the concept must encompass both the "realm of public issues" which considers "context" (e.g., race, gender, class, forms of social organization) and "setting" (e.g., bureaucracies, labour markets, non-work-related organizations), as well as the "realm of personal troubles" which includes "situated activity" - the day-to-day activities and symbolic communication with setting and context - and the "social self" - consisting of the influence of the other components on the "psycho-biography of the individual" (95; see also Layder 1993: 72). Moreover, each realm is underlined by the historical context(s) constructing their development and form.

Acknowledging the need to apply the concept of criminological imagination more narrowly, this thesis applies the rubric Frauley (2010) provides with some limitations. With the research object being an administrative system that doles out punishments mainly in the form of fines, my thesis's analyses center around the public realm's "context" and "setting" components to Frauley's definition of criminological imagination. While not diving extensively into the "realm of personal troubles" that Frauley also calls for, in part due to limited scope of a masters' research 
project, this research starts the project of connecting these two separate realms - public and private - together, as they relate to the personal experiences of individuals sanctioned under the $\mathrm{POA}^{31}$.

To accomplish this, my research investigates: how the regulatory system is produced, established, and implemented as a state response to the established and defined 'regulations'; how the "different degrees of seriousness with respect to the various provincial offences" (Ontario Law Reform Commission [OLRC] 1973a: 59) are decided and recognized; as well as how the state chooses to regulate and what tools are used and which are not. Therefore, my research applies the concept of criminological imagination as both an idea that calls on criminologists to move beyond traditional domains and micro analyses within the field of criminology, while also attempting to pave the way in its analytical application to the study of administrative regulatory systems.

Although critical criminology can proclaim to have established a "wider constellation of deconstructionist radical agendas" (Carrington \& Hogg 2002: 3), it has only begun to tap into the potential of the criminological imagination and the "imaginative criminology movement" (Frauley 2015). In fact, one can make the argument that while critical criminology may have escaped the individualizing straitjacket of mainstream criminology, it has only itself recently fled the walls of the 'totalizing institution' of the CJS to explain punishment, justice, and social control. With a historically narrow focus of studying the latter through "master categor[ies]" (Frauley 2015: 619) - crime, criminal law, prison, and the CJS - Velloso (2013a) sees a "criminocentric dogmatism" still lingering in the field of criminology.

Calling on criminologists to overcome what Velloso (2013a) sees as a remaining "ideological" and "epistemological obstacle" (171), referring its movement as the "third

\footnotetext{
${ }^{31}$ For examples of the 'personal troubles' faced by individuals within Canadian administrative systems such as the POA, please refer to Ballingall (2016), Gallant (2015), Gillis (2012), Hopper (2015), McDonald (2017) along with the others mentioned throughout this thesis to add greater context and to begin the process of connecting the two realms.
} 
ontological turn" (167), he urges researchers to widen their research to include "institutional normative systems" (e.g., administrative legal systems, civil courts, immigration, and military law) to establish an "open model" that "incorporat[es] the different possibilities of legal processes and institutional forms of punishment" (174) found in society. In doing so, Velloso (2013a) seeks to better understand and provide greater nuanced into the "penal complex" (175) that forms around the various institutions and systems of punishment both outside and within the CJS.

While Velloso (2013a) arguably overemphasizes the existence of an such issue, the body of literature explored in the previous chapter of this thesis does emphasize many of the gaps either just starting to be explored and/or still understudied when it comes to systems of punishment and social control. Whether in complicating our notions of punishment and social control in the field of decriminalization (see Natapoff 2015a, 2015b), administrative systems and sanctions (see Beckett \& Herbert 2010; Beckett \& Murakawa 2012; Velloso 2013b), or the role and impact of the fine in both the CJS (see Harris 2016; Martin et al. 2018) and outside of it (see O'Malley 2013), these areas within the field of criminology, including its critical strain, have yet to be adequately theorized or researched. This case is further made in relation to the POA, touching many of the field just mentioned (i.e., decriminalization, administrative systems, and fines), there have been little studies undertaken beyond the SSA (see Chesney et al. 2013), corporate crime (see Bittle \& Snider 2015), and sentencing principle (see Libman 2011, 2012a, 2012b) in understanding the creation and application of the POA's model of punishment and social control. Put simply, whether looking at a "petty offence system" (Natapoff 2015b: 265) or more specifically "monetary sanctions" (Harris et al 2018), there is a need for research to examine, illuminate, and in some cases, deconstruct our conceptions around these systems and how they are operating. 
Simply put, with these different systems and forms of punishment playing a role in addressing social conflicts or 'disorder', as perceived and defined by the state, the penal complex in Canadian society is more dynamic than our research has suggested. Exemplified in research done locating the impact of penalization on the homeless (see Chesnay, et al. 2013; Hermer \& Mosher 2002), or in the use of monetary fines in the US (Harris 2016), more studies such as these are needed if we are to obtain a comprehensive understanding of how different forms of penalization consolidate and help re-emerge "different punitive logics" (Velloso 2013a: 167) within a divergent set of institutions and system. In highlighting the nuances and complexities to Canada's penal complex, criminologists will be better positioned to "evaluate systemic trends", and thereafter advocate and promote more "broader and combined propositions for law reform and anti-penal policies" (174-180).

It is within this endeavour, the third ontological turn, that I re-orient the critical criminological enterprise into the uncharted waters of the regulatory administration of the POA. Taking on the interpretive lens laid out by critical criminologists, I examine more broadly notions of order, security, safety, and harm in this system of penalization. In doing so, I adopt "an expanded criminological imagination" that "provide[s] a [more] holistic account of social harms" (Barton et al. 2007: 210) and responses created and addressed by this administrative system of social control. Using these building blocks, I expand and deepen criminology's understanding of punishment, justice, fairness, governance, and social control within the post-industrial Western society of Canada. In the end, I hope to provide nuance and clarity to the penal complex and assist other criminologists in pursuing anti-penalization and anti-punitive policies. 
In light of my pursuit of "decriminaliz[ing] criminology" (Shearing 1989) to continue the work that various other researchers have paved the way in creating, I also utilize and re-orient the sociology of punishment framework with a study of problematization to which I now turn to.

\section{2 - Re-introducing a Sociology of Punishment with a Focus on the Study of Problematizations}

Guided by critical criminology's focus on the social structures (i.e., economic, political, and cultural) shaping systems of punishment and social control, while taking its framework into an understudied field (i.e., administrative systems), my thesis similarly does the same with a sociology of punishment framework.

Oriented by its core theoretical and ontological founding while simultaneously broadening its boundaries, the pursuit and creation of a "sociology of punishment" by Garland (1990) reminds us of the 'polysemy' (i.e., plural meanings and functions) that 'punishment' and/or 'penalization' possess (see Brown 2009: 212). Constructed from a "complex set of interlinked processes and institutions...[with] a stored-up depth of historical meaning" (16-17), that includes an "ensemble of social forces" and a diverse set of functions and purposes, punishment cannot solely be understood from an instrumental or technical purpose in relation to its juristic counterpart, crime. A conceptualization that builds off the work of others (i.e., mainly Rusche and Kirchheimer 1939/2003) and is arguably touched on in the literature discussed in the previous chapter (e.g., Canton 2017; Moore \& Hannah-Moffat 2005; Simon \& Feeley 1992), Garland (1990) invites research to not just consider how social structures shape punishment, but the inverse question also: how the social world is influenced and/or shaped by penality (p. 22). Simply put, punishment shapes our social environment as well as simultaneously being shaped by it.

Fitting within the dialectic of punishment dynamic explored in the literature review of this thesis (see section 2.2 of this thesis), Garland's (1990) project is one that pursues punishment as a 
"social institution...[that] somehow contrives to condense a whole web of social relations and cultural meaning" (287), including its coercive, rational, and bureaucratic features, with its morally and culturally expressive ones. Its task is one that "reveal[s] institutional dynamics, characteristics, and effects" (286) that not only acknowledges the various purposes and meanings of punishment, but simultaneously exposes its limitations as well as the unwanted, unforeseen, or ignored consequences in attempting to fulfill or meet them. This creates an opening that allows for alternative suggestions to be made on "ways of organizing [punishment's] tasks" (292), one that creates more comprehensive anti-punitive or anti-penal policies and models.

That said, one critique of or limitation to Garland's conception of the sociology of punishment is its limited focus on what Braithwaite (2003) describes as a "genealogy of punishment" that only traces the "criminal justices branches" (23). Somewhat ironically, this problem was also discerned by Young in 1987 when examining the existing literature on the fine, stating then: "[the fine] is used such a great deal yet hardly registers in [criminology's] conception of punishment at all" (16). Thus, to address the criminocentric dogmatism in Garland's sociology of punishment, as Braithwaite and Young call for in their own separate ways, the sociology of punishment paradigm must also be expanded upon within the 'third ontological turn' to include regulatory systems as well as forms of punishment that fall outside the traditional categories of prison and its carceral structures.

This thesis takes up these projects. Moving away from a criminocentric dogmatism as well as applying a criminological imagination, it undertakes Braithwaite's proposition of broadening the scope of inquiry to include regulatory systems of punishment to help establish new "genealogical sociologies of punishment" (24). This is done to provide a more complete and nuanced picture of the different manifestations of punishments that emerge, take root, and shape 
society and our social worlds. This thesis focuses on punishment's monetary form within the regulation system; however, instead of business regulations, which Braithwaite is calling for, I examine minor offences (e.g., driving, municipal, liquor offences) within administrative sanctions and the regulatory regime. More specifically, I examine how the POA's system of punishment and deterrence scheme may potentially reproduce the need for 'tougher' sanctions, more regulations, and therefore the "created sense of their own inevitability" as well as reaffirming "status quo" notions about punishment, deterrence, and deviance more widely in society (Garland 1990: 3).

Lastly, in pursuing a sociology of punishment as well as a critical criminology framework, I adopt a study of problematization model to my analysis, also called a "what's the problem represented to be?" (WPR) approach. As defined by Bacchi (2012), a 'problematization' is a method of analysis that examines the "historical process of producing objects for thought" (1) along with investigating how and why these things - behaviour, phenomena, processes - emerge and/or become a problem in need of a solution (Foucault 1985: 115). Expanding on Foucault's project, Bacchi (2012) argues that problematizations are not only located in "crisis" points, but are equally found in public policies. Simultaneously seeing policy proposals as relying on "problematizations" (2012: 5), Bacchi argues that our subjectification along with the creation and establishment of the institutions and systems governing us are heavily defined and formed through problematizations (2009: 31).

As my research questions focus on locating the rationales at work within the POA and an examination of data sources such as public policies and policy proposals of and about the POA, a study of problematization provides a valuable framework to my study. More specifically, my thesis explores the emergence of the POA through several key events occurring over its thirty-eight-year history. Thus, part of my object of research investigates how problematizations shape and 
construct the POA, and the attempted tactics or solutions to the problems it deems necessary to address. In taking this form of inquiry, this thesis seeks to examine and deconstruct the phenomenon of decriminalization as it is found in the POA, along with the 'objects for thought' at the center of its operation and their potential roles in shaping punishment, justice, and the binaries formed by the POA's discursive and non-discursive practices (e.g., law-abiding citizens vs. fine defaulters).

Building off the other theoretical lens already drawn from (i.e., critical criminology and a sociology of punishment), which includes understanding the plural forces and dynamics shaping punishment, social control, the fine, and their systems (as explored also in the literature review), this thesis understands the knowledges underlying them to come from "diverse elements" (Dean \& Hindess 1998: 8). Framing this process as part of an "assemblage", the latter concept acknowledges that government is not a "definite and uniform group of institutions [but] an inventive, strategic, technical and artful set of 'assemblages"” (8). Ensuring that the notion of punishment as a 'social institution' is pursued as identified by the sociology of punishment and critical criminology paradigms, this thesis recognizes that the POA is established from divergent elements, which as other studies point out (Dean 1999; Osborne and Rose 1997; Rose and Miller 2010) include bureaucrats from various government departments, as well as other non-government agencies, 'experts', and/or 'professionals'.

All in all, a conceptualization that grapples with examining and discerning how our social structures shape our knowledges, discourses, and practices, and/or how various 'experts' or individuals help to either reinforce or resist them through new problematizations and/or policies, 
this approach fits within this thesis ${ }^{32}$. It is with these building blocks established by my theoretical framework, along with the existing gaps located in my literature review, that I now turn to the methodology for this thesis.

\section{Chapter 4: Methodology}

I now turn to discuss the methodological implications of this research project and its theoretical orientation. Before doing so, it is necessary to revisit the research question and subquestions:

To what problems is the POA a response to? How have these problems emerged and been constituted within the provincial government of Ontario?

Subsequently, to address my main research question, I ask the following subquestions: what role does these configurations contribute to the regime of punishment and justice established within the POA? What subsequent outcomes does this system and its approach produce?

In the spirit of the 'deconstructionist radical agenda' characteristically applied by critical criminologists, I pose these research questions with the objective of gaining an understanding into the social construction of the POA's administrative system as well as its role and relationship to notions of justice and punishment in our contemporary society. As previously mentioned, this project deconstructs the knowledges embedded in this institution not simply to gain insight into or to illuminate its existing power relations and discourses, but also to emancipate societies from unwanted forms of domination and pursue a "political spiritualite" (Foucault 1991: 82) that "enhance[s] the contestability of regimes of authority that seek to govern us in the name of our own good" (Rose 1999: 60).

\section{1 - Epistemological Foundations}

\footnotetext{
${ }^{32}$ To be clear, although this thesis focuses on government and public policy records, as outlined in detail my methodology chapter just below, the documents contain reports, presentations, expertise, and therefore 'knowledges' from multiple levels of government, departments, bureaucrats, and outside stakeholders (e.g., Association of Municipalities [AMO], paralegals and lawyers, Ontario Association of Chiefs of Police, to name a few) that become a part of the assemblage constructing the POA, and consequently, helping to define its role, vision, and purpose(s).
} 
This research study first and foremost takes a post-positivist framework to its research. Also referred to by some as an "interpretive research design" (Schwartz-Shea and Yanow 2012), this framework grapples with the "possibility of multiple interpretations" existing about the social (84-85). In light of the challenge, including post-positivism's acknowledgment of research's inability to completely be absolved of any subjectivity, its approach attends to "meaning-making" of the social by locating and generating "contextually grounded knowledge" $(53,67)$.

Understanding 'contextually' grounded research and knowledge to come from "how human beings...make collective sense of their particular worlds" (46), post-positivists see meaning as holding various cultural, political, and historical contexts which "frame" the possibilities of thought for individuals as well as its institutions (46). An epistemology that coincides with the theoretical paradigms of this thesis (i.e., critical criminology, sociology of punishment, study of problematizations), a post-positivist research design believes these "nuances" (48) to be relevant to a study - regardless of the research subject (e.g., humans, institutions) - to ensure a "thick description" is garnered (Geertz 1973 as cited in Schwartz-Shea \& Yanow 2012: 48).

To ascertain this knowledge, a post-positivist research design comprises of an "abductive" logic of inquiry with a "iterative-recursive" process (26-34). In it, researchers begin "with some degree of prior knowledge" (31) to their study that is continuously "assessed and reassessed in the field" (53), whether from "familiar literature" (30) or empirical material (i.e., reports, news articles, experience in the field) about one's research topic. From here, the "sense-making" (30) process continues in a "circular-spiral pattern" (28) where the researcher recirculates in a nonlinear fashion between the two (i.e., empirical records and academic literature) to gain a more indepth understanding of the puzzle and the pieces that lay before it. Put simply, this approach openly recognizes a researcher is unable to account for all variables prior to going 'into the field'; to 
counter this fact, post-positivists advocate for flexibility to allow the research design to change as data is gathered and analyzed to ensure a rigorous study is achieved (54-57).

Continuing in the tradition of the many works discussed in the previous two chapters, as well as post-positivism's focus on "the systems of symbols" (46), this thesis takes a qualitative approach in examining the discourses and language located within the POA. Language, according to a post-positivist paradigm, is found at "the nexus of meaning, context, and action" (46). Aware, as already mentioned, that such discourses contain "assumptions, values, and presuppositions" (Bacchi 2009: 7) that set limits upon the possibilities of what an individual thinks and says in relation to "a given "social object or practice" (McHoul \& Grace 1993 as cited in Bacchi 2009: 35), this thesis simultaneously exposes and renders fragile the outcomes and role of this dynamic within the POA. Therefore, although this study recognizes that not everything is reducible to language or discourses (Bacchi 2009: 35), it also understands the critical role both play in "constructing worlds, problems, and persons as governable entities" (Dean 1999: 64). Oriented by this epistemological lens, this thesis now turns to its method of collecting its empirical records.

\section{2 - The Search, Pursuit, and Collection of Data in Cultivating a Genealogy}

In researching systems of penality, Garland (1990) explains that government documents are records that "describe and justify penal practice[s] to the public", including "signifying" the various facets that shape the meaning and form punishment embodies in society and its institutions (254-255). While this study acknowledges, as other Foucauldians have raised (see Bacchi 2009; Dean 1999) that the rationalities and knowledges within government institutions and regimes assemble from various 'experts' and organizations, governments are still considered "an important player" (Bacchi 2009: 26) in their establishment. 
Furthermore, as Bacchi (2009) also argues, public policies are creators of meaning (7) that "effect" and "modify" our ways of being, thinking, and lived experiences (15). As sources that are critical in providing insight into our current system of governance (e.g., the POA), the deliberation in the creation and official implementation of public policies can be found within various government documents (e.g., reports, presentation decks, committee hearings, bills, to name a few). Designed under these considerations, this thesis largely sought out and inspected government and public policy records about the POA to examine and address its research questions.

To review records, a genealogical approach was undertaken to uncover the long-term trends found in my research questions, whether in relation to the "stored-up depth of historical meaning" (Garland 1990: 17) to punishment within a decriminalized and/or regulatory system, or the "“history' of the current problem representation[s]" (Bacchi 2009: 10) found within the POA. Labelled as a "history of the present" (Foucault 1977: 31), a genealogy begins by examining "the present situation", comprising of how a 'problem' and/or 'objects' (e.g., decriminalization, punishment, justice) are currently framed (1988: 262), followed by an attempt to 'trace' their connection to the past, including earlier roots and 'problematizations' (Bacchi 2012: 2).

The goal of this inquiry is to render "fixed essences" (i.e., objects, practices, and/or problems) fragile by identifying moments and contingencies upon which current practices, objects for thought, and institutions materialized (1-2). Characterized by its "destabilizing effect" (Bacchi 2009: 10, emphasis in original), a genealogical approach aligns with this research project's theoretical framework and objective of seeking to deconstruct notion of punishment and justice within a "genealogy of the regulatory state" (Braithwaite 2003: 12), specifically in reference to decriminalized systems and minor offences (i.e., driving-related, bylaw, liquor offences). 
To locate these 'moments', also described as "emergences" (Foucault 1998: 376), a researcher 'descends' (see 373-376) and identifies "specific points in time when key decisions where made" (Bacchi 2009: 10). To accomplish this, I began by examining the 'present situation' found within the POA through my a priori knowledge as a POA clerk for seven years (see preface chapter) as well as exploring available sources through multiple online search engines: the University of Carleton's library database, Google, and the Toronto Public Library ${ }^{33}$.

The objective of this search was two-fold. Firstly, I sought to 'expose' myself to various documents and to 'deepen' my understanding of the POA, both fulfilling the recursive process of post-positivist research designs (Schwartz-Shea \& Yanow 2012: 73, 85-89) and the "vast accumulation of source materials" required for a genealogy (Foucault 1998: 370). Secondly, I sought to secure a stable source of government records to examine. I began by seeking out annual reports from MAG and a local municipal POA branch, which for this study was the City of Ottawa, as it provided the most ease to access due to its location, familiarity, ease of navigating, as well as its suitability due to its relative size in comparison to other POA branches.

Sadly, the online searches provided only limited records, creating similar challenges and limitations all too common and familiar to academics studying monetary fines and minor offences within regulatory or decriminalized systems of justice and punishment (see Harris 2016: 163; Martin et al. 2018: 477-488; Natapoff 2015b: 257, 265), not to mention those who have studied the POA (see OAPSB 2011: 20-21). Despite this shortcoming, the search did provide greater clarity into the POA program and aided in locating where certain key decisions emerged.

\footnotetext{
${ }^{33}$ The latter search engine was selected based on its extensive reference library containing a diverse set of provincial government records, which is likely in part related to the fact that the City of Toronto is both the province of Ontario's capital and where its main legislative bodies and government departments are located.
} 
In light of the discoveries and difficulties raised from these initial searches, I then pursued government and public policy records through freedom of information (FOI) and/or access to information (ATI) requests. An increasingly popular tool used to gather data in the field of social science (Walby \& Luscombe 2018), FOI requests are considered a useful option to study the "activities" of governments and potentially may offer "the most in-depth data" about their departments, programs, and transformations over time (Walby \& Larsen 2011: 32). Providing a "back-stage" (see Piche, Kleuskens, \& Walby 2017) to both systems and programs understudied and lacking in publicly-available documents - such as the POA - FOI requests were undertaken to obtain data to address my research questions and provide as scrupulous a genealogy as possible.

Guided by the FOI strategies outlined in Jobb $(2015)^{34}$, I initially casted a wide net with multiple FOI requests made to various government entities both provincial and municipal involved in the POA - 11 in total (seven to MAG and the Ministry of Community Safety and Correctional Services, and one each to the Ministry of Transportation of Ontario [MTO], Archives Ontario, the City of Ottawa, and the Ottawa Police). In general, these applications requested records pertaining to discussions about the objective(s), mandate, vision, purpose(s), and/or role(s) of the POA, as well as any annual reports, presentation and/or briefing notes related to or discussing the POA. Assuming that "the records are available" (Jobb 2015: 26), while also utilizing knowledge gathered from my time as a POA clerk and through the initial online searches, I narrowed my FOI requests through various strategies, including: specifying time periods (i.e., time intervals of four years) ${ }^{35}$, specifying working groups, as well as specifying types of records (e.g., final reports, briefings notes and memos, ministerial briefing booklets, presentation decks, and other statistical data

\footnotetext{
${ }^{34}$ Examples of these strategies include 'doing your homework' (i.e., research on the research object) to aid in 'wording the request', as well as presuming 'records are available', requesting a waiver of fees, and writing multiple request (see Jobb 2015: 21-32).

${ }^{35}$ Based on prior knowledge, I undertook an expansive search that began in 1973 (chosen from the earliest document I found discussing such a system like the POA) and went all the way to 2017 (when the FOI requests were being sent out).
} 
points). Despite these attempts, the process began to take considerable time; while some requests were responded to more swiftly (within one to two months), others provided very little in sources and/or demanded greater resources in the form of fees, luxuries (i.e., in time and money) that were not readily available for this study. As such, quick and careful decisions and clarifications had to be made to receive data in a timely and cost-efficient manner ${ }^{36}$.

In the attempt to stay true to providing a 'history of the present' and a thorough genealogy of the POA, I decided to focus on examining and actively pursuing and narrowing FOI requests that comprised of the contemporary period (going as far back as 2011) as well as two 'events' in the POA history where major transformations (i.e., emergences and key decisions) to its governance structure were uncovered in my descent ${ }^{37}$. To clarify, the latter two emergences specifically refer to the creation of the POA in 1980 through Bill 74 (The Provincial Offences Act, 1978) and Bill 75 (The Provincial Courts Amendment Act, 1978) as well as its transfer to municipalities in the 1990s through Bill 108 (The Streamlining of Administration of Provincial Offences Act, 1997). Furthermore, to expose myself to as many government sources in the 'assemblage' of knowledges and discourses constructing the POA, I also included publiclyavailable committee hearings, debates in the legislature, and records obtained from both the Carleton and Toronto libraries discussing these policies, adaptations, and/or reforms.

\footnotetext{
${ }^{36}$ To give the reader a sense of the timeline of the FOI process for my thesis, requests were sent out in November of 2017 and were not officially completed until late April of 2018 (when all records to which I was provided access were finally received). There are a variety of reasons for why this process took over 6 months to complete, with many of them explored in Brownlee and Walby's (2015) book about FOI and ATI requests. To give a simple example from my thesis, many delays simply came about from the continuous email exchanges I had with the FOI analyst in charge of my files, as I attempted to minimize the time and cost to my requests by further narrowing their timelines, the type of records being requested, or requesting a waiver or reduction of fees. The main problem faced in these interactions was that government employees sometimes took weeks to respond to my communications (whether by email, phone, or letter-mail), as the analyst(s) was required in many cases to confer with their department along with others associated with the records before releasing them.

${ }^{37}$ An example of such an active pursuit can be with my request to Archives Ontario. Although initial access to records was provided very quickly (in December) and led to a required trip to Toronto to review them, upon examining the records, I observed that practically no records (except for one) was released in relation to Bill 108 (The Streamlining of Administration of Provincial Offences Act, 1997) and the transfer of the POA to municipalities. As a result of this, and knowing the fact that records more than 20 years old cannot be withheld (exempted) under particular sections of the provincial legislation governing FOI requests, an appeal was initiated (letter sent in early January 2018) with a mediation process resulting (ending officially in April of 2018) in access being given to 15 separate documents - totalling hundreds of pages - containing reports, briefings, even emails from various departments apart of the 'assemblage' of knowledge forming the POA and this specific public policy.
} 
Moreover, as FOI requests from the City of Ottawa and Ottawa Police turned up short in generating adequate sources about a local POA branch, I gathered municipal POA records using four different Google searches to compliment the various provincial documents obtained in relation to the POA's present iteration - referred to as POA Modernization - from other FOI requests. To ensure a rigorous approach, each search contained a specific phrasing established from knowledges discovered in the initial online searches and/or "homework" done for the FOI requests (Jobb 2015: 22-24). These search terms comprised of the following: 'POA Modernization', 'MAG Modernization POA', 'POA Ontario Annual Reports', and 'MAG Modernization Provincial Offences Act'. All POA municipal records were collected that were revealed within the first five pages of each search, the latter being a self-imposed restriction to mitigate for the countless pages (i.e., on the web and in reports) that one can discover online.

The goal of these descents, beyond supplementing the provincial FOI records of this period, was to secure once again a diverse set of sources from the assemblage of the POA; this was especially necessary considering the POA system has exclusively been operated by municipalities since 2001, with the provincial largely playing the role of the mediator in public policy discussions while also providing oversight. In the end, my data collection, based on the records and data excavated through the approaches outlined above establishes my very own "kitchen sink" (163), a term Harris (2016) used to describe her data set in her study of monetary sanctions in the US.

Importantly, this thesis is not suggesting that periods of the POA unexamined by this research are insignificant; simply put, they did not contain in my searches (i.e., descent) the same type of disruptions and/or seismic changes discovered in the 'key decisions' selected. As Foucault (1998) famously said: "a [g]enealogy is gray, meticulous, and patiently documentary" (369), and with no telling where it will take your research, it simply requires "relentless erudition", flexibility, 
and patience (370). Inspired by these words, and those from Harris and others who have endeavoured to explore the neglected field of fines and their systems of punishment, I have attempted to provide as equal, 'full' and diligent an account of the POA as able.

\section{3 - Selection and Characteristics of Data Collected}

Upon completion of my data collection, I had approximately 198 records $^{38}$, with a large portion (approximately 91) resulting from the quick approval of my initial Archives Ontario request (see fn. 37). The records' characteristics are varied, going as far back as 1973, with some records containing one page to others containing over a hundred. They also comprised of various types of records, including: briefing notes, presentations decks, cabinet submissions, reports, books, memos, a press release, debate points for legislation, public consultations letters and their responses, an instruction manual for justices, emails, pamphlets, policies, as well as committee hearings and debates within the Ontario Legislature. Overall, this 'sink' full of records provided rich content of the 'front' stage (i.e., public representations of the POA) and 'back' stage (i.e., the inner-workings and discourses used in developing POA policies) to make the problems, knowledges, and discourses of the POA discernable.

As previously mentioned, a selection processed was undertaken to minimize the number of sources to code as well as narrow the scope of the research study for a suitable genealogy of the POA within the time provided for a thesis. As such, before a record was coded, it had to meet a predetermined set of characteristics (i.e., questions):

1) Records must be within the specific time periods chosen (1977-1980, 1996-1999, 2014-2017); and (include at least one of the following characteristics)

2) Records must contain discussions related to purpose(s), objective(s), mandate, or vision of the POA;

\footnotetext{
${ }^{38}$ These numbers were determined based on excel spreadsheets I created to properly organize the records and documents obtained in my data collection process. They do not however account for the various news articles, court cases, reports found outside of my data collection and statistical data provided by MAG and MTO and reviewed for this project.
} 
3) Records must define or explore notions of justice and punishment (i.e., in relation to their role in the POA); and lastly

4) Records must discuss, help construct and/or represent the 'assumed' and 'implicit' problems the POA is meant address (see Appendix 1)

The time periods of the first criterion were when both 'key decisions' selected (Bill 74 and 75 in 1978, Bill 108 in 1997) were being developed and discussed in the legislature, and therefore selected to ensure a detailed 'history of the present' about the POA was attained. The remaining characteristics were derived from my research questions and assisted in removing documents that fail to explore the various research objects for this study. After applying my selection criteria to the records collected, I was left with approximately 100 documents to code.

\subsection{Content Analysis}

As outlined in post-positivist design, where research questions " "tel[1] the researcher what the research-relevant data and their likely sources... are" (Schwartz-Shea \& Yanow 2012: 79), they also provide signals as to the research method a study should take to analyze this data. Given that my research questions are directly pursuing the construction and representations of problems about the POA within various official government records, including the discourses and rationales (i.e., language) that underscore them and their notions of punishment and justice, a content analysis was used to examine such representations.

As defined by various scholars, a content analysis is "a careful, detailed, systematic examination and interpretation of particular body of material in an effort to identify patterns, themes, biases and meanings" (Berg \& Lune 2012: 347; see also Leedy \& Omrod 2005; Neuendorf 2002). Explained further, a content analysis is a "research technique" that is used to make both "replicable and valid inference from texts" (Krippendorff 2004: 18) through carefully designed 
categories (i.e., codes, patterns, themes) and selection criteria of data to ensure a rigorous approach (Berg \& Lune 2012: 350).

On that note, there are several reasons for selecting this method. To begin, as Fairclough (1995) explains, text and language are both equally discernable sources that allow researchers to make "ground[ed] claims" (209) about the social processes, structures, and relations. Moreover, texts are also, historically, excellent "barometers of social processes" (209) that provide indications of change and transformation in our practices and social relations occurring over "long periods of time" (Berg \& Lune 2012: 375). In short, as I am largely interested in observing "what is [or is not] present" through reoccurring themes and patterns (376), and not the "linguistic analysis" of a text (e.g., semantics, counts of terms and words) (Fairclough 1995: 188) as is common to a critical discourse analysis, a content analysis was deemed most suitable for this study.

\subsection{Coding}

Concisely framed by Berg and Lune (2012), a content analysis is primarily "a coding operation and data interpreting process" (350). In other words, a crucial component of any research method studying language and/or text is its coding system, as it is the process for "abstracting" the various patterns and/or themes that are present within the "unstructured and messy" data gathered (Morse \& Richards 2002: 111).

To achieve the above and ensure a rigid coding system, I initiated an open coding process (Berg \& Lune 2012: 364-367) through a three-step method. In step one, I simply began by familiarizing myself of all the records collected by reviewing their content broadly and registered each report into an excel spreadsheet according to the type of document examined (e.g., memos, reports, handwritten notes, presentation decks, statistics), how it was obtained (e.g. FOI request or publicly available), the date of the report, as well as its overall subject matter (e.g., public 
consultations, second reading debate points, POA fine enforcement). From this initial stage, I was able not only to become more immersed in my data, its content, and potential themes ${ }^{39}$, but also to establish my data selection criteria for my analysis given the scope of records.

Following this step, I investigated each record by reviewing whether the document met, at minimum, two components of selection criteria created: the time periods selected (i.e., 1977-1980, 1996-1999, 2014-2017) and at least one other criteria (refer to section 4.3 - Selection and Characteristics of Data Collected). Records that met these criteria were then carefully coded. This involved reading the records and writing observations pertaining to the potential themes and categories that were guided by my research questions; and while the themes were almost exclusively generated from an inductive process that saw me 'submerge' myself into the records (Abrahamson 1983: 286), this thesis, taking a post-positivist approach, also employed an abductive process. Deemed a vital process to a good study by Berg and Lune (2012), once a theme or pattern is identified, a researcher "must consult" previous works to examine if "confirmed" in the research of others and where similarities and differences are discovered $(375)^{40}$.

At the end of this step, which included carefully examining each coding sheet and discerning reoccurring themes, each theme was then organized into overarching categories. The categories were constructed through my iterative and recursive process, as derived from various points in my coding process (i.e. research questions, themes located in the data, review of academic literature). The five categories are: the problematizations of the POA, the master patterns, the mentality of rule (i.e., power relations and governmentality), the construction of punishment and

\footnotetext{
${ }^{39}$ A theme, according to Morse and Richards (2002), is "something more pervasive than a topic or category...[that also] runs right through and is not necessarily confined to specific segments of text" (121).

${ }^{40}$ One example from my study is the 'redistributive' feature of the fine within the POA. Having located discourses within the records discussing the revenue component of the fine, I then examined pockets of literature which focused on this particular discussion (i.e., literature on the fine and decriminalization). Noticing that many theorists had raised this point in their own findings, I include the notion while expanding on its impact within the POA's specific model of decriminalization and system of penality.
} 
its objectives/functions, and the construction of justice and its objectives/functions (see Appendix 2 for full coding sheet).

After all themes were selected and placed in their specific 'coding category', a final round of coding was done, to ascertain that the first round of coding was thorough and did not miss any patterns fitting the original themes uncovered. To ensure a meticulous genealogy, which encompassed tracing the different problematizations and potential developments in the other created categories, observations located in the records were also sorted by the time period selected and placed into three separate coding sheets (with the same themes placed on each of course); this allowed my research to better delineate how patterns, problems, objectives, and/or functions may have (or have not) shifted over time in the POA. Just as any other aspect of the research process, codes were refined "on the fly" (Berg \& Lune 2012: 370) when examining the records, to secure not only concrete codes, categories, and themes, but also an accurate interpretation of the data. From this methodological process, I now turn to the findings of my genealogical study.

\section{Chapter 5: The Sociology of the POA, Decriminalization, and its Problematizations}

The construction of today's 'modern' version of the POA is the result of the implementation of numerous policies in its 38 -year history. In this thesis and chapter, I examine three time periods characterized by a significant transformation in the POA's infrastructure - its creation (1977-1980), its transfer from the province to municipalities (1996-1999), and finally its more recent pursuit of 'modernization' (2014-2017). As explored in the prior chapter, these periods were chosen as areas where "key decisions" (Bacchi 2009: 10) are made or "emergences" (Foucault 1998: 376-379) are located, establishing the direction of this legal administrative system. 
Guided by my main research questions and theoretical framework, which comprises a 'study of problematizations' or WPR approach (see Bacchi 2009, 2012), this chapter begins my 'history of the present' to the POA by tracing what "particular shape" (2009: 11) problems, and their subsequent solutions and policies, take within government records ${ }^{41}$. Consequently, shaping the design of decriminalization in the POA, together with its model today, this chapter also commences the process of destabilizing the phenomenon's (i.e., decriminalization) 'fixed essence' along with the configuration of punishment and justice established within the POA model. To do so, this chapter injects its sociology of punishment and critical criminology framework by delineating the various social structures (e.g., rise of the automobile and neoliberal political economic policies) shaping the POA's system of decriminalization as well as the "master changes [i.e., patterns]" (Cohen 1985: 16-17) at its centre. Beginning the process of exploring the outcomes and attempts by the POA to 'eliminate the debtor prison' found under the previous model, this chapter lastly begins to question "what fails to be problematized" under its regulatory model and how it could possibly be "thought about differently" (Bacchi 2009: 12-14, 19).

To investigate these matters, I begin each period by outlining the 'problems' that emerge and are construed as areas the POA and its policies are intended to 'fix' or focus on. Following that, I examine the latter's "origins, purposes, and effects" (19) as well as the tactics and 'discourses' that mould into the practices or "prescriptive texts" (Foucault 1986: 12-13) that makeup the POA and its various roles and goals. To conclude, this chapter considers what this

\footnotetext{
${ }^{41}$ As mentioned in my methodology chapter, these records include 'knowledges' from various government and non-government entities. The POA 'assemblage', although largely governed by MAG and municipal POA branches (as of 2016), also includes at the provincial level - Ministry of Community Safety and Correctional Services, MTO, Ministry of Finance, Ministry of Municipal Affairs and Housing, and ServiceOntario. While at the municipal level, it includes: Association of Municipalities of Ontario, Municipal Court Managers' Association of Ontario, Ontario Municipal Tax and Revenue Association, Association of Municipal Managers, Clerks \& Treasurers of Ontario, Municipal Finance Officers' Association of Ontario, Police Association of Ontario, and the City of Toronto (see MAG 2016a: 11). That said, other organization have created 'knowledges' that have become apart of the construction of the POA, including work done in the 1970s and 1990s by OLRC (see 1973a, 1973b, 1973c, 1990), and in 2011 by its current name - the LCO, as well as the OAPSB (2011).
} 
configuration of the POA disregards by discussing some of the forgotten 'roots' to the POA's genealogy as well as the re-emergence of old problematizations.

\section{Chapter 5.1 - 1977-1980: The Emergence of Administrative Justice (The Creation of the POA)}

"A flood of minor, non-criminal offences threatens to engulf the administration of justice if new ways are not found to dispose of them with more speed and efficiency....the adoption of proposals must necessarily in the long term, result in a dramatic reduction in the demands of costs, manpower and facilities presently required to be met in the system within which are now being administered" (SCRC 1977a: 1, 10)

As far back as the early 1970s, reports like the one completed by the OLRC (1973a, 1973b, 1973c) - a task given to this body by the Minister of Justice and Attorney General in 1970 (see 1973b: xiii) - have discussed the need for "more convenient, economic and efficient disposal of the civil and criminal business" (xiii) of the judicial system. That said, as the above quote alludes to, and the forthcoming examples demonstrate, the main source clogging the system of justice, which was fully administered and financed by the province only starting in 1968, derived primarily from cases considered 'minor' and 'non-criminal' in nature ${ }^{42}$.

For the provincial administration throughout this period of developing the POA system (1977-1980), “the problem”, as the Attorney General Roy McMurtry states, largely stemmed from its "volume" (MAG 1978a: 3; see also Lawlor 1978; McMurtry 1978a; SCRC 1977a). Statistical records show that 3.1 million provincial offences were received in the fiscal year of 1975-1976, 1.3 million of which fell under the Highway Traffic Act (HTA), 120,000 under the Liquor Control Act/Liquor Licence Act, and 1.6 million under bylaw offences (i.e., parking tickets and other

\footnotetext{
${ }^{42}$ As the OLRC report (1973b) mentions, which is also stated in the more recent book Ontario Court of Justice [OCJ] - A History (Cohl, Lightstone, and Thomson 2015), starting in 1968 the province of Ontario assumed the full financial responsibility of the "provision, maintenance and operation" (OLRC 1973b: xiii) of the court system from one where municipalities had a fiscal role (Cohl et al. 2015: 128-129). Important to note as well, starting in 1968 there was a growing volume of criminal and family law cases that began to be heard in these newly established provincial courts (128-130). I raise these issues - the growing costs and volume of cases the province faces - as they clearly become a central concern or an 'implicit problem' for successive Ontario provincial governments to 'fix', including the provincial administration in 1977-1980. These 'problems', and the practices that emerge in light of them, are explored throughout the chapter/thesis.
} 
municipal offences) (SCRC 1977a: A-16); a vast quantity in contrast to the 250,000 criminal offences received by the provincial courts in that same period (MAG 1978a) ${ }^{43}$.

At the center of this growing 'problem' of volume was the serious drain and effect these 'non-criminal' matters were having on Ontario's judicial system, hindering the latter's capacity to effectively function. The source of the issue was understood by the government to be the same procedural process and parallel sentences provided to a non-criminal matter (e.g., traffic offence) as a criminal one. In the initial enforcement and court process for non-criminal offences, an automatic summons was issued for all infractions, leading in many cases to what the government characterized as "needless trials" (MAG 1978b: 1) for individuals presumed to have "never intended to appear [in court to contest their offence]" (1978c: Tab J - 1; see also SCRC 1977a: A$4, \mathrm{~A}-5)^{44}$. Likewise, in relation to sentencing, a large number of individuals were also jailed for charges laid and unpaid fines, placing greater stress on the province's issue of volume concerning "overcrowded jails and detention centers" (Smith et al. 1978: 3) and the debtor prison existing during this period (MAG 1978a: 14; see also Lambert 1978; MCS 1978; SCRC 1977b: 1). In short, the judicial process in place prior to the POA was regarded by the provincial administration to be using an unreasonable "proportio[n]" (MAG 1980a: 3) of resources - police officers, court officials, justices of the peace - to process all 'non-criminal' cases at each stage of the judicial system (see 1980b, 1980c: 6).

Intertwining this issue of volume and resources, however, is the problem of "cost or inconvenience" (SCRC 1977a: A-9), or as the committee report studying the former procedural

\footnotetext{
${ }^{43}$ As mentioned in the literature review (see section 2.2.1 of this thesis), the rate of provincial offences charges laid and processed by the courts in contrast to criminal matters is at a similar proportion today (3.3 million provincial offences [excludes parking tickets] issued in 2014 and 2015 in contrast to 328,000 criminal charges in that same two-year period).

${ }^{44}$ According to the province's records, of the 1,276,000 "Summary Conviction Tickets served" in 1975/76 fiscal year, 780,000 of them resulted in "trials in absentia" (i.e., the defendant not appearing on their court date) (SCRC 1977a: A-4). The concern here is that the government is inferring from there that these individuals never wish to dispute their charges and therefore focus largely on policy solutions that address exclusively that aspect. The ramifications are later explored later in the chapter and thesis when examining the outcomes of this approach.
} 
code (i.e., the SCA) concluded elsewhere: the "colossal waste of money, time, paper, manpower, and facilities" (1) spent to process, operate, and administer these cases. As records during this period of study indicate, concerns about "squander[ing] limited resources" (MAG 1978c: Tab H 2), "expensive unnecessary ritual[s]" (SCRC 1977a: A-5), procedural "technicalities" (MAG 1980b), "trials running into millions of dollars each year" (MAG 1978a), and "cost to the taxpayers" (MAG 1980c; see also SCRC 1977a: 3) were all center of mind for the provincial government in managing these cases and its judicial system.

Consequently, it is within the problematization of volume and costs by the province, construed as far back as 1973 (see OLRC 1973a, 1973b, 1973c), that the creation of a new procedural code emerges - Bill 74 (The Provincial Offences Act, 1978), along with a separate administrative system for such offences - Bill 75 (The Provincial Courts Amendment Act, 1978) (McMurtry 1978b). These 'prescriptive texts', as well as reports, memos, and other records creating these policies and their direction, outline a vision and objectives for the Act and Administration, "stressing convenience, clarity, efficiency, and simplicity" (MAG 1978a; see also 1978b; SCRC 1977a). Included in these principles is the need for "flexibility" (MAG 1978b, 1980c: 20, 24) and a "streamline[d]" (MAG 1978a: 8, 1980b: 7; SRCR 1977c: 4) process that allows cases to be expediated while also providing the POA with the ability to take more stringent measures where it believes necessary.

A major shift that emerges from these problematizations and their discourses is the establishment of 'decriminalizing' minor offences (i.e. largely driving and bylaw offences, but also includes public drunkenness and other charges as well ${ }^{45}$ ) within the new procedural code (i.e.,

\footnotetext{
${ }^{45}$ Based on the data provided at the start of this section, $81 \%$ of the volume of minor offences comes from traffic and bylaw offences (see also Smith et al. 1978: 1-2 and Woods, Gordon, \& Co. 1978: 3).
} 
Bill 74). To elaborate, this transformation arguably arises as a result of government's concern about the economic sustainability to its justice model, as its discourses repeatedly construed minor offences as both a pressing burden on the administration of justice "to the detriment of serious business" (SCRC 1977a) and a great waste of time and expenses to resolve them (MAG 1980a: 3). In turn, it is subsequently only under these contingencies that government concedes its former approach (i.e., the SCA) to be "impractical", "undesirable" (SCRC 1977a: 2), and therefore in need of "urgent reform" (McMurtry 1978a).

One practice (i.e. technique) that embodies this shift and emergence during this period is the creation of a new tool of punishment to sanction these offences, referred to as a "certificate of offence" or "offence notice" (MAG 1980c: 8-9; see also 1977a: 14, 1979: 5-9; Appendix 3, Morris 1978; SCRC 1977a: A-3 to A-15). Establishing the 'modern fine' as it exists today in Ontario, an offence notice allows a peace officer (i.e., a person designated by the province to enforce the law) to issue an 'infraction' for offences considered 'minor' with a "minimum penalty" (i.e., monetary sanction) in relation to the "gravity of the offence" (SCRC 1977d: 7) ${ }^{46}$. Instead of being automatically sent to trial as was previously done, 'defendants' are now required to select between three options within 15 days $^{47}$ - pay the fine, file a not-guilty plea at a court office and await a trial date by mail, or plea guilty with explanation in person with a justice of the peace in the hopes of the fine being reduced. Failure to actively select an option results in an automatic "default"

\footnotetext{
${ }^{46}$ Arguably as well, the establishment of "strict-liability" offences by the Supreme Court decision - R. v. Sault Ste. Marie (1978) - is also a contributing factor allowing the use of "offence notice" (i.e., ticket with only a fine) to emerge as a form of punishment. Therefore, the importance of the 'legal order' establishing our judicial systems, an argument made by Young (1987), is certainly a factor in the legitimacy and thus use the modern fine gains in this administrative system.

${ }^{47}$ In my experience working at POA offices in Ottawa (employed from 2009 to 2016), an individual is provided with much more time to select an option (approximately 44 days); this is in spite of the fact that offence notices to this day still says 15 days (see Appendix 3; see also "Lifecycle of an Offence" in Sudbury 2017). Although the grace period is certainly convenient to 'defendants' (a term used by the province instead of accused to reflect this new procedure - see MAG 1980c: 8), this is largely unbeknown to most and only discovered if they choose to speak to a clerk (by phone or in person). Legislatively, under the Act (1990) section 9(1)(a): a "defendant is deemed to not wish to dispute the charge" after 15 days has elapsed from the date of issuance. This gives municipalities and justices of the peace the option to issue a conviction for Part I (e.g., traffic offences) if no response is given by a defendant within that time, but once again in my experience, a 30 -day period is at minimum provided by many, if not all, POA administrations. This raises the question why the back of ticket only says 15 days if more time is provided, who is this system being 'flexible' and 'convenient' for, as providing more time at the onset and being openly transparent about it might give people the time they need to come in and dispute their ticket instead of potentially feeling forced to pay.
} 
conviction and/or the imposition of additional sanctions (e.g., wage garnishment, demerit points, driver's licence suspension, forfeitures, or even a jail sentence) (MAG 1980c: 9-12, 20-22). Ultimately, the goal and objective of "emphasizing" this tool (i.e., the certificate of offence), as stated by the province in the instruction manual for justices of the peace, the main arbiters of the POA, is to "bring about drastic savings" to the current judicial system (MAG 1978a: 14, 1979: 112).

Along with the creation and expansion of other practices, including the "North York Traffic Tribunal" providing people with the ability to plea guilty in person at a "time convenient to [them]" (1978a: 4), this technique constructs punishment and justice as 'flexible and speedy', 'inexpensive and convenient', and 'efficient'. Yet, paradoxically, considerations of other practices, such as 'day fines" ${ }^{48}$, are considered too "complex, costly, and time-consuming" (SCRC 1977d: 9) to administer. Moreover, the use of imprisonment as a sanction is still retained and deemed a necessary "last resort" (MAG 1980c: 21-22), purportedly kept to prevent "a gift of immunity [to scofflaws ${ }^{49}$ ]" (SCRC 1977d: 13) and protect the "crucial value" of recognizing one's debt to society even if the "payment [through a monetary fine]...takes time" (MAG 1978b: 2) ${ }^{50}$. Thus, although the province states the creation of the POA as being more "comprehensible and accessible to the citizens" (McMurtry 1978c) while ensuring the 'right to a trial' is protected (MAG 1979: 22), the records demonstrate that these techniques are largely introduced to "relieve the enormous

\footnotetext{
${ }^{48}$ As explained in the same report, a day fine is a system where the court imposes "a fine to order the offender to pay a certain number of units or fractions of the offender's income" from the previous year (SCRC 1977d: 8).

${ }^{49} \mathrm{~A}$ term actually used in the report over the concerns of the potential removal of having the option of imprisonment at the province's disposal, the meaning of the term refers to someone "who flouts the law" by willfully ignoring or failing to comply to it.

${ }^{50} \mathrm{In}$ fact, part of the concern with the previous system and procedures - the SCA - was that it was felt that "the option as to serving the jail term appear[ed] to be in the offender['s hands]" (SCRC 1977d: 10), with some opting to 'pay their debt to society' by serving their sentences concurrently on a weekend. Important to note also, following a FOI request \#MAG-A-2017-02241 made in 2017, the use of jail for "defaulted fines" matter was only officially abolished by the Ontario government in 2001, which ironically coincides with the responsibility of the POA being fully transferred to the municipalities. Looked at more closely in the next chapter, the use of imprisonment however is still regularly used in the POA, based on stats given from 2004 to 2017, with rates peaking at 2,914 in 2009 before slowly dropping to 1,862 in 2017 (see Appendix 4, 5a and 5b).
} 
administrative burden", both in volume and costs, imposed by administering such offences, to "liberate the courtroom for other matters" (MAG 1978c: Tab P: 3).

Decriminalization, a term used in earlier records (see SCRC 1977a; Smith et al. 1978; Woods, Gordon, \& Co. 1978) but symbolically replaced later by the notion of a change in "procedural code" $" 51$, is in this period seemingly more about managing the 'problems' involved in the administration of the POA (i.e., cost, volume) than with relieving the actual people penalized under it. As a result, the creation of the POA is not so much about being 'less punitive', as incarceration is kept with the imposition of consecutive sentences for fine defaulters (see fn. 53 of this thesis; MAG 1980c: 21-22; SCRC 1977d: 10), and more an attempt to better ration the province's system of justice (i.e., its resources). It is also under this function that the 'modern fine' becomes an "appropriate" form of punishment, meeting the needs of being "flexible, adaptable, [and] inexpensive" (SCRC 1977b: 2) for the state to regulate activities it warrants as "useful [and productive] to society" (MAG 1978a: 2) ${ }^{52}$. Its proliferation and establishment as a tool of punishment primarily utilized in this system is thus also, from the state's perspective, about the cheap and efficient qualities to administer, deemed vital to its ability to govern over its territory and the changing order of this period.

With a focus on "savings" (MAG 1977b, 1978a, 1979; SCRC 1977a), "efficient court scheduling...[and] optimum use of court resources" (McMurtry 1978b), the Act (i.e., Bill 74) and the establishment of the Provincial Offences Court (i.e., Bill 75) is conceptualized as a "convenient and economical vehicle for the enforcement" of the various statutes under its guise (SCRC 1977a:

\footnotetext{
${ }^{51}$ In one record reviewed, a draft to the "explanatory note" to Bill 74 (i.e., the Act) is adjusted to say "provision of procedures for the prosecution of provincial offences in a provincial code of procedure without reference to the Criminal Code (Canada)" rather than its previous iteration of "decriminalization of the procedures in so far as possible" (MAG n.d.). The term "decriminalization" although located in some documents is sparingly used in 1977-78 and is non-existent by 1979 when the policies - Bill 74 and 75 - receive royal assent.
} 
2). It is under these premises that an administrative system of justice, embedded with "new principles and approaches to minor offence[s]" (12), is born.

Stated differently, the emergence of the POA's 'decriminalized' system, created under the problematizations of volume and cost, is one that suggest its model is more representative of a "regressive economic policy" than truly the pursuit or objective of attaining and creating a "progressive penal reform" (Natapoff 2015a: 1060). Under this configuration, through discursive (i.e., discourses in records) and non-discursive practices (e.g., issuing a POA 'offence notice'), the transformation to the regime of punishment arguably also aligns itself to the POA's economic conceptualization. Under this rationalization, the province going forward not only sees 'drastic savings' from its new decriminalized approach, but also potential revenues from it. It is under this notion, that I now turn to the second period examined: the emergence of the redistributive feature.

\section{Chapter 5.2 - 1996-1999: The Emergence of the Redistributive Feature (The Business Case of the $P O A$ )}

Ontario's municipalities are facing enormous changes and challenges as we approach the $21^{\text {st }}$ century. 1998 will herald a fundamental transformation of municipal and Provincial roles and responsibilities....Since 1992, annual Provincial funding to municipalities has declined by $\$ 1.0$ billion. $\$ 700$ million of that was cut by the current Government. In 1998, municipalities will lose another $\$ 1.0$ billion annually because of Who Does What [WDW]. At the same time, the Province's expectations that property tax dollars will fund Provincial programs is growing.... That is one reason why the revenue side of the reform equation is critical to municipalities...I think [POA revenues are] an example of the type of revenue source that municipalities are going to be looking for and are going to need, as time progress... and if you're going to force the responsibility on us, then we want the revenue"(comments made at the Standing Committee on General Government in relation to Bill 108 by Mr. Anderson, Chairmen of the Region of Durham for AMO ${ }^{53}$ 1997a; see also AMO 1997b)

\footnotetext{
${ }^{53}$ As their report and initial statement to the Standing Committee on General Government explains, the AMO (1997b) is a non-profit organization with a mandate of "promot[ing], support[ing], and enhance[ing] strong and effective municipal government" (13), or as described in one recent municipal report: "[a]s the leading voice of Ontario's municipalities to the Province, AMO is best positioned to advocate for a province-wide solution" (City of London and Middlesex Region ["London"] 2016: 5). According to their website today, AMO (2018) is stated to represent over 444 municipalities that include Ottawa, Mississauga, Timmins, and many more. On top of their participation in committee meetings related to Bill 108 in 1997, the AMO has been actively involved in recent discussion in relation to the POA (see MAG 2015a, 2015b, 2015c to name a few), as well as the WDW panel (Government of Ontario ["Ontario"] 1997, Ontario Legislative Library [OLL] 1998) and other municipal-provincial projects.
} 
In May of 1996, 16 years after the official enactment of the Act and POA, the WDW Panel - a committee of both provincial and municipal members - was tasked by the Harris government of Ontario to locate where roles and responsibilities could be realigned between the provincial government and municipalities (OLL 1998: 1, Ontario 1997). This initiative was commissioned by the provincial government in an effort to create "a more efficient and effective distribution of responsibilities between municipalities and provincial governments" (Graham \& Philips 1998: 176), which largely consisted of the latter looking for ways to "reduc[e] their transfers" to the former ones and other partners (i.e., schools, colleges, universities, and hospitals) (Ontario 1997: 1). It is within this environment and under these conditions that the POA is placed in a new policy direction: its transfer to municipalities through Bill 108 - Streamlining of Administration of Provincial Offences Act, $1997^{54}$.

As the quote above by the AMO (1997a) and records of this period (1996-1999) indicate, what spurs this change in the POA is the (re)problematization of cost and savings once again; however this time, it is not only in relation to the issue of savings to the province, but also 'downloading of cost' (i.e. responsibilities) unto municipalities, and the emergence of the 'redistributive' 55 feature (i.e., revenue), and thus a new role, function, and objective of the POA.

Describing its purpose, Bill 108 (1998) is construed as "[a]n act to deal with prosecution of certain provincial offences, to reduce duplication and to streamline administration", which as the Attorney General Harnick (1997a) explains, focuses primarily on "eliminating waste”. In other words, from the provincial government's point of view, the goal was to "achieve the Government's

\footnotetext{
${ }^{54}$ The vast majority of POA functions and operations were transferred to the cities with Bill 108, however some responsibilities were maintained by the province with costs still fully paid back by municipalities. They included prosecution of Part III matters (i.e., summons), provincial appointed of justices of peace and their training, as well as ensuring "quality of justice" was maintained (MAG 1998). Furthermore, the administration and prosecution of parking tickets was already "voluntarily" transferred to the municipalities back in 1993 under Bill 25 (Elliot 1996: 4-5), which 60 municipalities had already opted-in to and accounted for 95 percent of all parking tickets in the province by 1996 (MAG 1996: 11).

${ }^{55}$ As a reminder from my literature review, this concept comes from O'Malley (2009a) when discussing the money's characteristics (21-22).
} 
policy and fiscal objectives" through the transfer of the POA to municipalities (MTO 1996: 1).

Repeatedly mentioned in the records, is the criteria that the "contribution to Ministry saving targets" must be met by municipalities (MAG 1996: 3, 8; Management Board of Cabinet [MBC] 1996a: 3, 1996b: 1, to name a few). This included the province seeking to cut " $\$ 24$ million in expenditures [through the transfer]" (MTO 1996: 1) by evaluating municipalities on the size of the “expenditure reduction" they would generate for the province (MAG 1996: Appendix 1 - 2) and their "willingness to accept existing staff" (3). Put simply, the province saw the "devolution of the POA as a savings initiative" (Elliot 1996: 5) to meet its own fiscal targets in light of the financial issues it was facing ${ }^{56}$.

Meanwhile, for the municipalities of Ontario, as the AMO's comments (1997a) indicate, concerns at the time centered around the absorption "of additional responsibilities [from the province] without offsetting revenue" (City of Brampton 1997) as they attempted to "hold the line on property taxes" with “ever-shrinking resources” (Town of Orangeville ['Orangeville'] 1997). Thus, for the municipal governments, the POA becomes viewed as a "much-needed" source of revenue (Orangeville 1997; see also Region of Ottawa-Carleton [ROC] 1999), one the province continuously guaranteed would be provided through Bill 108 - the POA Transfer Project (Elliot 1996: 5; Flaherty 1997; Harnick 1997b, 1998; MAG 1996: 5; Ministry of Solicitor General and Correctional Services [MSGCS] 1997: 3; WDW 1996).

It is through this issue of a lack of revenue, to give out by the province and one provided to municipalities, that the function and role of this system of social control and punishment expands

\footnotetext{
${ }^{56}$ In the reports provided there are different estimates given as to the exact savings the province would gain from the POA transfer. In some records, the number is \$7.98 million for the initial transfer (1997-1998), with annualized savings of \$16.9 million by 1998-1999 (Elliot 1996; MBC 1996a, 1996b). In another report, the initial savings is the same, but estimated annualized savings to be \$13.1 million instead by 1998-1999 (MAG 1996). Apart of these numbers, an amount that did not change throughout the records, was the additional \$3.1 million from the facilities costs (Elliot 1996 : 2; MBC 1996a). Regardless of the exact figures, the emphasis located in these records is the province's goal of meeting its savings target.
} 
from its POA model in 1977-1980. Under the problematization, the POA is represented by the province as economical, as was the case in 1977-1980; but more importantly now with a 'profit' being made over it costs, the POA is conceptualized as an economic asset to be traded in return for all various responsibilities being downloaded onto the municipalities in this period. As one report explicitly states: "[d]uring the development of the devolution proposal, there was an explicit understanding that the POA initiative would be a net revenue gain and this was a fiscal trade off for assuming some of the other more costly programs" (MSGCS 1997: 2, emphasis added) ${ }^{57}$.

One central factor contributing to this new role and function of the POA, is the establishment and reinforcement of the redistributive feature under its model of decriminalization by both governments ${ }^{58}$. Throughout the records examined, the POA is 'sold' by the province as a new "source of revenue" (MAG 1996: 5), one for that matter, that is deemed "attractive" and "substantial" by municipalities, with estimates approximating a total of $\$ 65$ million ['M'] in revenues based on the annual average of the previous four year (1992-1993 to 1995-1996) (Flaherty 1997) $^{59}$. At the same time however, located in the MTO report (1996), is the importance of "conviction-driven" "sanctioning programs" to the provincial government, as its impact includes the potential lost of $\$ 27 \mathrm{M}$ in the "sales of info products to auto insurance industry alone" (12). Thus, although the province is promoting the transfer of the project as a revenue source for

\footnotetext{
${ }^{57}$ Actually, in one memo from the ROC (1997), this is explicitly admitted: "The Province has stated that Bill 108 will be one vehicle by which municipalities will be able to offset the increased costs of social services and long term care imposed... The transfer of administrative and prosecutorial responsibilities from the Ministry of the Attorney General to the Region in respect of the Act charges would provide Ottawa-Carleton with a substantial new source of revenue previously unavailable to it" (56). This message of "exchange for assuming responsibility" and retaining "significant" revenues "for municipal purposes" (ROC 1999: 1) is also echoed in a 1999 memo.

${ }^{58}$ Although the revenue component was discussed in the initial period examined (1977-1980), it was sparingly mentioned. In those records, discourses in relation to revenue exclusively centered on the notion of obtaining "revenues" from fines being lost to people sent to jail (see MAG 1978a: 14, 1978b: 2, 1979: 112). By 1996-1999, the revenue component is much more prevalently discussed, as the emergence of the POA as a 'redistributive' system or new form of 'money transfer' is introduced to the provincial government. Having said that, this is not to suggest that this change in discourse about revenues in the POA did not potentially emerge sooner than in 1996, in fact this is likely the case. For example, in one record obtained from MAG in 1989, which was sent out to all cabinet ministers, the Attorney General of Ontario clearly states that "provincial offences fine levels" are to be raised in that same year in order to "keep current both their deterrent impact and revenue implications" (Scott 1989: 1). Nevertheless, what is being argued here is that there is clear shift that has taken place from discussions in 1977-1980 to those had in 1996-1999, and one that sees a new function or role become central to the POA's objectives by this point, especially in relation to the municipalities. The role of the fine and its relationship in creating this redistributive component to punishment is explored more fully in later sections and the next chapter. ${ }^{59}$ To provide a municipal estimate, according to two separate memos obtained from the City of Ottawa, estimates in 1997 and 1999 ranged from $\$ 3$ to $\$ 4$ million dollars in annual expected net revenues for the ROC $(1997,1999)$; this amount does not include revenues from parking tickets.
} 
municipalities, including as a 'trade-off' for added responsibilities it has placed upon them, the province is also equally interested in the 'profits' to be made by this judicial system.

With the creation of revenues emerging as a clear objective of the POA, one for both the province and municipal governments, policies and practices are once again directed to provide "flexibility for municipalities to realize maximum efficiencies" by locating areas that can further “streamlin[e] POA procedure[s]" (MAG 1996: 16-17, Appendix 1 - 23; see also MBC 1996b: 5, MSGCS 1997: 3). As outlined in the records, the province sought to provide "financial incentive[s]" to municipalities to "operate the system [more] efficiently" (MAG 1996: Appendix 3 -12-14), along with imposing no restrictions on how municipalities could spend the revenue it generated. These conditions were in turn pursued by the municipalities, believing them to likely result in more revenue by further lowering the costs to administer the POA (MAG 1996: Appendix 1 - 21). Likewise, however, the province would also save, as they still bared some operational costs due in part to the challenge in assessing them for municipalities to pay thereafter ${ }^{60}$.

To summarize, as also found in records from 1977-1980, the nature of the pursuit of 'efficiency' is seemingly more centered on the 'savings' to be made as well as the larger 'revenue source' that comes with it for municipalities than about "the continued integrity of the POA justice program" (MAG 1996: 1; MSGCS 1997: 1), or “ensuring a fair, effective and beyond reproach" administrative system of justice (MAG 1996: 8). With discourses from this period centering on the 'fiscal trade off' along with little evidence or added practices undertaken to "ensure... a better

\footnotetext{
${ }^{60}$ Under the agreement established in Bill 108 (1998), monitoring and adjudicating (i.e., justice of the peace) costs were to be remitted back to the province from municipalities, including all surcharges (i.e., the Victim Fine Surcharge). The problem however, at least up until 2015-2016, has been that the "cost recovery rates do not reflect actual costs" (MAG 2015a: 8) as increases in costs over the years (e.g., salary and benefit increases to justices of the peace) have not annually been accounted for, leaving the province to pay some of the POA operating costs. Furthermore, according again to MAG (2015a), the province was also paying for $50 \%$ of monitoring costs, which was set at $\$ 563,000$ per year in 2002 (5). This policy began to change starting in 2015-2016, with municipalities forced to bear all costs, an aspect examined more fully in the next section of this chapter.
} 
justice system" that is "more cost-effective" (Castrilli 1997), the POA model is once again chiefly shaped by the economic problematizations located within its public policies.

To expound in more detail, the expectation of net revenue and municipalities' ability to maximize that potential, along with the province's pursuit of maximizing savings, are the main discourses found in the records observed during this period, which in turn is related to the representation of the problem the POA is to address: a lack of funds to transfer and thus a need to save and obtain revenues where governments deem possible. The concern with an expectation of net revenue with a program, such as the POA, is that its dependence lies, as recognized by both governments, with "charge volume, payment history and operating costs" (WDW 1996: 4; see also Newman 1997).

Coincidentally, as one Auditor General of Ontario [AGO] report determined in 2008, the rate of POA charges rose drastically following the POA's transfer, increasing 57\% overall, while seeing a more drastic increase in some cities (e.g., Ottawa - 155\%, York $-95 \%$, Toronto - 78\%) (230). Seeing a correlation between these figures and the POA's transfer, the AGO report (2008) determined that the province and MAG failed to provide any oversight to the "significant increases in the charging practices of certain municipalities" (229), criticizing provincial oversight as solely focusing on "delivery of court services and related financial and operational matters" (228); and while this critique was disputed by the province ${ }^{61}$, charges continued to mount into next decade (see Appendix 6), while municipalities began to establish their own 'performance standards' to

\footnotetext{
${ }^{61}$ In response to this recommendation, MAG stated that it "monitors volumes of Provincial Offences Act charges... on a monthly basis" and disagreed with the AGO consideration that the increase in tickets issued was correlated to the municipalities now reaping the revenues from those charges. The ministry argued the decision to issue a ticket lays "within the sole discretion of an enforcement officer" and that volume of tickets is dependant upon "population growth, commuter patterns, the creation of new offences" (AGO 2008: 229).
} 
monitor issuance levels (see Alboca 2014; Gillis 2012; Kingston 2018; Soupcoff 2012; Warmington 2013).

All in all, with this system of justice and punishment - during this period - now beginning to describe offenders as "consumers" (Flaherty 1997) and "customer[s]" (MAG 1996: 1), a permeation of the business-like discourses develops under the rationality of this administration and its pursuit of 'efficiencies'. Consequently, the vision that emerges at both provincial and municipal levels of government, one captured in the direct quote that began this section, is reminiscent once again of a "regressive economic policy" outlined by Natapoff (2015a) in her critique of what she labels the "dark side" of decriminalization (1077; 2015b: 264). With a rise in the volume of charges (see Appendix 6) and the practice of imprisonment for defaulted fines only officially becoming removed in 2001 - ironically the same year the responsibility of POA system is officially transferred to municipalities - comes the creation of a "local justice" model (Flaherty $1997)^{62}$ and with it the emergence of the "Billion Dollar Problem"63.

\section{Chapter 5.3 - 2014-2017: The Emergence of 'The Billion Dollar Problem' (The Modernization Period of the POA)}

"Cautionary signals relating to lower charge volumes and lower than average annual gross revenue have not improved in the last three (3) years. The Department has thus far successfully mitigated these pressures through its ability to adapt its resources, reduce some costs and streamline operations. Enhancements in fine collection, increase [r] egulated fees, and potential cost reductions that may be realized through alternative serviced delivery models will assist in mitigating the negative effects of the current charge/revenue decline as we move into 2016" (City of Guelph ["Guelph”] 2015: 18)

\footnotetext{
${ }^{62}$ A concept also mentioned elsewhere (see Harnick 1997b; MAG 1998), the term refers to the "additional responsibilities" (Flaherty 1997), and "more control" given to municipalities over "justice issues that mainly impact [their] community" (MAG 1998: 2). Also allowing the province to "focus [its] justice resources" on matters deemed more serious (i.e., 'dangerous' criminal offences) (Flaherty 1997), the concept of 'local' justice fits within the larger structural changes taking place during this period. This latter transition is explored in the last section of this chapter.

${ }^{63}$ A term that is from a 2011 titled report from the OAPSB, it refers to the $\$ 1$ billion dollars worth of provincial offences outstanding in the province of Ontario. Since then, as of 2016-2017, the amount of defaulted fines - including all outstanding fees and surcharges - is now approximately $\$ 1.45$ billion (Bovdis 2017; MAG 2016a), with 75 percent of them being issued in the last decade (Bovdis 2017: 8). These numbers exclude parking tickets, which are mainly issued but fully processed by the municipalities.
} 
"As law enforcement activities decline so do current revenues. This has been a consistent trend not just in Windsor but also in the province over the past five years. Although the POA Program has other sources of revenues (notably aggressive enforcement efforts targeting old or defaulted fines) the bulk of receipt is highly dependant upon the number, type and quality of newly charges laid, as well as the attendance of trained officer at trials in disputed cases" (Windsor-Essex POA ["Windsor-Essex"]2016: 18)

In the contemporary period of the POA (2014-2017), labelled by the provincial government as the "modernization" project (see MAG 2015b, 2015c, 2016a, 2016b, 2016c), the "central problems' of the system - cost, volume, 'inefficiencies' - along with the established objective and/or function of generating revenue, are roots that trace back to the past sections explored in this chapter. Now under the auspice of municipalities, with 52 separate POA branches (i.e., local justice model) or agreements in place with the province (Bovdis 2017), these roots at the center of the POA's 'history of the present' are similarly entangled once again, as 'POA Modernization' continues to represent or construe its problem as mainly economic ones.

As just mentioned, two 'problems' mainly discussed in both the provincial and municipal records examined ${ }^{64}$ during this period, are concerns about 'volume' and 'cost' to administer the POA judicial system. Repeatedly mentioned in documents, is the issue of "the high volume of minor offences [i.e., traffic-related and parking offences]" to process within the POA (MAG 2015d: 2-5, 2015e: 10; see also City of Oshawa 2015: 2; City of Hamilton [“Hamilton”] 2015: 2; York Region ["York"] 2015, 2016a: 2) ${ }^{65}$. The central aspect in relation to this 'problematization'

\footnotetext{
${ }^{64}$ It is worth mentioning that the exploration of municipal records, although in many cases displays identical or similar goals, objectives, and issues (e.g., collecting revenue, reducing costs, the issue of volume) that POA branches experience, they will in some cases have differences, including in approaches to attaining or addressing them, and in other instances, have trends that run counter to one's found provincially. For example, in York Region (see 2016a: 9), they had a lower charge volume in 2012/2013 with a subsequent higher one in 2014 and 2015, where provincially the opposite trends took place. These differences are one area of research that needs to be understood if we are to comprehend the shape and nuances of "the local "culture of punishment"" (Harris 2016: 100) located in different municipalities (i.e., POA branches).

${ }^{65}$ To further add, on the OCJ website, the data clearly shows that the issuance of HTA offences along with those under the CAIA account for approximately 85 to $90 \%$ of all the infractions issued under the POA (OCJ 2015b, 2016a, 2017a). That said, there are exceptions or differences to consider, including from a year-to-year basis. For example, in Ottawa in 2015, only about $70 \%$ of tickets are for HTA or CAIA offences with the difference (13\%) coming from municipal by-law tickets, an average significantly higher than the province-wide one (3.26\%). By 2017, the average of HTA and CAIA rose to $83.6 \%$ in Ottawa, while municipal bylaw offences accounted for $7.4 \%$ of tickets issued, still much steeper than the provincial average (2.7\%) (see OCJ 2015b and 2017a). Once again, this data does not account for parking tickets statistics issued by municipalities, which are issued in vastly greater numbers than the provincial offences included in the OCJ and MAG data obtained.
} 
relates largely to the cost-effect it imposes onto the system to process and thus, the province and municipalities. Echoing the "needless trial" problem (MAG 1978b: 1) of the 1970s, an issue the POA was said to have resolve in its creation in 1979, the focus of the system once again is concerned with the "higher operational costs" (York 2016b: 9) and (mis)use of "valuable court resources" (Hamilton 2015: 2) that re-emerges as cost to administer and process cases climbs (see also MAG 2015e: 10-11, 2016c: 6-7).

This occurs in part due to the additional "MAG related costs" (York 2016a: 28) 'downloaded' onto municipalities, along with the added imposition (i.e., responsibility) of prosecuting the majority of Part III offences starting in 2018, where an automatic summons to court is issued due to the 'serious nature' these matters are deemed to hold (MAG 2017c) ${ }^{66}$. In each instance, the province argues that the current fees and rates - whether for justices of the peace, prosecutors for Part III matters, or oversight monitoring costs - are "out of date" and "no longer reflec $[\mathrm{t}]$ the true cost" to administer the POA and thus are adjusted accordingly to ensure municipalities fully reimburse them (MAG 2016d: 1-5; see also Chatham-Kent POA ["ChathamKent'] 2017). Meanwhile, municipalities are also raising concerns about 'set-fines' not rising with inflation (Windsor-Essex 2014, 2016), as additional fees on fines - outlined in Ontario Regulation 945 - are deemed not representative of the true cost of delivery (MAG 2017c; York 2016b: 5), along with a shortage of justices to adjudicate POA matters (York 2016a: 3) and a need to improve 'collection tools' at their disposals (Chatham-Kent 2017). In short, the upsurge in cost is related to the issue of volume, alongside the rise in cost to human and court resources (e.g., justices of the

\footnotetext{
${ }^{66}$ Examples of such cases include driving under suspension, stunt driving, driving with no insurance, as well as offences under the Occupational Health and Safety Act and the Environment Protection Act of Ontario. This consequently results in more 'significant' court resources (i.e., costs) automatically being expensed by municipalities (Windsor-Essex 2014: G-1).
} 
peace, police witnesses, court staff), which subsequently leads the province and municipalities to pursuit and demand adjustments (i.e., increase in fees and fines) to make up for the increases.

At the same time however, as the quotes at the start of this section and analysis of records from the 1990s illustrate, there is another variable influencing the practices (i.e., calls for higher fines and additional fees) demanded and pursued by the municipalities: revenue. Consistently found in the municipal POA records during this period (2014-2017) are concerns around the 'shrinking revenues' being obtained from the system of punishment, which in part are and acknowledge by the POA branches as such, tied to the number of tickets issued, along with those disputed (i.e., more cost required to process) or never fully paid (i.e., source of lost revenue) (Guelph 2015: 18; Windsor-Essex 2016: 18; see also Chatham-Kent 2017; Sudbury 2017; York 2016a: 28). To monitor the 'portion of revenue' they collect annually, municipalities establish performance targets and/or indicators (e.g., number of payment agreements, percentage of costs in relation to gross revenue, net revenue budgeted targets) in an attempt to maintain the POA as a "self-funded" (Guelph 2015: 17) and "net positive revenue" provider for cities (Chatham-Kent 2017: 2; Windsor-Essex 2016: 17; see also London" 2016: 5; MAG 2017c; Windsor-Essex 2014: F-3; York 2016a: 4); all of which, as exclaimed by the Windsor-Essex POA branch, is achieved in an "extremely challenging economic environment" (2014: G-1, 2016: 17) ${ }^{67}$.

The economic environment noted by the Windsor-Essex branch arguably has multiple meanings. The first, explored during the transfer period of the POA (1996-1999), relates to the major fiscal issues municipalities continue to face in funding services and projects (see AMO

\footnotetext{
${ }^{67}$ An excerpt from a recent news article by Hale (2018) writing about the POA branch in Cornwall and Stormont, Dundas and Glengarry counties, captures I believe, the representation of the problem(s), the pursuit of objectives, and current dynamics at work in many of the POA branches across Ontario today. The except begins with the City Treasurer for Cornwall explaining: "Because the number of tickets is falling, so our revenue is falling. The province charges us for the cost of having a justice of the peace, which is rising. They charge us for monitoring, which is the provincial oversight, and that's increasing," [the counties' Treasurer] said. 'Nothing ever seems to decrease cost-wise.' Despite all this, the courts are not losing money. The courts have always made more money than they cost, but now the revenue is shrinking every year at a time when Cornwall is strapped for cash" (Hale 2018, emphasis added).
} 
2017). The second meanwhile, touched on in this section, refers to the fiscal situation confronting the POA, including the entangled relationship between revenue, costs, and the problem of volume.

The latter 'fiscal situation' pertains to two other trends facing the POA in this period -a lower rate of charges being issued and a rise in defaulted fines. As Appendix 7 shows, the volume of tickets has steadily been decreasing from its peak of 2.2 million issued in 2009 to 1.5 million in 2017, which correspondingly has led to a reduction in the total available 'gross fine revenue' in a year (from $\$ 262 \mathrm{M}$ in 2009 to $\$ 232 \mathrm{M}$ in 2017). Evolving also in this period, but emerging at the start of the POA transfer to municipalities, is the "ballooning crisis" (Windsor-Essex 2016: 13) of the 'Billion Dollar problem' - a reference to the \$1B in fines owed as of 2011 that reached $\$ 1.4 \mathrm{~B}$ by 2016/2017 (Bovdis 2017, MAG 2016a: 3-5; see also OAPSB 2011) - which in turn has seen annual rates of defaulted fine amounts reach approximately $\$ 40 \mathrm{M}$ in 2000 , peak at $\$ 100 \mathrm{M}$ in 2009 before also slowly declining to $\$ 6 \mathrm{M}$ in 2018 (Appendix 7) ${ }^{68}$. From these statistics, the trend between volume and 'shrinking revenue' are exposed, yet so are the volume's overall shifts with the increase in fines owed (i.e. defaulted) each year. In other words, while a higher volume of tickets may provide more 'revenues' for municipalities to collect, its approach may also lead to a surge in defaulted fines, which creates new costs and challenges for the POA system to manage ${ }^{69}$.

It is under these conditions and 'problem areas' - shrinking revenues, lower volume of tickets, rising costs and defaulted tickets owed - that the slogan and vision of "POA Modernization" (MAG 2015b, 2015c, 2015e, 2016b, 2016c; York 2015) emerges. As the records

\footnotetext{
${ }^{68}$ All figures referenced here, except the $\$ 1.4 \mathrm{~B}$ in outstanding fines, do not account for additional fees and surcharges (including Victim Fine Surcharge [VFS], court costs, default fee and collection fees); therefore, amounts are in actuality much higher (both fines outstanding and revenues collected). The concealment of the data publicly displayed by the provincial government is an issue explored in chapter 7 of this thesis.

${ }^{69}$ The OAPSB (2011) report claims the increase in tickets issued has led to an increase in costs to pursue these matters and actually created a "deterrent" that prevented municipalities to pursue civil enforcement of unpaid fines (11). In light of this conclusion, the Windsor Essex POA annual report of 2016 breaks down the relationship between revenue and volume further then other branches. Describing it as "fine revenue generation", the POA branch states that the relationship is significantly dependant upon the "type and quality of new charges laid" and the "final resolution of the fines" $(7,18)$. 'Type' and 'quality' are vague adjectives that are not well defined in the report and therefore can have several meanings, including referring to 'steeper fines/charges' (i.e., type) that provide more revenue to municipalities or possibly the need for 'quality' fines to be given to ensure cases are less likely to be disputed or needing any form of collections or civil enforcement.
} 
state, the purported goal of "POA Modernization is to simplify court processes and to ensure resources are used both effectively and proportionately" (MAG 2015c: 1, 2016b: 14, 2016c: 1516) with the vision of creating "[a] fair, accessible and sustainable system that resolves provincial offences in an appropriate and proportionate way" (2015e: 33).

And yet although this message contains a "progressive penal reform" (Natapoff 2015: 1060) discourse, the "[e]xpected benefits" (MAG 2016b: 18, 2016c; 19), and thus objectives to the outlined vision and goal of 'POA Modernization', largely center once again on the economic problematizations the POA faces. These benefits, as delineated in the documents, include “[r]educ[ing] municipal costs", "[i]ncreas[ing] municipal POA-related revenues", and creating a "simpler" process that frees up "enforcement officers from time consuming trial-related duties" (2016b: 18, 2016c: 19); subsequently allowing officers, as a result of this last 'benefit', to potentially issue more tickets in the face of current "lower charge volumes" (Guelph 2015: 18).

To achieve these 'objectives', the province and municipalities actively pursue what MAG (2017b) labels "revenue initiatives" (2). These 'initiatives' encompass: raising the "late fee" for fines that go in default in 2016 from $\$ 20$ to $\$ 40$ to provide an estimated $\$ 21 \mathrm{M}$ in additional “municipal revenue” (2016c: 12), allowing municipalities through Bill 27 (The Burden Reduction Act, 2017) to subject "collection agency costs" to enforcement sanctions on a fine forcing "fine defaulter[s]" to pay the full fee (2017b: 5), and further "enhanc[ing] POA fine enforcement" and "initiatives" to collect fines in default (2014a: 1, 2014b: 3-4) ${ }^{70}$. The latter practices include the

\footnotetext{
${ }^{70}$ It is important to note that the issue of providing additional (i.e. 'enhancing') fine enforcement tools has been heavily discussed and demanded prior the period I am examining (2014-2017). In fact, various measures were added beforehand, including in 2009 simplifying access to collection agencies as well as the process for municipalities to utilize the "civil and small claims court" process by repealing the two-year limitation imposed, while in 2010 allowing fines to be added to property tax rolls (see MAG 2011, 2015a: 16). Furthermore, some fine enforcement practices have existed going back to the creation of the POA in 1979 (e.g., suspension of driver licence, use of civil enforcement, garnishment of wages), or at the time of the POA transfer project in the 1990s (e.g., reporting default fines to consumer agencies) (see MAG 1980c: 21, 2015a: 14, 2016e: 10). That said, the focus on the issue in this section is on the fact that it is these practices that are still the focus of the POA and what it deems necessary to address the 'problems' as represented by the assemblage responsible for the program.
} 
ability to deny plate renewals to any (co-)owner of a vehicle with outstanding fines for drivingrelated offences, establish a "debt-transfer plate denial" to their most "active" plate ${ }^{71}$ (Bovdis 2017; MAG 2017c, 2017d), require fines be paid in chronological order (MAG 2016a: 11), and improve access to MTO databases to obtain and track current addresses of fine defaulters $(8)^{72}$.

Meanwhile to further reduce costs and 'misuse' of court resources, other "streamlining reforms" (2016c: 15) have focused on expanding the amount of charges able to be settled through "simplified ticketing procedures" (i.e., imposing set-fines over summons, allowing the potential for more out-of-court settlements [e.g., walk-in guilty pleas, or a first-attendant facility [FAF]), expanding the "use of electronic documents and appearances by teleconference or video conference", and allowing municipalities to create an "administrative monetary penalty systems for parking matters" $(11,2015 \mathrm{a}: 12)$. The overall goal of many of these measures in the end is to minimize the "municipal requirements for justice of the peace" (2015a: 20), while establishing "alternative service delivery models" (Guelph 2015: 18) whether through an 'online dispute resolution' and/or administrative monetary penalty system for a wide variety of POA charges ${ }^{73}$ (see Hamilton 2015; MAG 2015c, 2015d, 2016c: 15, 17; Town of Caledon 2015).

Consequently these 'prescriptive texts', coveted by governments (i.e., provincial and municipal) as forms of modernizing the POA, are at their core once again 'regressive economic policies' centering on "[m]itagating [m]unicipal [and provincial]" impacts (MAG 2015a) and maximizing 'POA-related revenues', rather than taking any aim at creating 'anti-penal' and/or progressive penal practices.

\footnotetext{
${ }^{71}$ For the specific public policy for these two actions, please refer to Bill 31 (Making Ontario's Roads Safer Act, 2015).

${ }^{72}$ Other revenue and cost-saving 'initiatives' include increasing the reinstatement to $\$ 198$ from the $\$ 150$ rate that existed when I began to work there (see MAG 2017c: 7), as well as fines doubling in many cases in 2009 (OAPSB 2011: 11). One example during my time at the POA was the increase in red light offences (see HTA sec. 144) - both camera and in-person issued offences - from $\$ 180$ to $\$ 325$.

${ }^{73}$ This consists largely of minor offences (parking matters, driving-related offences), exact same cases and issue as found in the 1977-1980 period.
} 
A practice that exemplifies this regressive economic approach, in the face of the problematizations mentioned above, is the creation of a more "aggressive" (Windsor-Essex 2016: 11) and "effectiv[e]" (London 2016: 4) collection strategy by POA branches (see Chatham-Kent 2017; Guelph 2015: 18; MAG 2016b: 19; Sudbury 2017; York 2016a: 4, 11, 31). According to the records, the "substantial receivable portfolio" (London 2016: 3) to be obtained from the over \$1B of defaulted fines is deemed not only a significant and important source of revenue $(5$, see also York 2016a: 5) but "mission-critical to the financial well-being of the [POA] operation" (WindsorEssex 2014: F-3). Simultaneously however, due to rising costs overall and the "labour-intensive" resources (Windsor-Essex 2016: 10) required to pursue these fines, a "POA Write-off Directive and Guideline" 74 is crafted by MAG (2015a), along with the additional 'cheap' fine enforcement tools (as outlined above), to guide branches to ensure "time, money, and effort is not wasted pursuing fines deemed uncollectible by the municipality" (15).

In short, as both a 'revenue initiative' and area where 'streamlining reforms' take place, the strategy for POA collection is defined purely as an attempt to "maximize default collection efforts and encourage payment in full" (Sudbury 2017: 3; see also York 2016a: 4). And although acknowledging that in many instances fine defaulters are either unemployed or limited in their ability to pay (Bovdis 2017: 8; London 2016: 5; Windsor-Essex 2016: 12), POA branches offer no alternatives for defaulters beyond applying for an extension of time to pay, a re-opening to dispute their case, an appeal to higher court (see Sudbury 2017: 3), and no recourse with collection agencies to "reduce fines due to hardship" (London 2016: 4) 75 . Thus, the 'modern' POA collection

\footnotetext{
${ }^{74}$ The term "write-off" in this case does not mean that the fine is removed from the system and thus absolves a fine defaulter of their debt. Instead the term simply refers to "the cessation of active collection" by the municipality or POA branch (MAG 2008: 1 cited in London 2016: Appendix A, see also Windsor-Essex 2016: 13). In many instances, the subsequent protocol once 'written-off' is to then transfer the file to various private collection agencies to attempt to retrieve monies owed on behalf of the branches (London 2016: 4, Windsor-Essex 2016: 12, York 2016a: 32-33).

${ }^{75}$ In my time as a 'POA City Clerk' and 'FAF attendant' at the POA offices in Ottawa, there were many barriers to even getting an extension of time to pay or a re-opening to a defaulted fine case, if in the latter option, you wanted to attempt to get the fine reduced or dispute the charge. First off, both applications required a justice of the peace to approve your request, which in Ottawa, usually took a week to get a response from. Therefore, if your license was suspended for an unpaid fine(s) and you were unable to pay your fine(s) right away, you were required to wait at least a week
} 
practices largely attempt to retrieve the debt owed through a full monetary payment, while also being able to place additional charges (i.e., collection fees) on the fine to make up for the cost downloaded onto the administration to obtain the actual 'principle' of the sanction.

A discussion that only touches the surface on the impacts and outcomes of the POA's model of decriminalization, including the central object (i.e., cost, volume, revenue) to achieving its vision, function(s), and purpose(s), the discourses and subsequent practices initiated here continue to primarily attempt to recover administrative costs while also generating revenue for governments. With fine collection rates reaching 83\% in 2017 from $69 \%$ in 2010 , garnering an added $\$ 22 \mathrm{M}$ in revenue in 2017 from an increasingly lower rate of issuance (31\% as of 2017 , see MAG 2017c: 4), this has led MAG to actively promote these numbers as 'offsetting' the transfer of higher costs and more responsibilities imposed onto municipalities (2015a: 6, 19, 2016a: 1-4, 2016c: 12, 2017b: 4). Meanwhile, municipalities seeing these figures, including the lower charge volume and subsequent shrinking revenues it has been facing, have begun to pour more resources (i.e., human and monetary) into their collection units (see Guelph 2015: 11; London 2016: 3; Sudbury 2017: 5; York 2016a: 5, 31).

The main concern in these transformations, easily continuations of roots found in the previous periods discussed, is what they potentially conceal, neglect, or fail to consider in their

and half to get your licence back, and that is only if your extension or re-opening got approved (it takes minimum four business days to remove a suspension from the MTO database once the suspension code is removed from the POA branch database, the latter being done so only if the ticket(s) is paid or a request by a justice is granted through an extension or re-opening). Secondly, a request for re-opening largely meant providing proof that you were reasonably unable to dispute your ticket(s) within the original time provided (44 days), and therefore, the form was not always conducive to the situations faced by some defendants, and in certain instances, city clerks were reluctant to suggest this process based on the perceived likelihood of it being granted. Thirdly, when applying for an extension of time to pay, showing effort to pay (i.e. "good faith intention[s]" London 2016: 4) was almost an absolute necessity, as in many cases, the extension would explicitly get denied for this reason or was presumed by POA staff members to be the reason as they are not always privy to the reason for denial. Also, in cases where fines owed by an individual exceeded $\$ 1,000$, they were generally referred to the city's collection agency. In these cases, it was well-known by the POA staff that a down payment of approximately $20 \%$ was usually required if an individual was to obtain a payment plan with them. Overall, the rigidity with payment plans, in my time working there, was only been getting stronger, as extensions became shorter and more demanding (e.g., requiring a person to pay a higher monthly fee than requested) to ensure people comply with all requirements; the consequences of failing to do so resulting in fines defaulting once again and depending on the charge(s), being re-suspended and re-denied one's plates. When failing to comply with an initial extension, they can become much more difficult to obtain, not to mention fees being re-added, including the requirement to pay another $\$ 198$ reinstatement fee to get your driver's licence back (once the ticket is either paid in full or you are approved for a new payment plan). 
repeated approaches, as other criminologists have pursued in their works (e.g., Beckett \& Murakawa 2012; Chesnay et al. 2013; Harris et. al 2017; Natapoff 2015a, to name a few). The 'Billion Dollar Problem', as it is phrased, is arguably not just a reference to the over $\$ 1 \mathrm{~B}$ in fines owed, but also the \$1B municipalities have added since given responsibility over the POA (from $\$ 485 \mathrm{M}$ in 2002 to $\$ 1.45 \mathrm{~B}$ in 2016 according to Bovdis $2017: 3,7)$. Its emergence is an indication of a system that is failing, and one arguably getting worst, yet the POA's model of decriminalization continues to operate under a 'repackaged' approach constructed from parallel yet distinct economic problematizations that cascade from one another.

On that note, before exploring some of the impacts and effects of this dynamic more closely (explored in the next chapter), I first finish this chapter by analyzing the role played by social structures on the POA and modern fine, while also taking up Garland's call of asking the inverse question: how have the POA and its modern fine shaped, produced, and/or preserve the latter's structures and order.

\section{4 -The Dialectic Roles of the POA, Decriminalization, and Modern Fine within the Social Structures}

Reverting to a point made in the literature review, institutions of punishment and social control are "exemplary sites" (Blomberg \& Cohen 2003: 7) to examine macro-trends and their influence on society. The story and evolution of the POA over its 38-year history, as explored in this chapter, is no exception. Touching on the works of various others - Bottoms (1983), O’Malley (2009a, 2009b, 2010a, 2011, 2013), Rusche and Kirchheimer (1939/2003), Simon and Feeley (1992, 2003), Zedner (2016) - and of course Natapoff (2015a, 2015b), the POA and the establishment of its version of the modern fine are in part the products of an attempt to modernize the bureaucracies of social control and punishment. 
Based on the genealogy delineated above, the "master changes [i.e., patterns]" (Cohen 1985: 16-17) to emerge not from the prison or CJS but instead the creation of the POA's regulatory system are configured based on both a managerial and economic rationality. Patterns that are interconnected to each other, the POA's managerial component embodies its own version of a "systemic rationality and efficiency" (Simon \& Feeley 1992: 452) ${ }^{76}$. Whether attempting to mitigate the overcrowding experienced in its correctional facilities (see Smith et al. 1978), the enormous burden placed upon it due to volume and costs (MAG 1978c: Tab P - 3, 2015d: 2-5; York 2016a: 6, 2016b: 5), including pressures imposed by the courts in the 'Askov' or 'Melo' decisions (Castrilli 1997; Kormos 1997) and the 'Jordan' principle today (Star Editorial Board 2018; Trinh 2018), the POA attempts to "reduc[e] costs and work for the administration" (Rusche \& Kirchheimer 1939/2003: 163) by "[t]aming the system" (Garland 2001: 115) through a "purposive-rationality" (1990: 185) that rations available judicial resources (i.e., human and monetary) and "[social] control strategies [more] rationally" (Simon \& Feeley 1992: 452).

Consequently from this managerialist pattern, the POA system is also heavily constructed by an “economic rationality” (Zedner 2016: 8) and/or a "cost-benefit logic" (O’Malley 2013: 387). While the two authors mentioned here largely focus on the pursuit of such administrative systems and sanctions to reduce costs to government's justice and/or penal administrations, findings of this thesis suggest a more complex dynamic that includes the 'economic' goal and function of generating revenue for governments. Though in the 1970s the initial objective of reclaiming 'revenues' lost from fine defaulters going to jail to serve their sentences was prevalent (see MAG 1978a: 14, 1978b: 2, 1979: 112), by the 1990s the profit motive became an essential and driving

\footnotetext{
${ }^{76}$ A system enacted finally under the POA in 1980, it is also important to note that discussions about "effective management techniques" in light of various constraints faced by a judicial system (e.g., limited courtroom availability, demands for greater service, and restricted number of qualified support personnel) were raised back in 1973 by the OLRC (1973b: 4), who first recommended establishing a POA system for certain offences.
} 
component of the POA's operation, one that the provincial and municipal governments actively pursued (see AMO 1997a; MAG 1996: 5; MSGSC 1997: 3, to name a few). Today, this pursuit continues (see Guelph 2015: 18; MAG 2016c: 18; York 2016b: 5), with the POA construed as a "self-funding" "net revenue positive" program (Windsor-Essex 2014: G-1, 2016: 17). Indeed, many branches have in recent years deem the collection of defaulted fines as "mission critical to the financial well-being of the operation" in light of shrinking revenue and rising costs concerns (Windsor-Essex 2014: F-3; see also Guelph 2015; London 2016; Sudbury 2016; York 2016a).

This latter dynamic found in the POA Modernization period of today is paradoxical, as there is simultaneously a tendency to try and minimize costs and resources through its managerial and cost-benefit approach while seeking to maximize revenues through those exact same patterns. For example, with concerns of shrinking revenues correlated to a 'lower charge volume' that makes it ostensibly easier to manage the POA (Guelph 2015: 18; Windsor-Essex 2016: 18), local municipal POA branches, aided by the province, seek at the same time to maximize "POA-related revenues" (MAG 2016b: 18, 2016: 19) by cutting costs through "easier payment options", "improved fine enforcement" tools, the development of an "online courts services [system]" (2016c: 15, 19, 2016b: 18), as well as by increasing fees and fines and pursuing defaulted fines more rigorously (see previous section for details).

Delving deeper into the POA and paradox of its master patterns, it is clear that the administrative system (i.e., POA) and sanction (i.e., the modern fine) that has emerged in Ontario is, in part, a result of a changing order and subsequently the social structures within it. Taking on Cohen's (1985) "different theoretical agenda" (272) of locating the social forces outside 'the state' when it comes to social control systems, this chapter sees two social developments shaping the 
POA and its modern fine's form and function: the rise of the automobile and issue of circulation as well as the "political economic project" of neoliberalism (Fanelli \& Thomas 2011: 142).

While the importance of a population's disposable income is still a major component to the fine's use and proliferation in the POA, it is not narrowly determined by it as Rusche and Kirchheimer (1939/2003) argue, stating: "[t]he poorer the population of a country, the less frequent is the use of fines" (172-173). Rather, the rise and establishment of the POA and 'modern fine' within Ontario is arguably most related to the growing centrality of 'commodities' - such as cars, houses in the suburbs, technology - in our lives and the growing complexity that these innovations introduce into our infrastructure (i.e., roads and highways, suburbs, street signs, parking), including the attempt to regulate and govern these emerging spaces. In other words, the "democratization of the automobile" (Plowden 1971 as cited in O'Malley 2013: 382), a notion that arguably comprises the "rapid rise in incomes" for many Canadians, a growing population (from roughly 12 million in 1946 to 24 million in 1979, see StatCan 2015b) with a large percentage migrating or living already in cities, and more women joining in the workforce all during the "postWorld War Growth" (1946 to end of the 1970s) (Yalnizyan 2010: 9; see also Cote \& Fenn 2014: 7-8), has played a significant role in the government's need to manage and economically rationalize its administrative system of justice including minor offences (i.e., driving-related, municipal by-laws, and liquor offences) $)^{77}$.

Therefore, as the latter paragraph alludes to, the need to locate a "more convenient, economic and efficient disposal of the civil and criminal business" (OLRC 1973b: xiii) was also predicated on the issue of circulation and productivity within the alternating but still continuing

\footnotetext{
77 To encapsulate this transition further, StatCan data examined by Friedman, Trebilcock, and Roach (1990) shows the rise in vehicles registered per 100 Ontario residents went from 18.8 registered vehicles in 1940 to 39.1 in 1970, and jumped up to 63.0 in 1980 (5). In fact, according to another StatCan report in 2007, between 1956 and 2006 Ontario had the "largest fifty-year growth in population and vehicles" in all of Canada. In comparison to today $(2017 \mathrm{a}, 2017 \mathrm{~b})$, the rate of vehicle registered per 100 people in Ontario has slightly reduced since 1980 , now sitting at approximately 61.3 registered vehicles per 100 Ontarians.
} 
capitalist order. Mirroring a biopolitical form of governance, as defined by Foucault (1991, 2007) whose model in social control system have been examined by others (see Bottoms 1983, Lianos 2012), the Ontario government sought to govern its population more effectively by creating a specific category for provincial and regulatory offences (i.e., actions and/or behaviours) that it considered "useful" (MAG 1978a: 1), "legitimate", and "necessary" to society as well as in the "public interest" (1980c: 5). Conceptualized under these terms to help improve its "management of the state" (Foucault 1991: 92), the government in turn, through the POA, purportedly pursued the removal of the 'ceremonial trappings' of the CJS (e.g., label of dangerous criminal, threat of jail, steeped in centuries cultural assumptions about offenders) (McMurtry 1978b; see also MAG 1978a: 1) and imposed "new responsibilities" (MAG 1978b: 1-2) onto the population in part to eliminate "the expense and wasted time" it previous had placed on subjects (MAG 1980a: 3).

A system created to help government better 'manage' the population through more “flexible, adaptable, [and] inexpensive" (SCRC 1977b: 2) with 'cheap' and 'convenient' enforcement tools such as the modern fine and collection enforcement practices (i.e., additional fees, suspension of licence, lower credit rating, to name a few), the POA and its techniques are also defined and shaped by the political economic project of neoliberalism that began to emerge in Ontario during the 1970s and 1980s.

Defining the concept first, neoliberalism, taking Braithwaite's (2003) point about the "regulatory growth" that came with the shift to privatization (10), is not simply reducible to 'an absentee state' or system of deregulation (see Peck 2003: 226) ${ }^{78}$. Instead, the term can be described

\footnotetext{
${ }^{78}$ In relation to the POA, Braithwaite's (2003) argument holds true. As the LCO report (2011) mentions, in 1974 (according to a report done by the Law Reform Commission of Canada [LRCC] that same year) there was approximately 20,000 regulatory offences in each province, as well another 20,000 federal offences (14). By 1983, according to Canada's Department of Justice, the number of federal regulatory offences alone reached over 97,000 (LRCC 1986: 38 as cited in Libman 2011: 16). By 2017, with over 1.5 million charges laid in the province of Ontario (see OCJ 2017a) to "offence-creating statutes to which the POA applies" (LCO 2011: 14), a figure that reached as high as 2 million between $2007-2012$ (see Appendix 6 ), the argument and conclusion has been made by Libman (2011) that "there is no reason to believe the number of regulatory offences at all levels of government has not continued to increase [since the Department of Justice's study in 1983]" (16).
} 
as a social policy that is a "fluid" and "ongoing" process that encompasses the reconfiguration of "political administration through multi-level governance arrangements" (Fanelli \& Thomas 2011: 144), which includes tax cuts (e.g., income and corporate), the transfer of various responsibilities to market-based models (i.e., the private sector or 'private-public partnerships') and lower-levels of government, as well as the "individualization of economic risks" (143).

As mentioned before, Ontario was not immune from this political orthodoxy. Experiencing some of the largest tax cuts of any province (see Ruckert, Caldbick \& Labonte 2015: 8-12), as well as significant cuts to municipal transfers (\$650M between 1995 to 2003 alone as cited in Fanelli 2014: 12), the province of Ontario has consequently established itself as one of "the most decentralized provincial-municipal structures in the country" (Fanelli 2014: 6) with municipalities increasingly relying on 'own-source revenues' while having some of the highest expenditures per capita of any cities in Canada (Kitchen 2002: 157-160) ${ }^{79}$. As explored in this chapter, particularly during the POA Transfer Project of the 1990s (see section 5.2), the POA was an important part of the restructuring and/or downloading of responsibilities that took place, especially when it came to the "revenue side of the reform equation" (AMO 1997a). Adding to it the imposition of greater responsibilities on the population upon the POA creation in 1977-1980, as well as the growing imposition of more costs (e.g., increase in fines, the default fee, and reinstatement fee, to name a few) on 'offenders' in 2014-2017, it is clear that the POA is also a 'creature' ${ }^{80}$ of the neoliberal political economic project that has been taking place in Ontario.

\footnotetext{
${ }^{79}$ According to the most recent StatCan data (2017c), property taxes accounted for just under $97 \%$ of all tax revenue collected by local governments, which totals $38 \%$ of all revenues they obtained (in contrast to federal and provincial grants provided, and 'other revenue sources' received from user fees, fines and other surcharges), and 67\% of the 'own source revenues' they collected. Moreover, according to Côté and Fenn (2014), Ontario municipalities are still believed to be by and large the most "responsible for funding a broader suite of services" compared to cities in other provinces (32, Table 4), which suggest at minimum, that Ontario municipalities likely still have high expenditures and spend more per capita than others.

${ }^{80}$ The notion's origins derive from a Supreme Court of Canada decision in 2001, which reaffirmed section 92(8) the Constitution Acts, 1967 to 1982 by stating that "[m]unicipal governments... are creatures of the provincial government...[who] have no constitutional status or independent autonomy" (Ontario English Catholic Teachers' Association v. Ontario 2001: 511). Consequently, this decision is cited by academics to describe the limited ability of municipalities to have any control in making policy decisions, including creating new revenue streams outside of the property tax system, which itself provides limited control to local governments (see Fanelli 2014: 5, Côté \& Fenn 2014: 11).
} 
Therefore, an important take away from the role the political economic structures on the POA and modern fine is that it is not simply a one-way street. Drawing from Garland's (1990) argument about the dialectic role existing with punishment and its social environment (22), the POA, with its modern fine and decriminalized approach to punishment, is not simply the byproduct of the neoliberal system and structures, it also played an active and arguably critical role in the way it emerged, established, and lingers on today ${ }^{81}$.

In the end, it is the pressures in part placed by these social forces - neoliberalism and the rise of automobility and issue of circulation - that not only help to produce the master pattern of the POA and their paradox, but they also contribute to the complete and total monetization of its model of decriminalization, punishment, and justice. That said, as a system that centers on locating more savings while also seeking to obtain greater revenues in a "extremely challenging economic environment" (Windsor-Essex 2014: G-1, 2016: 17), it is important to note that the latter is not just experienced by the POA, province, or municipalities, but also by subjects within their structures and systems of governance (see Evans 2018; Tencer 2018). Therefore, while O'Malley (2013) makes the assertion that without the "money sanction...mass regulation" is unlikely to be possible without a likewise "economically feasible innovation" (376), it also has - in the POA's example - led to the regulatory system of penality for minor offences becoming reduced to such a tool to serve one's debt to its community. With over $\$ 1 \mathrm{~B}$ owed and the cost of the program continuing to rise (as explored in section 5.3), there is an argument to be made about the depth of this tool's economically innovative quality as well as the POA's actual ability to implement

\footnotetext{
${ }^{81}$ There are variety of ways in which the POA continues to play an active in preserving or sustaining the existence of the neoliberal economic model, which include the growing expansion of privatization in parking enforcement (see Crawford 2017a; Molina 2018) and a potential broader shift in other areas of the POA coming in the future (see Gills 2018). Furthermore, with various stakeholders and academics calling for "a need to diversify and enhance local revenue sources" to ensure financial viability (Côté \& Fenn 2014: 52-53; see also AMO 2017; Fanelli 2014; Federation of Canadian Municipalities 2012: 15, to name a few), the outstanding balance of POA fines and therefore potential revenues to be made has been one area mentioned (Côté \& Fenn 2014: 51). The result of this is the perpetuation of penalization within the POA as purely monetary. Its outcomes and effects are more closely explored in the next chapter.
} 
"imaginative measures to fundamentally reroute a system which seriously and urgently needed reform" (McMurtry 1978a).

To review both this argument and where this 'rerouting' has actually gone under the POA's system of decriminalization and penalization during its 38 -year history, as well as examining the impact the economic problematizations have had on the "polysemy of punishment" (Walby \& Piche 2011, see also Brown 2009: 212) that forms within the POA, I take up this endeavour in the next and final chapter. Before doing so however, I now turn to concluding this one.

\section{Conclusion - Penalization, the Forgotten Root, and the Return of Problematizations}

This chapter has examined three main periods - its creation (1977-1980), its transfer to municipalities (1996-1999), and 'modernization' (2014-2017) - as a starting platform to analyze the genealogy of the POA and the phenomenon of decriminalization taking place in Ontario. Discerned in each section of this chapter, utilizing a study of problematization framework, the construction and transformation of the POA largely centers around economic problematizations, which in turn, reinforce and establish the main problem areas for this system of social control and punishment: cost, volume, and revenues.

Correspondingly, the 'prescriptive texts' (i.e., policies and practices) construed and crafted under these problematization, shape the objective(s), function(s) and vision to the phenomenon of decriminalization. In this case, as repeatedly mentioned in the chapter, the evolution of the POA embodies a regressive economic policy that pursues a "service delivery" model (MAG 2016b: 14) that minimizes costs while maximize POA-related revenues. Thus, the POA's model of decriminalization is far less about humane "anti-penal" (Velloso 2013a) policies or the "progressive penal reform" (Natapoff 2015a: 1060) discourses it states to embody. 
Contributing to the genealogy of the 'regulatory state' (see Braithwaite 2003, O'Malley 2013) with a focus on minor offences in the POA, this chapter then considered the role played by the various forces outside the state shaping its social control and punishment system, particularly the rise of the automobile, issue of circulation, and neoliberal political orthodoxy emerging and establishing itself during the periods reviewed. Seeing the role of the POA, decriminalization, and the modern fine as both an influencer and recipient to the social structures erected, this chapter discern both the master patterns at the centre of the POA, their paradox (i.e., to locate savings but also generate revenue), as well as the growing role of monetization in the POA's regulatory system and its sanctions.

One causality and/or neglected 'root' of this growing monetization of the POA is the story of the 'Fine Option Program' (FOP). A clause added to the Act under section 65 (a) in its creation in 1979 (see Leal 1978: 12) and now under section 67, this practice was meant to "permit an impecunious defendant [i.e., person unable to pay] to work off [their] fine in services of some value to the community" (MAG 1980c: 23). Deemed an alternative to imprisonment and costsaving measure, one added at the request of Ontario's Indigenous community (MAG 1978c: Tab $M-1)$, the program was and has never actually been officially implemented. This is in spite of the continuous attention garnered from the Ontario Legislature up until 1990 (see Drea 1978; McKessock 1984; Farnan 1988, 1989, 1990), a report outlining the positive impact it could have especially with vulnerable populations (Jolly 1981), and a version implemented by various other provinces and territories (see Manitoba 2018; New Brunswick 2018; Northwest Territories 2018; Nova Scotia 2018; Prince Edward Island 2018; Saskatchewan 2018; Student Legal Services of Edmonton 2015) with others considering it (see Murphy 2014; Smellie 2017) ${ }^{82}$. Instead here in

${ }^{82}$ There are variations of courses amongst these provincial programs, with other types of programs being piloted (e.g., distracted driving education course in British Columbia, see Canadian Press \& Cunningham 2018) to punishment and tackle issues, such as traffic safety, differently. Attempts 
Ontario, the program was finally enacted in 1990 (see FOP 1990), but swiftly lost its "[essential] administrative apparatus" in 1994 due to budget cuts (R. v. Wu 2003: 555), and became revoked in 2016 (see FOP 1990); an ironic twist considering the possibility such a program could achieve in addressing the POA branches' $\$ 1$ Billion Problem ${ }^{83}$.

The symbolism of this forgotten root reinforces the notion of decriminalization being established as a result of the 'problem(s)' facing the POA judicial system being continuously represented as economic ones rather than seeing its "imaginative measures" (McMurtry 1978a) as being re-routed into something more transformative, progressive, or "anti-penal" (Velloso 2013a: 180). Confronting what similar problems and problematization to those faced in the 1970s (e.g., procedures for provincial offences mimicking to closely 'a criminal trial', see MAG 2015d: 1-3), its pursuit of efficiency and costs reduction is seemingly endless, and yet its level of gross revenues have never been higher (just under \$194M in 2017 without accounting for additional fees and parking ticket revenues, see Appendix 7; MAG 2015a).

Having said that, part of the central objectives pursued under the "urgently needed reform[s]" (McMurtry 1978a) of the POA was also the elimination of the debtor prison existing under the SCA model of the 1970s, as well as the prevention of fines from defaulting and other perceived archaic or unwanted trappings found in the CJS system. Examined in the upcoming chapter, this thesis explores the effect and/or outcomes of the POA's problematizations and the policies proposals reviewed in this one. Reviewing the potential unwanted, unforeseen, or ignored

to remove the fine option program in Saskatchewan in 2017 was meant with strong resistance from non-for-profit organizations (Knox 2017, Young and Villani 2017), which eventually led the government to rescind their repeal, at least for the time being (CKOM News 2017). In the end, an organization such as the John Howard Society of Saskatchewan, who participates in the program, says it alone in the fiscal year of 2016-2017 arrange 3,278 tickets paid through 52,170 of community service hours in Saskatoon, Regina, and Moose Jaw (Hill 2017). According to its own website, in 2015, the John Hoard Society (n.d.) program matched more than 2,500 individuals with "volunteer placements" for a total of 140,000 "hours of volunteer support".

${ }^{83}$ This is not to suggest or argue for the use of such an alternative in the case of those who are being penalized unjustly for being homeless or having a substance abuse problem. These problems should be redressed through forms of diversion and harm-reduction programs. What is being suggested here however is for other cases, such as driving-related matter, bylaw offences, parking tickets, and other forms of minor offence, this could be an alternative form of punishment, or used as template to construct other ways individuals may pay one's 'debt' or 'harm' done to the communities. 
consequences (Garland 1990: 286-292) of the 'Billion Dollar Problem', it considers the possible trappings that have emerged within the penalization model of the POA while ultimately revealing how they are similar yet different to those found prior to the POA's arrival. With that said, I now turn to my final analysis chapter.

\section{Chapter 6 - The New 'Debtor Prison' of the POA}

As Garland (1990) lays out in the sociology of punishment framework, researchers seeking to understand punishment must not simply look at the "public statements" surrounding punishment as an object, it must also include examining the "pragmatic repetitive routines of daily practices" to uncover what "values, meanings, and conceptions" (255) are being potentially realized and expressed in the POA's system of penality. Similarly, a WPR approach also inquires into the "effects" produced by the problematizations at the center of the policies and phenomenon examined in this study (Bacchi 2009: 15-18). Aware of other dynamics (i.e., law enforcement, courts, 'street-level bureaucrats ${ }^{84}$, culture perceptions of POA offences) shaping the POA, this thesis narrowly situates the discursive practices within the non-discursive ones revealed in the POA, noting where consistencies and/or inconsistencies between the two can be located.

To complete this task and the 'mapping' of the POA's genealogy, I now turn to the effects discerned in the previous chapters (i.e., economic problematization, the social structures, and master patterns) on the orientation of punishment and justice. Under the guide of these discoveries, I begin by examining the "range of purposes" (Garland 1990) attached to punishment in the POA's model of decriminalization. From here, I turn to examining the outcomes of this system, arguing that the POA has slowly established its own form of 'shadow carceral state' (see Beckett \&

\footnotetext{
${ }^{84}$ Concept taken from Harris (2016) referencing frontline workers (e.g., court clerks, prosecutors) located in court administrations (124-133).
} 
Murakawa 2012) with people incapacitated through debt rather than within an actual prison, even though incarceration is still an option in this system. In the end, this chapter concludes by reviewing how punishment and justice has been 'altered', and yet in other ways, 'repackaged' under the POA's decriminalization model while also situating it within a broken "regulatory cycle" (see Libman 2012a; Verhulst 2008).

\section{1 - The 'Polysemy of Punishment' and the 'Revenue Trap' in the POA}

The result of these social, political, and economic forces (i.e., centrality of the automobile, urbanization, rationing of justice, and neoliberal economic project) and the subsequent shifts (i.e., the growing regulatory state, and its 'master patterns') outlined in this previous chapter, contribute to the establishment of a narrow construction of punishment, how it must be served (i.e., monetary payment in full), and the 'fine defaulters' with debts owed that have been emerging and developing over the POA's history. The character of punishment sketched below consists of an assortment of 'cultural meanings' and purposes that include: personal accountability, deterrence, costeffectiveness, and profitability (i.e., revenue generator) - a patchwork of elements whose shape has both contributed to and been influenced by the POA as well as the form of governance and social structures that has developed in Ontario.

In the establishment of the POA's decriminalization model, referred mainly by the provincial government as a "civil procedure" (MAG 1979a: 22; see also 1978c: Tab J - 2; McMurtry 1978a), the province sought to establish a system of punishment and justice that "prevent[ed] fines from being in default" and simultaneously eliminated the use of imprisonment to enforce the Act (MAG 1978b: 2; see also 1979: 127; MCS 1978: 1; Woods, Gordon, \& Co. 1978: 3). To achieve these objectives through the modern fine and its designation as an "appropriate means of conveying to the offender the community's disapproval of [their] conduct" 
(MAG 1978a: 14), punishment was first understood as communicating "the crucial value" of "recogni[zing]" one's obligation to pay your debt (i.e. fine) to the community (1978b: 2).

Succinctly stated in another report:

"[t]he Fine debtor's obligation is greater and more serious than that of the common judgment debtor and the reasons for requiring payment more compelling. It is in the nature of a punishment, one of the purposes of which is to deter the accused and other like-minded persons from similar conduct. The means of collecting and enforcing payment may quite properly be onerous and demanding insofar as the offender is concerned" (SRCR 1977d: 4, emphasis added).

As the quote indicates, the provincial government puts greater emphasis on the "personal accountability' (i.e., obligation) of an offender to pay the fine over one's ability to do so. Accordingly, the exclusive means to "acknowledge [one's] guilt and responsibilities" is by paying the fine, even if it is burdensome to the individual sanctioned (MAG 1978a: 15-16). Outlined in POA guidelines given to justices of the peace about the new code, the rationality "flows from the fact that the fine is not like a civil debt...[but instead] is a punishment" (1979: 128). Therefore, although the POA procedure is characterized as 'civil', the modern fine is implied to have qualities of expressing 'a form of censure' that contains a moral justification to inflict a high level of hardship on a person where the government believes it required (see SCRC 1977d: 1, 7) ${ }^{85}$.

Having said that, the above-stated justifications for the POA's approach demonstrates, as raised by Zedner (2016), that the retributive and personal accountability characteristics are situated within a "hybrid justification" of punishment (7), including the objective of creating "general" and "specific" deterrents (MAG 2015f: 8; see also 1978a: 17) ${ }^{86}$. Underscored by this 'hybrid'

\footnotetext{
${ }^{85}$ While some 'cost-effective' practices where initiated to mitigate some of the potential harms caused by the POA's approach (e.g., extensions of time to pay), in my experience as a POA clerk, the impression given by colleagues, in many cases, was little empathy for offenders and their circumstances and therefore resistance in offering such tools. This feeling I believe represented the classic cultural expression of punishment: 'you do the crime, you do the time'; a representation that is akin to some of the findings observed by Young $(1987,1989)$ in his interviews with Scottish Sheriffs about monetary penalties in the 1980s. That said, Young work was largely focused on criminal fines, not regulatory ones as this study raises. Thus, a crucial study contributing to this work would be to interview POA city clerks and other "street-level bureaucrats" (Harris 2016: 124) to better understand their cultural views of punishment, their roles, and the impact as well as influence they may have in the construction (or reinforcement) of punishment's values in the regulatory system. For a more recent example of such a study, please refer to Harris (2016: 124-150). ${ }^{86}$ To clarify, general deterrence refers to a construction of punishment that establishes a sufficient disincentive to dissuade the population from a behaviour/action deemed unwanted; meanwhile, a specific deterrence refers to the actions directed to a specific 'offender" (e.g., the price level of
} 
relationship, punishment within the POA consists of "[m]inimum fines" (SCRC 1977d: 7) that seek to create a suitable deterrence upon "the accused", "other like-minded persons" (MAG 1979: 128; SCRC 1977b: 4), and "similar activities" (MAG 1980b: 1) from taking place in the future. Under this premise, the use of jail for defaulted fines was kept for "certain narrowly prescribed circumstances" (MAG 1977c: 4), deemed necessary to preserve the "integrity" of the law by ensuring "sanction[s] are enforceable and known to be such" (SRCR 1977d: 16, see also 1977b: 2). In other words, jail was retained as a sentencing option (until 2001 for fine defaulting) to uphold the general and specific deterrents formulated within the POA and ensure personal accountability to the "obligation" of one's debt was (and still is) maintained (1977d: 13) ${ }^{87}$.

Once more however, as closely examined in the previous chapter, these penal objectives are also counterbalanced by the POA's managerial goals of creating "drastic savings" (MAG 1979: 112) and "reliev[ing] the enormous administrative burden" (1978c: Tap P - 3) placed on the judicial system. With the Act's "basic thrust" comprising of an elimination of defaulted fines and use of jail within its managerial pursuits (1979: 127), it introduces the element of cost-effectiveness to punishment's construction. Under this criterion, techniques are devised, including "extension of time" applications (1978a: 59, see also 1978b: 2), "licence suspension[s]" (1978b: 3), plate, permit, or registration denials (1978a: 16), and other "alternative" penalties, in order to "realize [the] potential benefits" that such an administrative system promises to provide both, according to MAG and government, to Ontarians and other departments (MCS 1978: 1).

While these 'alternative' forms of penalization fit O'Malley's (2009b) notion of "cheap avenues of incapacitation" (79), their goal was not simply to mitigate cost, but equally imposed to

\footnotetext{
a fine, potential demerit points, increase in insurance). Both types of deterrence - general and specific - work in harmony to establish or preserve the 'order' in place or sought out. For an example of these concepts in use, please refer to R. v. Baritiz (2006).

${ }^{87}$ See Appendix 4, 5a and $5 \mathrm{~b}$ of this thesis for current stats on individuals jailed through the POA.
} 
“encourage payment" (MAG 1980a: 22) and reclaim the "loss of revenue" (1978b: 2) incurred through a carceral sentence. As the instruction manual for justices' states:

"[t]he result of the present situation [i.e., use of jail as the 'exclusive sanction' for fine(s) non-payment and removing the 'option' given to offenders to 'avoid payment' through the former] is to deprive the community of fine revenue while causing the community to incur the substantial costs of incarcerating the offender" (1979: 118, see also 1978a: 15-17).

This conceptualization of the 'present situation', which implies what the role of punishment (i.e., modern fine) and its 'future administrative system' (i.e., POA) should be, is repeatedly characterized in this form (1978a: 3, 15, 1978c: Tab L - 1, 1980a: 22). In fact, the concern of 'deprived revenues' was so fundamental to the provincial government's policy goals, it decided to enact consecutive sentences in the Act in order to "preven[t] offenders from writing off hundreds of dollars in fines by serving two or three days in jail" (Smith et al. 1978: 13, emphasis added). This action was imposed in spite of the alarms raised by the MCS about its potential "negative impact" $(17,1978 \mathrm{~b}: 1)$ on achieving some of the purported objectives (e.g., reduction in jail population size and costs) the POA promised to deliver on, including MAG's own vision of "inexpensive justice" (1980a: 6) and the transition away from the "heavy-handed approach" habitually taken for criminal matters (1978a: 4).

These examples both reaffirm the 'economic problematizations' at the heart of the POA's 'decriminalization' and 'decarceration' program and its development, but also the objective, function, and characteristic of the modern fine as a revenue generator for the state. Furthermore, as touched upon in the prior chapter, whether through the neoliberal economic project, or the 'economic rationality' of the POA, the revenue function arguably became more "attractive" (Flaherty 1997) and "critical" (AMO 1997a) when the POA was transferred to local governments in the 1990s as a "fiscal trade-off" (MSGCS 1997: 3). 
It is under this 'fiscal environment' for Ontario municipalities that a "revenue trap" (Natapoff 2015a: 1098, emphasis added) emerges. Although not commonly considered in literature discussing decriminalization, as found in Natapoff's and my own research, a 'revenue trap' is defined as a situation in which a "threat arises from the fact that many lower courts and municipalities depend heavily on revenues from fines and fees imposed on minor offenders" (1098). In light of the municipal fiscal challenges (seen in Chapter 5) along with municipal POA branches fears over 'shrinking revenues' and 'rising cost' in the modernization period (20142017), data also reveals the growing central role 'POA-related revenue' is having on its penology since the 1990s. Since the transfer, annual fine revenues "collected by municipalities" have continued to rise, reaching $\$ 194 \mathrm{M}$ in 2017 - a rise of $\$ 9 \mathrm{M}$ from 2016 and $\$ 22 \mathrm{M}$ from its level in 2009 (MAG 2017c: 4) - with a strong possibility of reaching \$200M in 2018 (see OCJ 2018a). Figures, which have been generated as POA charge volume slowly decreases ${ }^{88}$ (see Appendix 7), they pale in comparison to the $\$ 100 \mathrm{M}$ estimate foreseen by the province in the 1990 s, numbers themselves based on revenues generated during that period (Flaherty 1997).

Moreover, when factoring in costs recovered by the province, annual "net municipal POA revenues" amassed $\$ 170 \mathrm{M}$ in 2014 , a drastic shift once again from the original estimate and expectation of $\$ 87 \mathrm{M}$ established in the transfer period (1996-1999) ${ }^{89}$ (MAG 2015a: 6). To be clear, all of these figures do not account for parking ticket revenues, which can be in tens of millions of dollars for some municipalities ${ }^{90}$, nor do they include the additional surcharges and costs imposed

\footnotetext{
${ }^{88}$ According to the data, between 2009 and 2016, charge volume dropped approximately 27\% (MAG 2017c: 4), and according to my estimate, in 2017, charge volume has now dropped from its 2009 rate by approximately 38\% (based on data located in Appendix 7 of my thesis).

${ }^{89}$ In another MAG report from 1998, the estimate was even lower at \$67M, which based itself on figures from 1995-1996 (3).

${ }^{90}$ To give one example, the City of Ottawa collected $\$ 19 \mathrm{M}$ in 2016 from parking tickets (Pringle 2017). This includes the growing partnership between private entities (e.g., universities, hospitals, private parking companies) and the municipality in revenue-sharing agreements that allow and deputize private officers to issue parking tickets with the City of Ottawa emblem and its enforcement tools (e.g., plate denial). According to the most recent data observed, these 'private-property' tickets happen coincidentally to be the most frequent ticket issue in 2016 (Pringle 2017), generating the City of Ottawa $\$ 18.6 \mathrm{M}$ solely from these infractions between 2013 and end of the first quarter of 2018 (Molina 2018 ). These tickets until recently (at least until 2016 when I worked at the POA) were $\$ 55$ dollars early payment price, and \$75 following that (after 15 days), but have now increased by $20 \$$ (early payment price $75 \$$ and $\$ 95$ following that, see ibid.).
} 
on the fine (i.e., fees, court costs, victim fine surcharge, collection agency costs) that continue to rise and be subject to other enforcement tools (e.g., suspension of licence) as greater imposition is placed on individuals to pay for the rising administrative costs of operating the POA (see previous chapter for details).

Therefore, although POA municipal branches' concerns about 'shrinking revenues' are arguably real, with costs rising from trials, additional responsibilities 'downloaded' (i.e., prosecuting Part III offences) and/or cost to add staff or resources to obtain unpaid fines (see Guelph 2015: 11; London 2016: 3-4; Windsor-Essex 2016: 10, as examples), the amount of gross revenue collected has never been higher and continues to soar well beyond the initial 'promise' the province made to municipalities ${ }^{91}$. Despite this fact, the pressing need for the POA-related revenues persist (see MAG 2016b: 18, 2016c: 19), whether described as "mission-critical" by one branch (see Windsor-Essex 2014: F-3) or by the president of AMO as an "administrative costs out of our property taxes" when not collected (Jones 2017a).

These characterizations along with the ever-growing 'POA gross revenue' acquired since its official transfer in 2001 and the continued policy objectives of further expanding municipal returns while reducing their costs (MAG 2016b: 18, 2016c: 19), are inescapably linked to the current fiscal environment facing local governments. From the 'revenue gap' on future municipal projects (e.g., infrastructure) (see AMO 2015, Frisque 2016), rising municipal staffing costs (Côté \& Fenn 2014: 45-47), to fears about more responsibilities being imposed on them and the overall pressures it has and may further place on municipal property taxes (see AMO 2017, Dollin 2018), a 'threat' (i.e. revenue trap) emerges that narrowly sees the function and conception of punishment

\footnotetext{
${ }^{91}$ Worth mentioning as well, according to same MAG report from 2015 , the "total cost recovery increase" for "adjudication cost[s]" will be $\$ 5.5 \mathrm{M}$ per year, which represents only $3.2 \%$ of the POA revenue collected in 2014 (2015a: 10)
} 
become about its potential profitability in providing a much-needed municipal revenue source.

This in turn shapes the POA's penal policies, including the limited options available for an individual to 'pay off' their fine(s) beyond paying in full (e.g., no fine option program, or other alternatives), and the perceptions constructed and perpetuated about fine defaulters.

To capture what is illustrated in those cases I turn to a 2014 annual report written by the municipal POA branch of Windsor-Essex program, which states:

Approximately one third of the POA Program's annual revenues represent defaulted fines taken in, on an as-received basis. Maintaining at least the current state of diligence upon payment of fines in arrears is thus mission-critical to the financial well-being of the operation. No less important is the realization that if respect for law enforcement as well as for the administration of justice is to be upheld, violators of public protection legislation must absolutely be prevailed upon to honour the monetary penalties imposed against them in consequences of their transgressions of regulatory laws of the land" (F-3, emphasis added).

The image painted by this quote is that in a 'program' that is actively worried about the "challenging economic environment" (G-1, 2016: 18) of "low POA enforcement activity" leading to less revenue (2014: C-1, G-1, see also 2016: 18), the function of the POA and punishment are first and foremost about conserving the fiscal viability - "net revenue positive" feature (2014: G1, 2016: 14) - of the administration. Of course, the creation of an 'aggressive' collection strategy is not unique to the Windsor-Essex branch. Other branches have also stated their goal of "maximiz[ing] default collection and encourage[ing] payment in full" (Sudbury 2017: 3; see also Guelph 2015: 11) in light of the "substantial receivable portfolio" (i.e., potential revenue) available (London 2016: 3), while also limiting resources based on "a variety of factors" (City of Barrie 2008: 1) that might deem a fine to be 'uncollectable' (1; London 2016: 4) and therefore not worth pursing ${ }^{92}$. With additional 'cheap' enforcement tools in recent years provided (see section 5.3 for

\footnotetext{
${ }^{92}$ In a more recent example, a 2015 City of Toronto report finds many civil enforcement options (e.g., garnishment of wages or bank accounts, imposing the debt against one's property) to be "expensive", and therefore "[a]s a result of this financial risk", states that "civil enforcement w[ill] only be used in circumstances when the amount of the fine merits the expenditure and risk" (report cited in Javed 2016). However, other branches,
} 
details) and little to no options providing financial compensation or alternative forms of settling debts owed, the function of punishment becomes synonymous with the ability to obtain revenue.

As a result, punishment becomes reduced, through this 'revenue trap' and its chase, to this redistributive feature over other determinants (i.e., deterrence, personal accountability, and more broadly, public safety), which subsequently, makes punishment become more about the money than the actual offence, and subsequently, the offender. To explore how the configuration of punishment, the means, impacts the 'end' of the POA's system - justice - I examine this in the next section.

\section{2 - The Construction of 'Simple' and 'Local' Justice in a Monetized System of Social Control and Punishment}

Defined by the various 'economic problematizations' - volume, costs, 'inefficiencies' - at the foundation of the POA throughout its 38-year history (see Chapter 5 for full discussion), the administration's construction of 'justice' has correspondingly centered upon a form that is "fair, expeditious, and inexpensive" (MAG 1980a: 6, italics added); summarized in posters placed in courthouses, public buildings, and newspapers when first introduced in 1979-80, the provincial government referred to this form as "Simple Justice" (Cohl et al. 2015: 148).

Within the concept of 'simple justice' however are two competing schemes. On the one hand, 'simple justice' was arranged as a shift away from the "old doctrines of the criminal law" and its "traditional procedure" to instead establishing its own 'simplified' version (MAG 1980b: 1). As outlined in MAG's booklet (1980c), when implemented, the goals of this new 'decriminalized' system were to "eliminate unnecessary technicalities, enhance basic rights and protections, and move the obstacle of delay from the conduct of legal proceedings" (5). Or, as laid

such as Windsor-Essex, have increased their use of "wage garnishment" from 38 cases in 2015 to 328 in 2016 (up $763.2 \%$ in just one year) and as a result expanded their "research capacities and methods" to improve its current system (2016: 12). 
out plainly in an earlier record, the POA "stressed" that its officials "use common sense rather than legalistic guidelines", diverge from the adversarial aspects found in criminal courts, and "deal directly with the merits of the case" as opposed to rigid procedural 'technicalities' (1978b: 2).

And yet on the other hand, underlying these characteristics of 'simple justice' and its escape from the rigidities of the CJS was the simultaneous development of a 'monetized' system of justice. As O'Malley (2013) describes, money did not simply become "the form of justice" through its means of punishment (i.e., the modern fine), but also the "primary shaper" of the entire system (387); an aspect discerned and explored in the master patterns of the POA (see prior chapter). Consequently, the 'flexible', 'streamlined', 'convenient', and 'cost-effective' features and functions of the POA's model of justice (see MAG 1978a: 6, 1978b: 1, 1980a: 6, 1980b: 1) were not solely to fulfill the objectives laid out in the previous paragraph, but also for the provincial government to attain the economically rationed form of justice it sought in order to effectively govern.

As previously illustrated, the POA's goals of minimizing 'defaulted fines' and the use of incarceration for defaulters, were developed for "collecting the revenue from fines which are now lost" as much as they were about "eliminat[ing] the taint of the debtor's prison from fine enforcement" (1978a: 14). As MAG outlines: "the use of effective means to enforce fine payment means that revenue increases at the same time as the expenses of incarceration decrease" (3). Expanding further, the belief was that through a variety of policies and practices, including 'cheaper' enforcement alternatives to jail (e.g., suspension of licence, extension of time, civil enforcement), an 'effective means' was achieved that simultaneously carried out the multiple purposes at the core of the POA's 'simple justice' model (see 1978b: 2-3, 1979: 112, 118, 127). 
By the 1990s however, this system of 'simple justice' was transformed once again through Bill 108 (Streamlining of Administration of Provincial Offences Act, 1997) and the transfer of the POA (officially completed in 2001), rationing the justice model further by intertwining it with a 'local justice' arrangement. A part of the neoliberal political economic project, 'local justice' consists of local governments - through the transfer of the POA - taking on "additional responsibilities" (Flaherty 1997) and "more control" over "justice issues that mainly impact [their] community" (MAG 1998: 2), while simultaneously also allowing the province to "focus [its] justice resources" on matters deemed more serious (i.e., 'dangerous' criminal offences) (Flaherty 1997, emphasis added).

The importance of the 1990s, including the provision that municipalities keep all net revenues collected in the POA (see MAG 1998), is not just the 'revenue trap' configured from the public policies during the POA transfer, but more importantly, the further entrenching of the economic rationing and rationality to the 'simple justice' framework of the POA as a result. In other words, the argument being made here is that the 'sense of justice', whether in creating a "regulatory cycle" (Libman 2012a; Verhulst 2008) form of justice that sees sanctioned people serve a sentence that allows them to return to their normal activities, and/or a 'simple justice' model that seeks to establish a proportional form of justice that eliminates the stigma and trappings of the CJS, is utterly lost due to the POA's fixation on the imperatives of monetization, efficiency, and fiscal sustainability.

Consequently, this lost, ignored, and/or neglected 'sense' or 'attainment' of justice is best exemplified in the outcomes of the POA, particularly the sparing acknowledgement by municipal and provincial government as to the potential inabilities of defaulters to pay due to social circumstances (see Bovdis 2017: 8; London 2016: 5). In its place, all that exist are anecdotal cases 
and sweeping stereotypical references that refer to defaulters as "scofflaws" (see Javed 2016; Jones 2017a; Rider 2018), “deadbeats" (see CBC 2015; Mitchell 2018), or people "laughing because they've gotten away with [paying]" (City of Toronto Councillor as cited in Pelley 2018) ) $^{93}$. For each story that brings up an unknown 'offender' with $\$ 215,000$ worth of fines, or 600 unidentified "accounts" with $\$ 50,000$ or more (Pelley 2018), there are stories like Gerry Williams - a former homeless man with $\$ 65,000$ in fines owed (CBC 2016), Keith Jaques - a person with former substance abuse problems that owed $\$ 10,000$ in driving-related fines (Gallant 2015), Dwight Perry, another homeless man with over $\$ 25,000$ in fines (O’Reilly 2018), or an unnamed recent immigrant with $\$ 30,000$ of unpaid fines who "could not afford car insurance" but needed his vehicle to travel to different worksites for his job as a tradesman (Murkherjee 2018) ${ }^{94}$.

Having said that, the POA's vision even today is purported to be about establishing a "fair, accessible and sustainable system that resolves provincial offences in an appropriate and proportionate way" (MAG 2015b: 4, 2015c: 5, 2015e: 33). Consequently, to provide a more indepth understanding and sketch of the 'personal troubles' mentioned above, alongside the forms and dynamics found to be at play within the discursive practices of the POA and its system of punishment, justice, and decriminalization - including the POA Modernization vision outlined here - this chapter now turns to taking a macro look at the outcomes of the POA's system.

\section{3 - The 'Shadow Carceral State' of Decriminalization}

\footnotetext{
${ }^{93}$ Out of the hundreds of documents I was given and found, I only was able to locate one report that specifically examined the issue province-wide: the OAPSB study in 2011. That said, as some news articles and local POA branch records I was able to obtain show, there have been some municipal reports and committee meetings studying its regional impacts. They include (outside POA reports already mentioned): Toronto (see Mitchell 2018, Pelley 2018, Rider 2018), York Region (Javed 2016, Queen 2016), Barrie and Orillia (Simon 2017), Guelph (Hallett 2016), Waterloo (Weidner 2017), City of Ottawa (2012), and Windsor (Cross 2017). The problem with all these studies, including the OAPSB (2011) one, is that they do not actually know the state of individuals abilities to pay, why 'offenders' do not pay, or why they have so many infractions and steep debts. Rather each study similarly makes, based on the information provided in the records, very narrow assumption about a vast majority of people willingly choosing not to pay because they can get away with it. Therefore, the studies solutions have largely focused on the need to establish more 'effective' deterrents (i.e., better fine enforcement tools) as this is seen as the area where reform is most pressing and needed.

${ }^{94}$ For more articles exploring such stories, or ones that explore the POA system's potential broader social harms from its penal policies, please refer to Monsebraaten (2015), and Slotek (2018).
} 
"The Act [i.e. creation of the POA] is intended to resolve the present anomaly of large numbers of person being jailed for failing to pay fines imposed for minor offences while extremely few persons are being sent to jail as a punishment for even the serious provincial offences. Recognizing the fine as the chief means by which the community's disapproval is to be brought home to persons who commit provincial offences, the Act establishes effective means for actually collecting those fines which are imposed. This will bring drastic savings in the present expenditures for detecting, arresting, and incarcerating defaulters while at the same time collecting the revenue from fines now lost when offenders are jailed for defaulting. More fundamentally, it will eliminate the taint of the debtor's prison from fine enforcement." (MAG 1978a: 14)

"The basic thrust of the Act [i.e., POA] is an attempt to keep fines from being in default and to end the automatic issuance of a warrant of committal when they are. If an offender does default, the court has a number of options at its disposal to maintain the integrity of the administration of justice." (MAG 1979: 127)

In Beckett and Murakawa's (2012) observations of an existing "shadow carceral state", they stressed the importance of studying what they label "subterranean politics and covert institutional innovations" alongside the "more overt" penal practices and outcomes (223). From their inspection, they further conclude the importance of "developing a scholarly conception of the penal state" outside of those made by the state; an endeavour they deem necessary in order to ensure that entryways leading to such systems and their punitive consequence ${ }^{95}$ are "illuminate[d] rather than obscure[d]" (224). Following the 'front' and 'back' stage examinations of the 'discursive practices' of POA explored thus far, this section now seeks to illuminate this issue raised by Beckett and Murakawa in relation to the POA and its system of penality, comprising also of how discourses are (or are not) being realized through its non-discursive practices.

As outlined in the above quotes, the 'basic thrust' of the POA's creation was to prevent fines from going into default, eliminate the use of jail as fine enforcement tool, and, as a result, institute a 'simple justice' model (see Cohl et al. 2015: 148), that would result in savings, generate

\footnotetext{
${ }^{95}$ In the body of literature examining various forms and systems of decriminalization, these 'harsh consequences' are often referred to as "collateral consequences" (Natapoff 2015a: 1089-1094, 2015b: 261-262). While systems of decriminalization are purportedly intended to eliminate these "punitive burdens" for simple minor transgressions (2015b: 261), they can and do in many cases, become long-term experiences that can span a life-time (2015a: 1089). This section explores this phenomenon in relation to the POA.
} 
revenues previously lost, and "ensure fair, expeditious, and inexpensive" justice for Ontarians (MAG 1980a: 6). Today, this latter "[v]ision" is still a purported objective of the POA, emphasizing the importance of settling "provincial offences in an appropriate and proportionate" manner, along with its goal of establishing a "fair, accessible, and sustainable system" for all Ontarians (MAG 2015c: 5).

To achieve this vision, the POA sought (and continues to seek) to "institute effective means" (i.e., fine enforcement tools) to collect fines (MAG 1978a: 1, 1980a: 5, see also 2014a: 1, 2014b: 3-4), exclaiming in the 1970s that "virtually nothing short of willful non-payment will result in incarceration" (1978a: 17). A penology that comprises, both in 1979 under MAG and contemporarily under the municipal 'local justice' model, of personal accountability, deterrence, cost-efficiency, and lastly, profitability (as explored in section 6.1), administrators of the POA have articulated the necessity of preserving the "integrity" (1979: 127) or "respect" for this “administration of justice" (Windsor-Essex 2014: F-3). A model fixated on payment exclusively through a full monetary penality, based in part on the narratives and discourses explored and located in the previous chapters (i.e., economic problematizations, rationing of justice, neoliberal project and revenue trap), the POA's model of decriminalizing has continued to fail to truly transform punishment and justice, including achieving many of the POA's own purported objectives.

Let us start with the POA's goal of eliminating "the present anomaly of large numbers of person being jailed for failing to pay fines imposed for minor offences" (MAG 1978a: 14). An issue it promised to deliver on when enacted in March of 1980 (see 1980a), available data shows (see Figure 1) that the percentage of offenders in jail for defaulted fines actually grew and did not 
drop below the pre-POA level (20\% in 1977-78) until $1993-94^{96}$, reaching as high as $37 \%$ in $1982-$ 83 (StatCan 1983: 85). Moreover, within those charges admitted to Ontario jails for fine defaulting, HTA and liquor offences were the two highest, with the former falling only slightly from pre-POA levels of 3,207 (18.5\% of all defaulted cases admitted to jail) in $1978-79$ to $2,586(14.4 \%)$ in 1983 84; while, liquor offences rose from their pre-POA level, going from 5,548 (33.8\%) in 1978-79 to 6,404 (35.6\%) (MCS n.d.: Table 2 as cited in McMahon 1992: 135).

In sum, the illustration provided by these numbers (found in McMahon 1992 and Figure 1) is not only the likely realization of the MCS's warning of the implementation of concurrent sentences in the POA (Smith et al. 1978: 1, 17), but more importantly, the POA's inability - until at last the mid-1990s - to curtail admissions to jail for fine defaulting and eradicate "the taint of the debtor's prison from fine enforcement" (MAG 1978a: 14) it promised to deliver on.

\section{Figure 1 - Percentage of Ontario jail population admitted for defaulted fine between 1977 to $1998 *$}

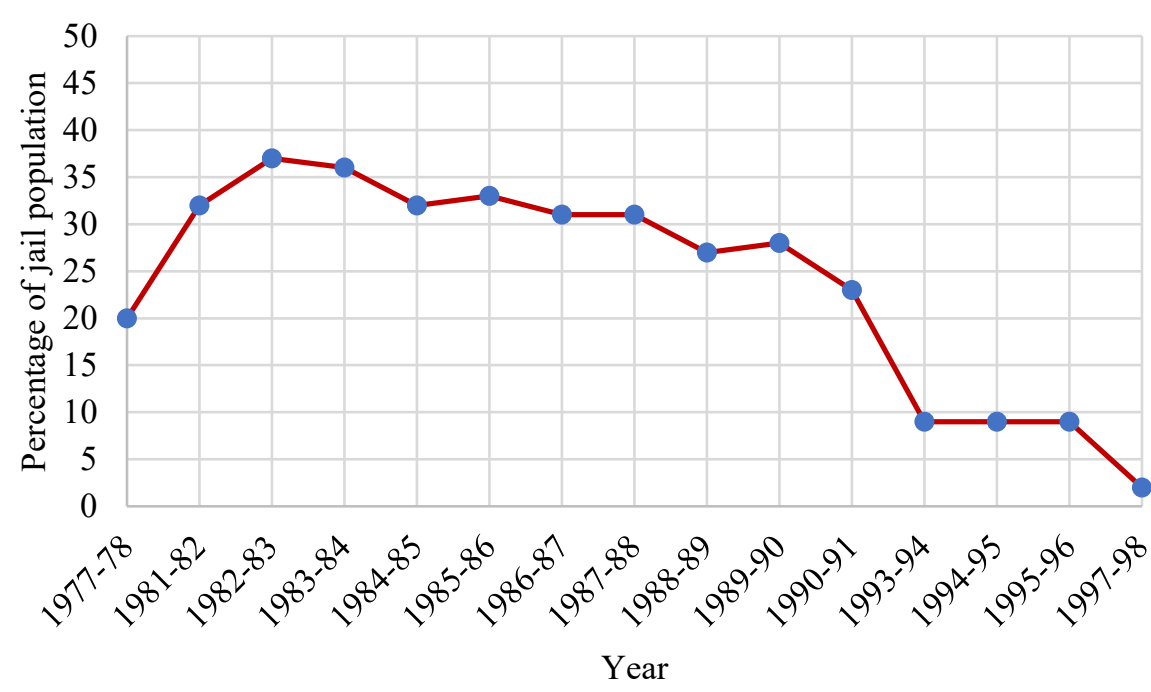

\begin{tabular}{|l|l|}
\hline Year & $\begin{array}{l}\text { Fine } \\
\text { Default } \\
\text { \% }\end{array}$ \\
\hline $1977-78$ & $20.0^{* *}$ \\
\hline $1981-82$ & 32.0 \\
\hline $1982-83$ & 37.0 \\
\hline $1983-84$ & 36.0 \\
\hline $1984-85$ & 32.0 \\
\hline $1985-86$ & 33.0 \\
\hline $1986-87$ & 31.0 \\
\hline $1987-88$ & 31.0 \\
\hline $1988-89$ & 27.0 \\
\hline $1989-90$ & 28.0 \\
\hline $1990-91$ & 23.0 \\
\hline $1993-94$ & 9.0 \\
\hline $1994-95$ & 9.0 \\
\hline $1995-96$ & 9.0 \\
\hline $1997-98$ & 2.0 \\
\hline
\end{tabular}

*Data was taken from two main sources: Smith et al. (1978), and StatCan reports from 1982 to 1996, and Reed and Roberts 1998. Unfortunately, within the records, no data was available for the years 1991-92, 1992-93, and no report in 1996-97 was found.

\footnotetext{
${ }^{96}$ This is of course based on records that were available, as mentioned in the notes to Figure 1, there were no data provided for the province of Ontario in StatCan reports for the years of 1991-92 or 1992-93. Even in later reports observed as well, no data was also provided, despite the fact that StatCan reports did by this point show the 5 -year trend on the percentage of fine default sentencing admissions for each province.
} 
**Data calculated based on data reviewed in Table 2 for the "number of admissions per category" (Smith et al. 1978: 10) and total admission records in Ontario for that same year (4).

\section{Figure 2 - Payment in Default per Year in Ontario between 1972 to 2009*}

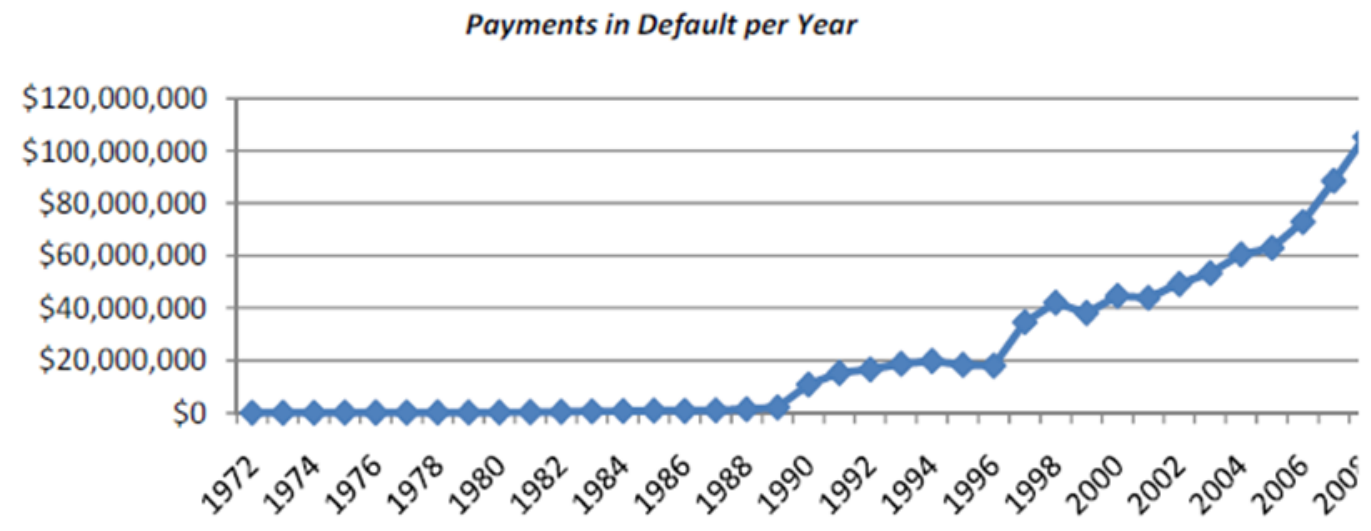

Source: ICON Database, as of July 2010

*This figure is directly taken from the OAPSB (2011:8) report that studied the rise of default fine payments in Ontario, totalling \$1B in 2011, hence the report's title: "A \$Billion Problem". Furthermore, their information was actually taken from the "ICON Database" (8), which is a reference the Integrated Court Offences Network, the system used by the Ontario Court of Justice for criminal and provincial offences (see Government of Ontario 2018). The network is a central tool for POA clerks, as it contains all pertinent information about pending, owed, and completed cases.

With that said, by the 1990s, the elimination of fine defaulters being admitted to jail was finally being realized as the number began to slowly decline in 1990-91 and more steadily in 199394. However, alongside this trend, at least with provincial offences, another pattern emerged that went against the other main purported pursuit or 'thrust' (see MAG 1979: 127) of POA's creation: the rise of fine default payments. As Figure 2 shows, as the sizable fall in jail admissions begins to take place in the 1990 s, the rate of provincial offence payments in default reciprocally starts to rise; quantified in the OAPSB (2011) report, the "number began taking off" in 1990, mounting to “nearly \$11 million that year", a stark contrast from its level of \$140,000 in 1980 (8). From there we see another uptick in $1997-98$ of over $\$ 20 \mathrm{M}$, this time reaching close to $\$ 40 \mathrm{M}$ a year, which again coincides with a decrease in the number of jail admissions (from $9 \%$ in $1995-96$ to $2 \%$ in 1997-98). In 2001 when the transfer of the POA is completed to municipalities through 52 branches 
and the practice of imprisonment for fine defaulting is 'officially' removed under Part X (i.e., the transfer agreement) of the Act (see sec. 165[1]), the rise of defaulted fines continues to soar (as Figure 2 highlights) reaching a highpoint of $\$ 100 \mathrm{M}$ in payments in default in 2009.

Elucidated by these trends, in each instance where the province was successively able to further reduce the number of jail admissions for fine defaulting, more and more cases were simultaneously being annually added to the defaulted fine total; and while the number has since decreased, dropping from just over $\$ 50 \mathrm{M}$ in 2010 to $\$ 6 \mathrm{M}$ in $2017-18$ (see Appendix 7 , OCJ 2018a $)^{97}$, as one MTO report from 2017 points out: “approximately 75 per cent of the total amount of fine payments in default is from the past decade" (Bovdis 2017: 8). Putting the MTO's findings into perspective, that means that based on the current best estimate provided (which accounts for various fees and surcharges) of $\$ 1.4$ billion in defaulted fines outstanding (see MAG 2016a: 11) ${ }^{98}$, over $\$ 1 \mathrm{~B}$ of its total comes from cases less than a decade old (exact number is $\$ 1,077,650,958.22$ ). The reasons for these trends and arrival of 'the Billion Dollar problem' are - as explored in the only other study conducted in Ontario about this particular issue (the OAPSB report from 2011) diverse; they include the increase in fines issued (see Appendix 6 and 7), costs to pursue fine payments, and the doubling to the price of fines in many instances $(11)^{99}$. Nevertheless, with over \$1B in added fine payments in default in the last decade or so, which encompasses an estimated

\footnotetext{
${ }^{97}$ As indicated in Appendix 7 and located in the OCJ report of 2018, these figures do not include additional fees and surcharges. Furthermore, in relation the 2018 OCJ report, data currently listed in the records uses figures from July 2017 to June 2018.

${ }^{98}$ To specify further, this figure, which was taken from a ministerial briefing booklet from June of 2016, does include additional fees and costs, including victim fine surcharges, court fees, and collection agency costs.

${ }^{99}$ As the OAPSB report was written in 2011, it also important to note that many of these fines continue to rise after it. In my time at the POA in Ottawa (from 2009-2016), as I have already mentioned, provincial offences fines and fees continued to increase, whether with red-light offences (from $180 \$$ to $325 \$$ ), parking offences (e.g.., no stopping zones, private property, fire route, tour bus zones, to name a few), reinstatement fee for a driver's licence suspension (from $\$ 150$ to $\$ 180$ ) or the default fee (from $\$ 20$ to $\$ 40$ ). Another example that I believe significant to mention is the increase in the minimum fine for 'driving without insurance', which rose in 1996 from $\$ 500$ to a range of $\$ 5,000$ as a minimum fine to a maximum of $\$ 25,000$ for a first-time offence (see R. v. Fagbemi [2000] as cited in R. v. Baritz [2006]; Sampson 1996). With the CAIA consisting of over $36.2 \%$ of all defaulted fines outstanding today, which totals over $\$ 520 \mathrm{M}$ of the $\$ 1.4 \mathrm{~B}$ owed yet only $6.9 \%$ of all the charges outstanding (just over 200,000 charges) (see Appendix 8), it is not hard to see the correlation from the implement policy in 1996, the same year when payments in default started to ascend (see Figure 2). This is especially made clearer when one considers the fact that only $\$ 268.8 \mathrm{M}$ was in default back in 1996 for all Part I and Part III provincial offences (MAG 1996: Appendix 6 -4), an amount that that is just over 50\% of the payments outstanding under the CAIA today alone. To examine all new fees, fines, and increases in set fines, please refer to the link found in OCJ (2018b).
} 
1.7 million (and likely more) charges of the 3 million currently on file ${ }^{100}$, the POA today is without question failing to achieve its basic objective of preventing fines from being defaulted on. Furthermore, while the province finally eliminated the practice of imprisoning fine defaulters in 2001, rather than actually removing "the taint of the debtor's prison from fine enforcement" (MAG 1978a: 14), it has instead simply shifted it to the POA's own decriminalized form of a 'shadow carceral state'.

As Beckett and Murakawa (2012) explain, the "shadow carceral state" sees the "tentacles of penal power" expand beyond the prison. In their work, they emphasize the "blending of civil, administrative, and criminal" institutions operating within "opaque, entangling ways, [and] ensnaring an ever-larger share of the population...through civil injunctions, legal financial obligations [e.g., fines and fees], and violations of administrative law" (222). Describing these forms of punishment as "serpentine" with many entry points and "few exits", Beckett and Murakawa largely explore the 'shadow carceral state' as an enhancement of "state carceral power" that sees individuals incarcerated in prison or jail through various examples (e.g., immigration detention, non-payment of legal financial obligation ${ }^{101}$, civility $\left.\operatorname{codes}^{102}\right)(222-223)$. That said,

\footnotetext{
${ }^{100}$ Based an estimate generated from OCJ reports (2015c, 2016b, 2017b) and MAG data provided through FOI requests going back to 2010 (see Appendix 7), over 610,204 total net charges were added since 2011 alone, accounting for just under $20 \%$ of all defaulted charges on file since June of 2018 (see OCJ 2018a). And according to MAG's data from 1996 (see MAG 1996: Appendix 6 - 4) which stated there were 1,337,151 outstanding Part I and III offences, there have been at minimum over 1.7 million charges added since then (as of June 2018), and with likely some of those 1996 charges paid off and no longer in default, it is therefore making more likely that recent cases (within 10 to 15 years) account for at least 65 percent or more of charges currently in default. To clarify, the first estimate numbers were obtained (also done in Appendix 7) by calculating the number of charges added annually added (or removed) under the column "Total Number of Charges with Fine Amounts in Default" located in each MAG report given. I mention 'removed' because as Appendix 7 shows, in 2017, there were 11,617 less cases on file than the previous year in 2016, which is in spite of the $\$ 5 \mathrm{M}$ added that same year in fine default payment amounts. The likely explanation for this is that as POA branches have actively implemented more rigorous write-off policies and practices, and therefore as a result, begun to remove cases from these records, as the OCJ and MAG reports state: "[p]ayment in default do not include unpaid fines...that have been written off by Municipal Partners" (see all reports at OCJ n.d.. which include the disclaimer). The important note to remember, as mentioned previously, is that tickets written-off are not debts that have or are forgiven, they are still outstanding and must be paid by individuals. Additionally, as the "uncollected fine amount column" shows, there are still several million of dollars that may not be in default but are also still outstanding and therefore are slowly being paid by individuals; the implications of this within a 'shadow carceral state' are explored in the upcoming pages.

${ }^{101}$ Legal financial obligations (LFOs) is a term used interchangeably with 'monetary sanctions' (e.g., Martin et al. 2018). As Harris et. al (2010) explain however, LFOs comprises "fees, fines, restitutions orders, and other financial obligations that may be imposed by the courts and other criminal justice agencies on persons accused of crimes" (1756). This thesis adds to this discussion in relation to minor offences under a regulatory and decriminalized system.

${ }^{102}$ Civility codes includes acts such as the SSA as well as other social control tools to "attempt to restore 'order' and 'civility' to urban landscape increasingly populated by the un-housed" (Beckett and Murakawa 2012: 231). For a couple example of other tools, I refer the reader to Beckett and Herbert $(2008,2010)$.
} 
based on their own definition (see 239: fn. 1), the exploration and comprehensive study of the 'shadow carceral state' - also referred to as the "shadow penal state" - includes cases where "significant hardship" is imposed that "mimic coercive practices" and carry "social and political opprobrium" (222-223).

Consequently, the creation of the POA's decriminalization and decarceration model can be understood drawing from this definition. By establishing a form of penalization in Ontario that has become the "primary normative punitive system" to address "conflicts", incidents, acts, and behaviours "related to the use of public spaces" (Chenay et. al. 2013: 163) with over 1.5 million charges issued in 2017, the POA can be conceptualized as a part of the 'shadow penal state' and/or 'carceral state' that sees its 'small incursions' (i.e., fines) become compounded into larger ones. More specifically, the POA entangles many individuals into an inescapable debt that leads to compounding sanctions (e.g., suspension of licence, loss of insurance, lower credit rating) and greater debts (e.g., additional fees and costs) that restrict one's mobility in society.

The emergence of this penal trend (i.e., shadow) within the POA, is best examined upon revisiting various data points (i.e., the non-discursive practices) illuminating the transformation of penality under its decriminalized system. Outlined in the records exploring the prevalence and use of jailing fines defaulters from the 1970s to 1990s, sentences for fine defaulting tended to be first and foremost "very short" (Reed \& Roberts 1998: 6). To give one case example, based on data reviewed from 1988-89, despite fine defaulters representing over $27 \%$ of Ontario's prison population for that fiscal year, their total sentenced time in the end only amounted to $8 \%$ of all time served in jail (OLRC 1990: fn. 47). Therefore, despite a significant portion of people imprisoned for not paying a fine, the 'payment' of those debts through these jail sentences were brief. 
Furnishing a more definitive number of fine defaulters annually jailed, according to the 1978 MCS report studying the impacts of the POA on Ontario's jail system showed prior to its enactment, a total of 21,664 cases for over 8,860 individuals were admitted in 1977-78 (whether for defaulting on fine(s) or no fine option at all) (Smith et al. 1978: 8-10). Discerning this data using McMahon's (1992) examination of MCS reports between 1978 (pre-POA level) up to 1984 (post-POA enactment), these jail admissions mainly comprised of HTA and liquor offences charges, accounting for over $50 \%$ of all charges admitted, from 3,027 (18.5\% of all cases sentenced that year) to 2,586 cases (14.4\%) for HTA matters, to between 5,548 (33.8\%) and 6,404 cases (35.6\%) for liquor ones during that same period $(135)^{103}$.

In sum, the location to the source of the problem the POA was purportedly established to address (i.e., reduction of fines being defaulted on, and people admitted to jail) was heavily concentrated within driving-related and liquor offences, with approximately 20,000 cases admitted annually for short stints in jail. In turn, penality under this form, while decisively exhibiting the blatant and/or visible display of the "punitive power" (Beckett \& Murakawa 2012: 222) of a state, its transformation and consequences under a decriminalized and decarcerated model are equally worrisome.

As can be seen in Appendix 7, between 2011 and 2018, there have been over 600,000 charges defaulted upon, resulting in an average of 76,275 charges added annually, an estimate that is almost four times higher than the 20,000 jail admissions processed in $1977-78$ or the 15,000 to 19,500 cases from the early 1980s (McMahon 1992: 135). Furthermore, in that same period (20112018 ), these charges contain over $\$ 245 \mathrm{M}$ in fine amounts outstanding, averaging out to $\$ 30.6 \mathrm{M}$

\footnotetext{
${ }^{103}$ Evidently as Figure 1 illustrates, these cases were still admitted to jail sentence into 1990 (see StatCan 1993:49 as one example where some data was provided). The data used above (from McMahon 1992 and Smith et al. 1978) was selected to show the contrast in the early period prior to and just after the POA's enforcement just after alongside the contemporary situation the POA faces in 2018.
} 
added annually or $\$ 401.54$ a charge; estimates that when considered in relation to Figure 2, do not even account for the worst of it, as rates of defaulting (in monies owed and likely charges added) were much higher between 2004 to 2009.

Delving deeper into these debts, figures show they are highly concentrated in the CAIA $(36 \%-\$ 520 \mathrm{M})$ and the HTA $(32.6 \%-\$ 468 \mathrm{M})$, with the former charges under CAIA seeing an average case holding over $\$ 2,500$ (see Appendix 8 ) ${ }^{104}$. For HTA matters, which make up over 1.3 million of the 3 million charges defaulted on (44\%), their average fine is smaller in contrast to CAIA ones, seeing an average of $\$ 353$ per charge (ibid.). A figure seemingly low, yet when one accounts for the fact that the vast majority of HTA debts owed are for 'driving while under suspension' offences (14.1\% of all POA charges according to OCJ 2018a) which contains an average fine of $\$ 1,200$ (without accounting for fees and surcharges), the reality is that the typical HTA fine defaulter owes more than $\$ 353$. Not to be forgotten either in examining the POA's debts, liquor offences encompass not just the second largest number of charges with payments in defaulted at 594,716 ( $44 \%$ of all charges) for a total of $\$ 85 \mathrm{M}$ ( $6 \%$ of the total amount owed), but also the third highest monetarily of all statutes under the POA (see Appendix 8).

These stats, for both liquor and HTA offences under the POA model, demonstrate an overall significant disparity when compared to the short sentences in jail discovered between 1977 to 1984 (see McMahon 1992: 135; Smith et al. 1978: 10), which simultaneously also contained a remarkably low rate of defaulting on fines also during that period (see Figure 2). Consequently, penality and punishment, in its new form under the POA, has thus become an experience that spans over a longer period, with debts over the last decade hardly being paid down, as defaulted fine

${ }^{104}$ With an average around of over $\$ 2,500$, it is likely that the main offence owed under the CAIA is for failing to have insurance, see fn. 102 for greater discussion about the evolution of this charge on the POA since 1996. 
amounts (from $\$ 749 \mathrm{M}$ in 2010 to $\$ 993 \mathrm{M}$ in 2018 , without accounting for all costs imposed) and cases (2.4 million to 3 million cases) continue to rise within its system (see Appendix 7).

The picture painted from this data illustrates the "complex and conflicted regulatory strategy" of decriminalization (Natapoff 2015a: 1102), which comprises many pitfalls raised by academics and journalists (see Beckett \& Murakawa 2012; Harris 2016; Kent \& Regoeczi 2014; Natapoff 2015a, 2015b; Sanchez 2018a; Sanchez \& Kambhampati 2018, to name a few). Perhaps this is best articulated by Harris et al. (2010), who state that: "the widespread imposition of 'collateral' or 'invisible' sanctions [transforms] punishment from a temporally limited experience to a long-term status" (1755). The figures and discussion above exemplify this statement. As the POA sought to eliminate its debtor prison, where approximately 15 to 20 thousand individuals served short jail sentences on an annual basis, it has slowly transitioned to a system comprising of a growing number of defaulted fines, and subsequently, rising debts owed by individuals. As a result, the POA has "ensnar[ed] an ever-larger share of the population" into a "shadow carceral state' where few "exits" exist beyond paying the debt in full (Beckett \& Murakawa 2012: 222223). Penalization under this model is thus not the body itself placed in an actual prison, but instead one that is mobile and follows an individual around in their daily lives, restricting their mobility both physically in their ability to drive (e.g., suspension of licence, loss of insurance), get a loan (e.g., poor credit rating), or through their wages (e.g., garnishment of wages once you have a job), and mentally as the stress of such debts are a stymying burden one is forced to shoulder.

Exploring the potential "subterranean politics and "covert institutional innovations" (223) that exists in the POA, records publicly made available (e.g., see OCJ n.d.) and those obtain in FOI records, both conceal certain information that potentially are obscuring (and may do so going 
forward if the status quo remains) the breadth and scope of the problem of defaulted fines and the pathways of penalization in the POA.

First, as mentioned many times in this study, the majority of records do not account for fees and surcharges in its totals despite many of them being mandatory for an offender to pay; this is best demonstrated when contrasting Appendix 8 to the OCJ report from that same period (see OCJ 2015 b $2016 \mathrm{~b}$ ), as the former shows an additional $\$ 400 \mathrm{M}$ to $\$ 500 \mathrm{M}$ outstanding when fees and surcharges are accounted for ${ }^{105}$. Alongside this 'innovation', another tactic that is found in almost all records examine (i.e., FOI and public reports) ${ }^{106}$ is the 'write-off' policy that allows branches to remove fines from their defaulted listings as long as all fine enforcement options have been exhausted ${ }^{107}$, and has been in default for at least two years. A policy in place since at least $2008^{108}$, in 2016 , there were actually 11,617 net charges removed but $\$ 5 \mathrm{M}$ in fine amounts added that same year (see Appendix 7); this means that the fine amounts added in 2016 exceeded those charges removed in that year, while no explanation is given as to why those fines were taken off in the first place. Since tickets 'written-off' are not forgiven and are still payments that must be paid by an offender, their removal from publicly available data does nothing to address the issue of the $\$ 1 \mathrm{~B}$ in fines added in the last decade. At best this policy may potentially help branches manage their files, however, at its worst and with greater assurances than the former's use, this policy tool aids in further concealing the depth of the problem the POA currently faces as well as the consequences located in the materialization of punishment under this decriminalized system.

\footnotetext{
105 That said, all of these figures once again do not account for parking tickets, which in the case of Ottawa was at $\$ 39$ million in unpaid fines as of 2017 (Crawford 2017b).

${ }^{106}$ While these figures are concealed in the reports provided at the provincial-level (largely MAG), there have been some local reports that do provide data pertaining to the amount and number of charges currently written-of "for accounting purposes only" (London 2016: 7). In Guelph's 2015 annual report, figures show they have written off 23,347 cases that are valued at over $\$ 8 \mathrm{M}$ (12), meanwhile London stated it removed over 30,000 cases valued at around \$5.19M (see 2016: Appendix B).

${ }^{107}$ It is unclear based on MAG's write-off guidelines (see London 2016: Appendix B) what "reasonable efforts" (i.e., exhausted) entails beyond the fine enforcement tools (e.g., garnishment of wages, collection agencies, licence plate denial, to name a few) simply being imposed or attempted.

${ }_{108}$ While some branches have discussed the need to "adopt a write-off policy" more locally (see Windsor-Essex 2016: 13), the guidelines have been provided by MAG going back as far as 2008 (see City of Barrie 2008; Guelph 2015: 12; London 2016: Appendix A).
} 
All in all, it is under these dynamics that the POA system is shrouded in darkness from a shadow that is not only casted onto fine defaulters, their experiences, and the entire administration, but one the POA has participated in casting itself. Stated differently, the 'shadow carceral state' in the POA, which comprises both the 'dark-side' of decriminalization (Natapoff 2015a, 2015b) and the 'invisibility' of fines (Harris et al. 2010), exists simultaneously through two separate dynamics. Firstly, they encompass both the transfer and shift of the debtor prison to the establishment of a new 'taint' that carries a long-term and burdensome status for many fine defaulters. Secondly, the lack of viable and sufficient data ${ }^{109}$ - including the creation and use of tools by the POA through a form of 'subterranean politics' - further obscures the 'taint' from even being made visible, known, and understood in the first place. With these issues in mind, I now turn to conclude on the implications of these observations in the POA and the regulatory cycle.

\section{Conclusion: Punishment, Justice, and the Broken Regulatory Cycle within Administrative} Systems

"Above all, it must be remembered that the intended product of the court system is justice, of which efficiency, convenience and cost are only constituent parts and do not together comprise the whole....Efficiency without fairness is not justice" (OLRC 1973b: 4, 10)

In summary, this chapter began by exploring the various facets and functions constructing the "social artefact" (Garland 1990: 17) of punishment in the POA. Locating a 'hybrid character' that included personal accountability, deterrence, and even potentially retributionist qualities, these features have become secondary to punishment's most essential characteristic: its redistributive quality. Touched on in previous chapters, resulting from the economic problematizations, social structures and forces, not to mention being reinforced by the 'master

\footnotetext{
${ }^{109}$ To explain a bit further, this issue included certain data point deemed not available (e.g., default rate, collection rate, and revenue collected not provided for years prior to 2010, rate of reinstatement of driver's licences when suspended for unpaid fines), lack of POA branch annual reports (with proper cost and revenue assessments of all provincial offences, including parking fines) created and made available publicly or through FOI requests (e.g., City of Ottawa), or any adequate study about the fine defaulters and their reasons - and potential struggles - in paying off their debts. Furthermore, the issue of needing better data has already been raised by the OASPB (2011: 22), and based on this conducted study, has yet to be adequately resolved.
} 
patterns' configuring the POA, the centrality of the 'revenue' aspect is arguably the creation of a 'revenue trap' that emerged in the 1980s and 1990s, as municipalities today struggle to maintain their fiscal sustainability, not to mention pay for projects and services through property taxes almost exclusively. In turn, with punishment as the means, and justice as its end, this section also reviewed how the latter is likewise shaped by its economic and monetized aspects, as the local and simple justice models constructing the POA's approach through localities focuses more on being 'efficient' for the municipalities themselves than about reforming punishment and justice.

Probing into how the discourses and analyzes discussed throughout this thesis may (or may not be) realized, including the overall purported objectives of the POA which encompass the elimination of the Ontario debtor prison system and the prevention of fines going into default (see 1979: 127), this chapter then examined the POA's outcomes over its 38-year history. Based on the data obtained publicly and provided by government agencies (e.g., Archives Ontario, MAG), my examination discovered a transition that shows not only the POA's inability over its first 10 years to curb rates of jail admissions for fine defaulting, but also once they did decrease starting in the 1990s, the problem was simply shifted onto the individuals through a new experience as the rate of payments in default began to soar. As a result, rather than eradicating the taint of the debtor prison and preventing fines from being defaulted on, the 'taint' has simply been transformed in the POA, embodying a new form under a 'shadow carceral state' where fine defaulters are imprisoned by their debts with little possibility or options of escaping beyond paying in full.

Intertwining these findings about the outcomes of the POA and what 'preserving' its “integrity” (MAG 1979: 127) or 'ensuring' its "respect" (Windsor-Essex 2014: F-3) requires or necessitates, the POA model of decriminalization and decarceration is hardly transformational for its previous experience. Established by discursive practices that center on the economic 
problematizations and neoliberal economic project that have shaped the POA's master patterns, the POA's largely 'regressive economic policies' is best exemplified by one POA branch as it laments:

"To make matters more difficult, in many cases, the offender[s] are either unemployed, working for cash, or on some other form of assistance which can't be garnished. However when employment is confirmed and the garnishment documents are in place, it becomes one of the most effective enforcement tools as it ensures a steady stream of income" (Windsor-Essex 2016: 12, emphasis added).

A report that also has initiated an objective of taking of a more "aggressive" approach to fine collecting in what it also labels "an extremely challenging economic environment" $(10-11,14,20)$, its pursuit of this form of justice is similarly located in other branches and provincial records (see Guelph 2015; London 2016; MAG 2016b: 18, 2016c: 19; Sudbury 2017; York 2016a: 31). Overall, there is also a clear indifference about the economic problems fine defaulters face, instead seeing POA branches continue to focus their attention on 'alternatives' (i.e., penal practices) that consist only of 'better' enforcement tools (e.g., expand licence plate denials, place more of the cost burden on fine defaulters) that attempt to collect those revenues that still continue to be lost today.

The larger issue with these 'alternatives' is not only in their inability to collect the revenue, but their inadequacy to do so in many cases (seeing, at minimum, approximately $20 \%$ of all fine amounts go uncollected annually) as default fine amounts continue to mount. Ironically, much like the taint of the debtor prison, the ever-expanding shadow carceral state of the POA ironically faces a similar dilemma as it did back in 1978 prior to its implementation. As Smith et al.'s (1978) report expressed about the problems confronting Ontario's system of punishment then:

"In almost all instances, the sole alternative to the use of fines for such offences is to commit the offender to a period of incarceration in one of the Province's correctional facilities (usually a jail or detention centre). In addition, almost all sentences involving fines, make a provision for a period of incarceration as a sanction in cases where the offender defaulted in the payment of the fine. The lack 
of alternatives has resulted in a substantial number of offenders serving brief periods of time in jail. Although the majority of these sentences are short, the accumulative effect of all such sentences over such a period of year accounts for a sizeable proportion of the time served in provincial correctional facility." (1, emphasis added)

In short, the problem then was "lack of alternatives" to the debtor prison, and based on the figures examined in this chapter, the same problem exists today in relation to issue of defaulted fines and the 'shadow carceral state' currently produced by the POA's approach. In this instance, the "sole alternative" given to fine defaulters is to pay, with more recent fine enforcement tools and practices only providing more of the same tactics (yet hoping for better results) by the branches as they attempt to further restrict an individual's mobility in enforcing payment, and simultaneously, fulfill their notions of 'justice being served'.

However, based on available data, the majority of 3 million charges outstanding are driving-related: comprising of $68.8 \%$ of the total fine amount, and $50.9 \%$ of all chargers (see Appendix 8), with these numbers being potentially greater as some may have been 'written-off' by POA branches for accounting purposes. The fear from this data is that a "traffic-ticket cycle" (Regoeczi \& Kent 2014) is potentially taking place - similar to the one experienced by the homeless under the SSA (see Chesnay et al. 2010) - where traffic tickets 'compounded' into more sanctions (i.e., loss of insurance, suspension of licence, and consequently, more fines) creating an inescapable way out for these offenders. Subsequently, these visible consequences of the POA's enforcement regime, with many more still casted under a dark shadow that is little understood, fails to also establish a "regulatory cycle" (Libman 2012a; Verhulst 2008) that would allow the offender to return in 'partaking' in the activities that are "useful" (MAG 1978a: 1) to society, but importantly as well, those central to allowing us to integrate and exist in it. 
In the end, if justice and accountability under the POA are only able to be served through a monetary fine and payment, as the Windsor-Essex (2016) quote above implies through its fine enforcement strategy and approach, then arguably the notion of "[e]fficiency without fairness is not justice" (10) raised by the OLRC in 1973(b) - one of the first organizations to recommend an administrative system for provincial offences like the POA - is not being lived up to. Rather, using another statement found in that same record, the notions of "efficiency, convenience and cost" for government have become, as a consequence, not simply "constituent parts" - as the OLRC had envisioned - but the "comprising whole" (4) of the POA with its modernization vision of 'fairness', 'accessibility', 'sustainability', 'appropriateness', and 'proportionality' (MAG 2015b: 4, 2015c: 5, 2015e: 33) being defined by it. It is under this discussion that I now turn to my concluding chapter.

\section{Chapter 7 -Conclusion: The Genealogy of the POA and the Unexamined Branches}

\section{1 - The Tensions of Punishment, Justice, and Money within Decriminalization and Administrative Sanctions}

For Young (1989), exploring the use of the fine in the CJS, one of his main observations was the "state of permanent tension" that existed between punishment, justice, and money (64). From it, he explained the emergence of a potential "disenchantment" created by monetary fines, as a 'sense of justice' and the purpose(s) of punishment became "estranged" from their original intentions or historical roots (i.e., an emotive response) (65). While this type of 'tension' is arguably present in relation to decriminalized sanctions and systems ${ }^{110}$, based on this study's findings, another one is also discovered. In the case of the POA, and potentially other models of decriminalization within our judicial systems, an agitation emerges from the 'redistributive' (i.e.,

\footnotetext{
${ }^{110}$ Recent POA cases and debates about the missing voice of victims at trials (see Burgess 2018), the demand and implement of more stringent punishments for careless driving matters (Cain 2017b; Egan 2018) and distracted driving matter (CityNews 2018; Jones 2017c) are just some examples of cultural elements that shape the use of fines within the POA's administrative system.
} 
profitability) component that exists within its approach, not to mention the pursuit of a costeffective scheme that preserves the "self-funded" (Guelph 2015) or "net-positive" (Chatham-Kent 2017: 2; MAG 2017c; Windsor-Essex 2016: 17, to provide a few examples) aspect for governments administering it.

A dynamic and/or problematization that first arose from an issue of 'cost' and 'volume' during the 1970s, which then cascaded and became connected to the 'neoliberal political economic project' of the 1980s and 1990s that it also helped to shape and preserve, the current iteration of Ontario's regulatory system - 'POA Modernization' - still confronts and operates with these issues (i.e., cost, volume) and functions (i.e., revenue generator) today (see Chapter 5). At the same time however, the evolution of its fine system and form of decriminalization is one that, when examining the outcomes of its approach, has arguably failed: as defaulted cases have reached over 3 million and fine amounts are still well over \$1B when one accounts for the various fees imposed on a fine defaulter (see Appendix $7 \& 8$ ). When inspected more closely (as done in Chapter 6), a trend is discovered that shows the POA not only failing to abolish the debtor prison system until mid-1990s, but upon doing so in 2001 through legislation, the system was simply imposed on offenders as fine defaulting rose drastically, creating the POA's own form of a 'shadow carceral state' (Beckett \& Murakawa 2012). Consequently, with discourses that center on fine defaulters paying their fines solely by a monetary payment in full (see Windsor-Essex 2016: 12; London 2016: 4), the tension that establishes itself is one that limits punishment and justice to become synonymous with their monetization, as the only 'exit' given to offenders is through the medium of money, resulting in punishment and justice becoming 'estranged' from any 'transformational' purpose or ones intended for regulatory systems (see Libman 2012a, Verhulst 2008). 
While some academics have focused on what the monetary sanctions offers in allowing “mass regulation" to be possible (O'Malley 2013: 376), or how these forms of 'micro-penalties' are "compliance techniques" a part of a complex Eliasian civilizing process (Hunt 2006), this thesis has sought to disrupt and destabilizes these narratives by injecting a critical criminological lens that sketches a more complex and conflicted story about decriminalization and its systems of punishment, social control, and justice. More along the lines of Garland (1990: 188) adaptation of Pashukanis's work (1924/1978) or Simmel (1978/2004: 443-448) comparison of money to the law and education, this thesis has argued that the establishment of 'mass regulation', made 'available' and 'validated' by the monetization of punishment and justice under regulatory systems (e.g., the POA), fails to adequately account for the inequities that exist in our present capitalist order, including the "harms of economic domination and the social injuries of class" (Garland 1990: 118).

In the end, the current narrow focus of punishment and justice under the POA's model of decriminalization, arguably goes against its purported "progressive penal" discourses of being 'fair' and 'appropriate' (see MAG 2015c: 5, 2015d: 2), operating more instead as a "regressive economic policy" (Natapoff 2015a) that maintains and perpetuates the current social structures as the 'state' (i.e., locally and provincially) seeks to operate within and through them. While O'Malley (2013) is seemingly content with the creation of a "class in debt" as a sacrifice to not having a "class in prison" (389), this thesis argues that this is an insufficient argument and/or dilemma imposed. Taking into consideration Harris's (2016) work, citing Rusche and Kirchheimer (1939/2003) in her conclusion, the fallacies of the POA, which establish their own form of "punitive logics" (Velloso 2013a) through debt and other forms of incapacitation (e.g., suspensions of driver's licence, loss of insurance, low credit rating, to name a few), can be and are in many cases futile forms of "severe punishment and cruel treatment" that are both repressive and the easy 
way out, as they give the "illusion of security" that the current system is working and necessary (Rusche \& Kirchheimer 1939/2003: 207).

To resist the restrictions and/or "narrow limits" placed upon penal reforms, such as those found with the POA, as well as initiating more comprehensive solutions than the 'class of debt' option currently offered, a diverse set of policy recommendations are outlined in the final section to begin the "constructive social activity" (207) of re-imagining and transforming punishment and justice as envisioned and desired for decriminalization and regulatory systems.

\section{2 - The Limitations of this Study, Where Research Must Go Next, and Policy Recommendations to the $\mathrm{POA}$}

Before delving into the policy recommendations, it is first important to explore the limits of this study, alongside where research must and may go next in exploring the subject of the POA and likewise systems of decriminalization, punishment, and social control. By selecting a study which focused on a content analysis of government records, this thesis was limited to examining "records that others have decided were worth preserving" (Berg \& Lune 2012: 376) as well as other common obstacles found in such studies, including: inferring causality and discerning the “deep structural meaning" (i.e., latent content) underlying messages in documents (355, emphasis in original). Given my attempt in this project to make sense of discourses regarding punishment, social control, and governance (i.e., why and how we are governed), this thesis was equally focused on the social structures and power relations contributing to their development particularly as defined and initiated by government. To address the issue of locating this latent content, "other means" (376) were taken to do so, including reviewing different pockets of literature (e.g., academic studies of municipal-provincial relations) as well as different forms of data and nondiscursive practices (e.g., number of tickets issued, defaulted fine amount, POA jail stats). 
On that note, this thesis was also aware that there are other dynamics shaping the POA beyond the records and the discourses contained within them, this includes law enforcement, the courts, and the other 'street-level bureaucrats' (see Harris 2016: 124-133) on the frontlines of the judicial system. Taking my own experiences as a POA clerk into account, as well as the various other Canadian research done on particular areas of this system, including the SSA (Chesnay et al. 2013; Hermer \& Mosher 2002; O’Grady et al. 2013), regulation of corporations (Glasbeek 2002; Snider 1993; Snider and Bittle 2015), and the role of Business Improvement Districts in urban governance (Lippert 2012; Lippert \& Sleiman 2012), this thesis adds to this body of literature, providing a macro-look at the evolution (i.e., genealogy) of the POA as it relates to minor offences.

In light of my contribution to understanding how punishment and justice are both constructed and implemented within the POA system, and while the others mentioned above provide important nuances and context to my own research, there are various areas research should examine in relation to the POA going forward. They include: an ethnographic study examining the experiences of fine defaulters themselves within the POA, the rise of privatization - particularly as it relates to parking enforcement and the growing role of collection agencies, the growing use of red-light cameras and photo radars that contributes to the rise of automated socio-technical environments (see Lianos 2000, 2003, 2012) as well as the establishment of a simulated justice model (see O'Malley 2010b, 2013), and lastly, a examining of the application and conception of punishment and justice found within the 'street-level' bureaucrats (i.e., court clerks) operating the system.

Having reviewed the study's limitations and the 'roots' still remaining for research to examine, there are also policy recommendations the POA program should consider implementing in order to mitigate some of the problems located in this thesis's findings. In relation to the practice 
of fines, the POA should consider two different policy initiatives: day fines and the actual implementation of a 'fine option' program. With the former being a system of punishment that takes into account the offender's income (see Drápal 2018; Kantorowicz-Reznichenko 2015), while the latter provides the option of providing non-monetary and/or communal sentence (Libman 2011: 275-276), both are measures that could address the intense and extensive burden that is commonly experienced in the POA and other fine systems (see Hampton 2015; Harris 2016; Harris et al. 2011). At the same time, for certain offences (e.g., drug-related offences and homelessness, as examples) forms of diversion program should be implemented to both eliminate the penalization of such social conditions faced by individuals as well as assisting these 'offenders' to reintegrate into society rather than create more barriers to initiate such a process.

In relation to driving-related offences, alternatives programs for traffic offences should be considered, including the Traffic Intervention Program in Cleveland (Kent \& Regoeczi 2014; Turner 2015) or the distracted driving pilot program recently done in British Columbia (see Canadian Press \& Cunningham 2018). Both programs embody the 'regulatory cycle' (Libman 2012a; Verhulst 2008) by seeking to help individuals return to activity while also eliminating the harms and consequences (e.g., insurance increases, debt, suspensions) found with a traffic ticket. Furthermore, for more immediate initiatives, various US states (e.g., California, Michigan, and Mississippi) have eliminated the practice of suspending a person licence for unpaid fines reasons, seeing little improvement in traffic safety (Sanchez 2018b). With over 100,000 suspensions issued annually in Ontario for fine defaulting since 1999, comprising over 50\% of all non-criminal code suspensions (see Appendix 9), there is little evidence provided or created by MTO showing it to have any positive effect on traffic safety ${ }^{111}$. Some other immediate actions include debt forgiveness

\footnotetext{
111 According to an MTO report from 2013, fatal and personal injury as well as property damage collisions all steadily dropping in Ontario since 1988, seeing fatal injuries go down from 1,076 to 470, personal injuries from 76,724 to 42,408 , and property damage collisions go from 228,398
} 
tied to individuals who are willing and actively partake in serving their sentence through alternative means (e.g., programs mentioned above), such as in the case of Mr. Jaques, as well as implementing speed bumps and other safety initiative to better regulate traffic.

With the above policies in mind, considerations must also be made at the more macrostructural level to ensure that the 'revenue trap', located in this thesis findings, is addressed too. This largely means establishing other revenues sources, whether through different forms of taxation or increasing provincial transfers, for municipalities to fund both this program as well as other services and future projects. These changes, and some of the initiatives above, could also mean a more progressive taxation model not just at the provincial level, but the federal one, to comprehensively address the various social problems that underlie programs such as the POA.

All in all, the concern in the end is not just the failure of the present model for individuals unable to conform to its system due to a lack of alternatives, the same issue faced 38 years ago when the POA was conceived and created, it is also the unsustainability it may imposed on various municipalities going forward. Facing various fiscal concerns, including the rising costs to staffing (Coté \& Fenn 2014: 45), and more being expected of POA branches in coming years, there is significant pressure being placed on them to mitigating the rising costs associated with their growing responsibilities by finding for more forms of revenue in the POA. The issue in this approach, as found in the current modernized system, is that it is unsustainable, as it simply leads to more individuals becoming entrapped with cities seeing little benefit from them.

to 188,999 within this 35 -year period (46). While collision rates continue slightly lower in 2016 , with fatal injuries reaching 439 and person injuries falling to 35,533 (2016:2), suspensions rates for fine defaulting rose in mid-2000 to over 155,000 in 2007 before dropping to approximately 109,000 in 2016 (see Appendix 9). This shows that there is little evidence of having an impact on traffic safety. Meanwhile in relation to getting people to pay through such tactics, since MTO possess no performance measures to examine this question (discovered from a request initiated by myself to discern its potential effect on this issue), there is therefore little evidence that this policy is achieving this goal either. 
If we are, as researchers and citizens alike, going to endeavour into utilizing more systems of decriminalization to regulate our societies, then we must be cognizant of its limitations and be proactive in mitigating them, because not doing so, will only lead to perpetuating the problems the system was intended to address, while also maintaining some of society's most harmful inequities. 


\section{References:}

Abrahamson, M. (1983). Social Research Methods. Englewood Cliffs, NJ: Prentice Hall.

Ashworth, A., \& Zedner, L. (2014). Preventative Justice. Oxford, UK: Oxford University Press.

Association of Municipality of Ontario [AMO]. (1997a, May 1). "Streamlining of Administration of Provincial Offences, 1997/Loi de 1997 Simplifiant l'Administration en ce qui a Trait aux Infraction Provinciales (Continued).” Standing Committee on General Government. 36 ${ }^{\text {th }}$ Parliament, $1^{\text {st }}$ Session. Retrieved March 25, 2018 from the Legislative Assembly of Ontario (Hansard): https://www.ola.org/en/legislativebusiness/committees/general-government/parliament-36/transcripts/committee-transcript1997-may-01.

Association of Municipality of Ontario [AMO]. (1997b, April). Bill 108: Provincial Offences Act, 1997: Presentation to the Standing Committee on General Government. (microfiche) Toronto, ON: Association of Municipalities of Ontario. (Microlog 97-04830).

Association of Municipality of Ontario [AMO]. (2015, Jun. 2). What's Next Ontario? Imagining a prosperous future for our communities: A Fiscal Overview. Retrieved April, 15, 2018 from: https://www.amo.on.ca/AMO-PDFs/Whats-Next-Ontario/Whats-Next-OntarioFiscal-Overview-Accessible-2015.aspx.

Association of Municipality of Ontario [AMO]. (2017, May 25). Local Share: Imagining a prosperous future for our communities - Proposed Action Plan. Retrieved April 15, 2018 from: https://www.amo.on.ca/AMO-PDFs/Local-Share/Reports/AMO-Local-ShareProposed-Action-Plan-2017-05-25.aspx.

Association of Municipality of Ontario [AMO]. (2018). Home page. Retrieved March 25, 2018 from: https://www.amo.on.ca/Home.

ArchCity Defenders. (2014). Municipal Courts White Papers. Retrieved January 17, 2018 from: http://www.archcitydefenders.org/wp-content/uploads/2014/11/ArchCity-DefendersMunicipal-Courts-Whitepaper.pdf.

Auditor General of Ontario [AGO]. (2008). 'Chapter 3: Section 3.07 - Court Services,' in Annual Report of the Office of the Auditor General of Ontario. Retrieved March 20, 2018 from: http://www.auditor.on.ca/en/content/annualreports/arreports/en08/307en08.pdf.

Bacchi, C. (2009). Analysing policy: what's the problem represented to be?. Frenchs Forest, N.S.W.: Pearson.

Bacchi, C. (2012). Why Study Problematization? Making Politics Visible. Open Journal of Political Science 2(1): 1-8.

Ballingall, A. (2016, October 4). Judge drops $\$ 65,000$ in fines against former homeless man. Toronto Star. Retrieved July 7, 2017 from: 
https://www.thestar.com/news/gta/2016/10/04/judge-drops-65000-in-fines-againstformer-homeless-man.html.

Bannon, A., Nagrecha, M., \& Diller, R. (2010). Criminal Justice Debt: A Barrier to Re-Entry. Brennan Center for Justice. Retrieved January 17, 2018 from: https://www.brennancenter.org/sites/default/files/legacy/Fees\%20and\%20Fines\%20FINA L.pdf.

Barton, A., Corteen, K., Scott, D., \& Whyte, D. (2007). 'Introduction: Developing a Criminological Imagination,' in Barton et al (eds.) Expanding the Criminological Imagination: Critical Readings in Criminology (pp. 1-14). Devon, UK: Willan Publishing.

Becker, H. S. (1963). Outsiders. New York, NY: The Free Press.

Beckett, K. and Naomi Murakawa. (2012). Mapping the shadow carceral state: Toward an institutionally capacious approach to punishment. Theoretical Criminology 16(2): 221244.

Beckett, K., \& Herbert, S. (2008). Dealing with disorder: Social control in the post-industrial city. Theoretical Criminology 12(1): 5-30.

Beckett, K., \& Herbert, S. (2010). Banished: The New Social Control in Urban America. New York: Oxford University Press.

Benns, W., \& Strode, B. (2016, Feb. 23). Debtors' Prison in 21st-Century America: For failing to pay parking tickets, court fees, and other petty municipal citations, black residents of Greater St. Louis are ending up behind bars. Atlantic. Retrieved March 12, 2018 from: https://www.theatlantic.com/business/archive/2016/02/debtors-prison/462378/.

Bereska, T. (2014). Deviance, Conformity, and Social Control in Canada (Fourth edition). Toronto, CA: Pearson Canada Inc.

Berg, B., \& Lune, H. (2012). Qualitative Research Methods for the Social Sciences. Upper Saddle River, NJ: Pearson Education, Inc.

Bill 74: An Act to establish a Code of Procedure for Provincial Offences. Third Reading, March $27,1979,31^{\text {st }}$ Parliament, $3^{\text {rd }}$ session. Obtained through provincial FOI request A-201700244. Toronto, ON: Ministry of the Attorney General of Ontario.

Bill 75: An Act to amend the Provincial Courts Act. Third reading, March 27, 1979, $31^{\text {st }}$

Parliament, $3^{\text {rd }}$ session. Obtained through provincial FOI request A-2017-00244. Toronto, ON: Ministry of the Attorney General of Ontario.

Bill 108: Streamlining of Administration of Provincial Offences Act. (1998). Royal Assent, June $11,1998,36^{\text {th }}$ Parliament, $2^{\text {nd }}$ session. Toronto: Ministry of Attorney General of Ontario. Retrieved September 7, 2017 from: https://www.ola.org/en/legislativebusiness/bills/parliament-36/session-2/bill-108. 
Bittle, S., \& Snider, L. (2015). Law, Regulation, and Safety Crime: Exploring the Boundaries of Criminalizing Powerful Corporate Actors. Canadian Journal of Law and Society 30(3): 445-464.

Blomberg, T., \& Cohen, S. (Eds.). (2003). Punishment and Social Control (Enlarged Second Edition). New York, NY: Aldine de Gruyter Inc.

Bottoms, A. (1983). 'Some neglected features of contemporary penal systems'. In D. Garland and P. Young (Eds), The Power to Punish. London, UK: Heinemann.

Bovdis, P. (2017, Jun. 3). Defaulted Provincial Offences Act (POA) Fine Collection: Expansion of Licence Plate Denial. Obtained through provincial FOI request MAG-A-2017-02149. Toronto, ON: Ministry of Transportation of Ontario.

Boyne, R. (2000). Post-Panopticism. Economy and Society 29(2): 285-307.

Braithwaite, J. (2003). What's wrong with the sociology of punishment?. Theoretical Criminology 7(1): 5-28.

Brown, M. (2009). The Culture of Punishment: Prison, Society and Spectacle. New York, NY: New York University Press.

Brownlee J., \& Walby, K. (Eds.).(2015). Access to Information and Social Justice: Critical Research Strategies for Journalists, Scholars, and Activists. Winnipeg, MB: ARP Books.

Burden Reduction Act, Statute of Ontario, 2017, c. 2. Retrieved July 16, 2018 from: https://www.ontario.ca/laws/statute/S17002/.

Burgess, S. (2018, Jan. 22). Family of Cornwall crash victim denied chance to face man responsible. CBC News. Retrieved March 5, 2018 from: https://www.cbc.ca/news/canada/ottawa/cornwall-careless-driving-victim-impact1.4494602 .

Byrne, J., \& Rebovich, D. (Eds). (2007). The New Technology of Crime, Law and Social Control. Monsey, NY: Criminal Justice Press.

Canadian Press, \& Cunningham, S. (2018, Jan. 9). B.C. pilot program offers workshop instead of \$543 fine for distracted driving. CTV News. Retrieved April 17, 2018 from: https://www.ctvnews.ca/canada/b-c-pilot-program-offers-workshop-instead-of-543-finefor-distracted-driving-1.3751443.

Cain, P. (2017a, November 2). Ontario's busy traffic courts can't cope with teens' marijuana tickets, lawyers warn. Global News. Retrieved November 9, 2018 from: http://nationalpost.com/news/canada/ontario-proposal-aiming-to-cut-costs-and-free-upcourts-would-disregard-right-to-a-fair-trial-critics.

Cain, P. (2017b, Sept. 20). Ontario plans harsher penalties for careless driver who hurt or kill. Global News. Retrieved December 5, 2017 from: https:/globalnews.ca/news/3755016/ontario-plans-harsher-careless-driving-penalties/. 
Canton, R. (2015). Crime, punishment and the moral emotions: Righteous minds and their attitudes towards punishment. Punishment \& Society 17(1): 54-72.

Canton, R. (2017). Why Punish? An Introduction to the Philosophy of Punishment. London, UK: Palgrave.

Carrier, N. (2010). Anglo-Saxon Sociologies of the Punitive turn: Critical Timidity, Reductive Perspectives, and the Problem of Totalization. Champ penal/Penal field Vol. VII. Retrieved from: http://champpenal.revues.org/7952.

Carrington, K., \& Hogg R. (Eds). (2002). Critical Criminology: Issues, debates, challenges. London, UK: Willian Publishing.

Castrilli, A. (1997, Feb. 12). "Streamlining of Administration of Provincial Offences Act, 1997/Loi de 1997 Simplifiant l'Administration enc e qui a trait aux Infractions Provinciales." Ontario. Legislative Assembly. Second Reading. $36^{\text {th }}$ Parliament, $1^{\text {st }}$ Session. Retrieved March 25, 2018 from the Legislative Assembly of Ontario website (Hansard): https://www.ola.org/en/legislative-business/house-documents/parliament36/session-1/1997-02-12/hansard\#P602_114681.

CBC. (2015, March 2). 'Ontario traffic dodgers may not get drivers license renewed: Traffic tickets deadbeats owe more than $\$ 1$ billion to provincial coffers'. CBC News. Retrieved April 16, 2017 from: http://www.cbc.ca/news/canada/kitchener-waterloo/ontario-trafficticket-dodgers-may-not-get-drivers-licence-renewed-1.2978127.

CBC. (2016, Oct. 4). Osgoode law student helps drop $\$ 65 \mathrm{~K}$ in fines for former homeless man. CBC News. Retrieved Sept, 12018 from: https://www.cbc.ca/news/canada/toronto/programs/metromorning/law-student-homelesstickets-fines-appeal-1.3788734.

CBC. (2017, October 30). Ontario MPP proposes law to fine distracted pedestrians. CBC News. Retrieved November 15, 2017 from: http://www.cbc.ca/news/canada/toronto/ontariozombie-law-distracted-walking-1.4378205.

Chatham-Kent POA. Legislative Services. (2017, Mar. 7). Provincial Offences Financial Status Report. Retrieved March 19, 2018 from: https://portal.chathamkent.ca/Council/CouncilMeetings/2017/Documents/May/May-8-9ai.pdf.

Chesnay, C., Bellot, C., \& Sylvestre, M. (2013). Taming Disorderly People One Ticket at a Time: The Penalization of Homelessness in Ontario and British Columbia. Canadian Journal of Criminology and Criminal Justice 55(2): 161-185.

Chriss, J. (2007). Social Control: An Introduction. Cambridge, UK: Polity Press.

City of Barrie. (2008). POA Fines Collection Policy. Retrieved March 19, 2018 from: https://www.barrie.ca/Living/City\%20Services/Documents/POA-Fines-CollectionPolicy.pdf. 
City of Brampton. (1997, May 1). "Streamlining of Administration of Provincial Offences, 1997/Loi de 1997 Simplifiant l'Administration en ce qui a Trait aux Infraction Provinciales (Continued)." Standing Committee on General Government. 36 ${ }^{\text {th }}$ Parliament, $1^{\text {st }}$ Session. Retrieved March 25, 2018 from the Legislative Assembly of Ontario (Hansard): https://www.ola.org/en/legislative-business/committees/generalgovernment/parliament-36/transcripts/committee-transcript-1997-may-01.

City of Guelph. (2015). Court Services Department - 2015 Annual Report. Retrieved March 20, 2018 from: http://guelph.ca/wp-content/uploads/CourtServicesAnnualReport2015.pdf.

City of Hamilton. Mayor and Members of General Issues Committee. (2015, Mar. 30). MAG Consultation on POA Reform LS15009 (City Wide). Retrieved March 19, 2018 from: https://pub-hamilton.escribemeetings.com/filestream.ashx?DocumentId=115221.

City of London and Middlesex Region. Corporate Services Committee. (2016, Dec. 13). Request for Write-Off of Provincial Offences Act (POA) Accounts Receivable. Retrieved March 19, 2018 from: https://publondon.escribemeetings.com/filestream.ashx?DocumentId=28610.

City of Oshawa. Council in Committee of the Whole. (2015, Apr. 21). Ministry of Attorney General Consultation re Administrative Penalty Systems. Retrieved from: http://app.oshawa.ca/agendas/city council/2015/2015 04 27/CM-15-11Report MAP AMPs.pdf.

City of Ottawa. (2012). "Report to Council on Ontario Association of Police Services Boards White Paper". Retrieved March 5, 2017 from: http://ottawa.ca/calendar/ottawa/citycouncil/csedc/2012/06-05/IPD\%20-\%20A\%20\%200APSB \%20unpaid\%20fines.pdf.

CKOM News. (2017, August 1). Non-profit benefit as province delays fine option changes. CKOM News. Retrieved July 16, 2018: https://www.ckom.com/2017/08/01/non-profitsbenefit-as-province-delays-fine-option-changes/.

Cohen, S. (1977). 'Prisons and the future of control systems" from concentration to dispersal'. In M. Fitzgerald, P. Halmos, J. Muncie, \& D. Zeldin (Eds.), Welfare in Action (pp. 217228). London, UK: Routledge \& Kegan Paul.

Cohen, S. (1979). The Punitive City: Notes on the Dispersal of Social Control. Contemporary Crises 3: 339-363.

Cohen, S. (1985). Vision of Social Control: Crime, Punishment and Classification. Cambridge, UK: Polity Press.

Cohen, S. (1998). 'Intellectual Scepticism and Political Commitment: the Case of Radical Criminology'. In P. Walton and J. Young (Eds.), The New Criminology Revisited (pp. 98129). London, UK: Macmillan. 
Cohl, K., Lightstone, S., \& Thomson, G. (2015). Ontario Court of Justice - A History. Retrieved Nov. 9, 2017 from the Ontario Court of Justice website: http://www.ontariocourts.ca/ocjhistory/.

Coleman, R., \& Sim, J. (2005). 'Contemporary statecraft and the 'punitive obsession': a critique of the new penology thesis'. In J. Pratt, M. Brown, S. Hallsworth, \& W. Morrison (Eds.), The New Punitiveness: Trends, Theories, Perspectives (pp. 101-118). Portland, OR: Willan Publishing.

Collier, S. (2009). Topologies of Power: Foucault's Analysis of Political Government beyond 'Governmentality'. Theory, Culture \& Society 26(6): 78-108.

Compulsory Automobile Insurance Act [CAIA], Revised Statute of Ontario, 1990, c. C.25. Retrieved from November 8, 2018: https://www.ontario.ca/laws/statute/90c25.

Côté, A., \& Fenn, M. (2014). Provincial-Municipal Relations in Ontario: Approaching an Inflection Point. IMFG Papers on Municipal Finance and Governance, No. 17. Retrieved May 5, 2018 from: https://munkschool.utoronto.ca/imfg/uploads/275/1560_imfg_no_17_online_full_colour. pdf.

Crawford, B. (2017a, Apr. 17). Gone in 30 seconds: The murky world of private parking enforcement. Ottawa Citizen. Retrieved August 26, 2018 from: https://ottawacitizen.com/news/local-news/gone-in-30-seconds-the-murky-world-ofprivate-parking-enforcement.

Crawford, B. (2017b, April 15). City of Ottawa owed \$39 million in outstanding parking tickets. Ottawa Citizen. Retrieved September 5, 2017 from: https://ottawacitizen.com/news/localnews/city-of-ottawa-owed-39-million-in-outstanding-parking-tickets.

Cross, B. (2017, Jun 8). Ramped-up fine collection nets local municipalities \$2 million. Windsor Star. Retrieved Sept 1, 2018 from: https://windsorstar.com/news/local-news/ramped-upfine-collecting-nets-local-municipalities-2-million.

Currie, E. (2002). Preface. In K. Carrington \& R. Hogg (Eds.), Critical Criminology: Issues, debates, challenges (pp. vii-ix). UK: Willian Publishing.

Curry, B. (2018, Aug. 22). Provinces cutting back as Ottawa spends more on infrastructure, PBO finds. Globe and Mail. Retrieved August 23, 2018 from: https://www.theglobeandmail.com/politics/article-provinces-cutting-back-as-ottawaspends-more-on-infrastructure-pbo/.

De Giorgi, A. (2006). Re-Thinking the Political Economy of Punishment: Perspectives on PostFordism and Penal Politics. Hampshire, UK: Ashgate.

De Giorgi, A. (2013). 'Punishment and Political Economy'. In J. Simon \& R. Sparks (Eds.), The SAGE Handbook of Punishment and Society. London, UK: SAGE Publishing Ltd.

Dean, M. (1999). Governmentality: Power and Rule in Modern Society. London, UK: Sage. 
Dean, M, \& Hindess, B. (Eds.). (1998). Governing Australia: Studies in Contemporary Rationalities of Government. Cambridge, UK: Cambridge University Press.

DeKeseredy, W. (2011). Contemporary Critical Criminology. New York, NY: Routledge.

Dollin, L. (2018, May 18). Where's the plan for Ontario's municipalities?. Globe and Mail. Retrieved from Sept. 1, 2018 from https://www.theglobeandmail.com/opinion/articlewheres-the-plan-for-ontarios-municipalities/.

Doyle, A., \& Moore, D. (Eds). (2011). Critical Criminology in Canada: New Voices, New Directions. Vancouver, BC: UBC Press.

Drápal, J. (2018). Day fines: A European comparison and Czech malpractice. European Journal of Criminology 15(4): 461-480.

Drea, F. (1978, Feb. 27). “Throne Speech Debate (Continued).” Ontario. Legislative Assembly. $31^{\text {st }}$ Parliament, $2^{\text {nd }}$ Session. Retrieved May 23, 2018 from the Legislative Assembly of Ontario (Hansard): http://hansardindex.ontla.on.ca/hansardeissue/31-2/1005.htm.

Duff, R.A. (2001). Punishment, Communication and Community. Oxford, UK: Oxford University Press.

Durkheim, E. (1984). The Division of Labour in Society. (W.D. Halls, Trans.). New York, NY: Free Press. (Originally published in 1893).

Edwards, A. (1988). Regulation and Repression: The Study of Social Control. Sydney, AT: Allen \& Unwin.

Egan, K. (2018, Jan. 30). How Ontario has toughened careless driving penalties. Ottawa Citizen. Retrieved March, 52018 from: https://ottawacitizen.com/news/local-news/how-ontariohas-toughened-careless-driving-penalties.

Elliot, D. (1996, Nov. 19). Transfer of Selected Administrative and Prosecutorial Functions Related to the Provincial Offences Act [Briefing Note]. Obtained through provincial FOI request A-2017-00244 and Appeal PA18-40. Toronto, ON: Fiscal Planning Branch, Ministry of Finance of Ontario.

Employment Standards Act, Statute of Ontario, 2000, c. 41. Retrieved November 8, 2018 from: https://www.ontario.ca/laws/statute/00e41.

Environmental Protection Act, Revised Statute of Ontario, 1990, c. E.19. Retrieved November 8, 2018 from: https://www.ontario.ca/laws/statute/90e19.

Evans, P. (2018, Mar. 15). Canadians' debt to disposable income ratio inches down to $170.4 \%$. CBC News. Retrieved November 20, 2018 from: https://www.cbc.ca/news/business/statistics-canada-debt-data-1.4577306.

Fairclough, N. (1995). Critical discourse analysis: the critical study of language. New York: Longman Publishing.

Fanelli, C. (2014). Under Pressure: How Public Policy is Constraining Ontario Municipalities. Canadian Centre for Policy Alternatives. Retrieved May 23, 2018 from: 
https://www.policyalternatives.ca/sites/default/files/uploads/publications/Ontario\%200ffi ce/2014/10/Under\%20PressureFINAL.pdf.

Fanelli, C., \& Thomas, M. (2011). Austerity, Competitiveness and Neoliberalism Redux. Socialist Studies/Études socialistes 7(1/2): 141-170.

Farnan, M. (1988, Nov. 7). "Electronic Monitoring of Offenders.” Ontario. Legislative Assembly. 34 ${ }^{\text {th }}$ Parliament, $1^{\text {st }}$ Session. Retrieved May 23, 2018 from the Legislative Assembly of Ontario (Hansard): http://hansardindex.ontla.on.ca/hansardeissue/34$\underline{1 / 1100 . h t m}$.

Farnan, M. (1989, Dec. 4). “Correctional Facilities.” Ontario. Legislative Assembly. 34 Parliament, $2^{\text {nd }}$ Session. Retrieved May 23, 2018 from the Legislative Assembly of Ontario (Hansard): http://hansardindex.ontla.on.ca/hansardeissue/34-2/1078.htm.

Farnan, M. (1990, May 30). "Correctional Facilities.” Ontario. Legislative Assembly. 34 Parliament, $2^{\text {nd }}$ Session. Retrieved May 23, 2018 from the Legislative Assembly of Ontario (Hansard): http://hansardindex.ontla.on.ca/hansardeissue/34-2/1038 90.htm.

Federation of Canadian Municipalities. (2012). The State of Canada's Cities and Communities 2012. Retrieved August 23, 2018 from: https://suma.org/img/uploads/documents/FCM\%202012\%20State\%20of\%20Cities\%20an d\%20Communities.pdf.

Fine Option Program [FOP], Revised Regulation of Ontario, 1990, Reg. 948. Retrieved May 27, 2018 from: https://www.ontario.ca/laws/regulation/900948.

Flaherty, J. (1997, May 1). "Streamlining of Administration of Provincial Offences, 1997/Loi de 1997 Simplifiant l'Administration en ce qui a Trait aux Infraction Provinciales (Continued)." Ontario. Legislative Assembly. Standing Committee on General Government. $36^{\text {th }}$ Parliament, ${ }^{\text {st }}$ Session. Retrieved March 24, 2017 from the Legislative Assembly of Ontario (Hansard): https://www.ola.org/en/legislativebusiness/committees/general-government/parliament-36/transcripts/committee-transcript1997-may-01.

Foucault, M. (1977). Discipline and Punish. (A. Sheridan, Trans.). London: Penguin.

Foucault, M. (1985). Discourse and truth: The problematization of parrhesia. J. Pearson (Ed.). Evanston, IL: Northwestern University.

Foucault, M. (1986). The use of pleasure: The history of sexuality (Vol. 2). (R. Hurley, Trans.). New York, NY: Vintage.

Foucault, M. (1991). Governmentality. In G. Burchell, C. Gordon, \& P. Miller (Eds.), The Foucault Effect: Studies in Governmentality with Two Lectures By and an Interview with Michel Foucault (pp. 87-104). Chicago, IL: The University of Chicago Press.

Foucault, M. (1998). Nietzche, Genealogy, History. In M. Foucault \& J.D. Faubion, (Eds.), Aesthetics, method, and epistemology (pp. 369-391). New York, NY: New Press. 
Foucault, M. (2003). "Society Must Be Defended" Lectures at the Collège de France, 1975-76. M. Bertani \& A. Fontana (Eds.). (D. Macey, Trans.). New York, NY: Picador.

Foucault, M. (2007). Security, Territory, Population: Lectures at the Collège de France. M. Senellart (Ed.). (G. Burchell, Trans.). New York, NY: Palgrave MacMillan.

Foucault, M. (2008). The Birth of Biopolitics: Lectures at the Collège de France, 1978-79. M. Senellart (Ed.). (G. Burchell, Trans.). New York, NY: Palgrave MacMillan.

Frauley, J. (2010). Criminology, deviance, and the silver screen: the fictional reality and the criminology imagination. New York, NY: Palgrave Macmillan.

Frauley, J. (2015). On Imaginative Criminology and Its Significance. Societies 2015(5): 618-630.

Friedland, M., Trebilcock, M., \& Roach, K. (1990). Regulating Traffic Safety. Toronto, ON: University of Toronto Press.

Frisque, G. (2016, Oct. 26). AMO warns of massive property tax increases and bleak future for municipal infrastructure. Orangeville.com. Retrieved Sept. 1, 2018 from: https://www.orangeville.com/news-story/6930758-amo-warns-of-massive-property-taxincreases-and-bleak-future-for-municipal-infrastructure/.

Gallant, J. (2015, June 28). Judge signals it's time to offer relief from 'backbreaking' fines. Toronto Star. Retrieved August 5, 2017 from: https://www.thestar.com/news/gta/2015/06/28/judge-signals-its-time-to-offer-relief-frombackbreaking-fines.html.

Garland, D. (1981). The Birth of the Welfare Sanction. British Journal of Law and Society 8(1): $29-45$.

Garland, D. (1990). Punishment and Modern Society: A Study in Social Theory. New York: Oxford University Press.

Garland, D. (1996). The Limits to the Sovereign State: Strategies of Crime Control in Contemporary Society. The British Journal of Criminology 36(4): 445-471.

Garland, D. (2001). The Culture of Control: Crime and Social Order in Contemporary Society. Chicago, IL: The University of Chicago Press.

Garland, D. (2003). 'Penal Modernism and Postmodernism'. In T. Blomberg \& S. Cohen. (Eds.), Punishment and Social Control (Enlarged Second Edition) (pp. 45-73). New York, NY: Aldine de Gruyter Inc.

Garland, D. (2018). Theoretical advances and problems in the sociology of punishment. Punishment \& Society 20(1): 8-33.

Geertz, C. (1973). The Interpretation of Cultures. New York, NY: Basic Books.

Gillis, W. (2012, December 4). Top parking officer single-handedly fined Toronto drivers nearly \$4 million in five years. Toronto Star. Retrieved November 10, 2017 from: 
https://www.thestar.com/news/gta/2012/12/04/top_parking_officer_singlehandedly_fined toronto drivers nearly 4 million in five years.html.

Gillis, W. (2018, March 8). Policing in Ontario takes 'a large step forward' with sweeping new law. Toronto Star. Retrieved August 24, 2018 from: https://www.thestar.com/news/gta/2018/03/08/policing-in-ontario-takes-a-large-stepforward-with-sweeping-new-law.html.

Glasbeek, H. (2002). Wealth by Stealth: Corporate Crime, Corporate Law, and the Perversion Democracy. Toronto: Between the Lines.

Gordon, C. (1991). Governmental Rationality: An Introduction. In G. Burchell, C. Gordon, \& P. Miller (Eds.), The Foucault Effect: Studies in Governmentality with Two Lectures By and an Interview with Michel Foucault (pp. 1-51). Chicago, IL: The University of Chicago Press.

Government of Ontario. (1997, December). Who Does What: Toward Implementation. (microfiche). Toronto, ON: Queen's Printer for Ontario. (Microlog 98-04065).

Government of Ontario. (2018). Integrated Courts Offences Network [ICON]. Retrieved September 3, 2018 from: https://www.ontario.ca/data/integrated-courts-offences-network.

Graham, K., \& Phillips, S. (1998). 'What Does What' in Ontario: The process of provincialmunicipal disentanglement. Canadian Public Administration/Administration Publique du Canada 4(2): 175-209.

Greater Sudbury POA. (2017). Provincial Offences Collection Strategy. Retrieved March 19, 2018 from:

https://agendasonline.greatersudbury.ca/index.cfm?pg=feed\&action=file\&attachment=16 881.pdf.

Haidt, J. (2003). 'The moral emotions'. In R. Davidson, K. Scherer, \& H. Goldsmith (Eds.), Handbook of Affective Sciences, Oxford, UK: Oxford University Press.

Haidt, J. (2012). The Righteous Mind: why Good People are Divided by Politics and Religion. London, UK: Allen Lane.

Hale, A. (2018, Apr. 23). Provincial offences court funding change annoys Cornwall, SDG. Cornwall Standard-Freeholder. Retrieved May 5, 2018 from: http://www.standardfreeholder.com/2018/04/23/provincial-offences-court-funding-change-annoys-cornwallsdg.

Hall, S., \& Scraton, P. (2005). 'Law, class and control'. In M. Fitzgerald, G. McLennan, \& J. Pawson (Eds.), Crime and Society: Readings in History and Theory. Milton Park: UK. (Originally published in 1981).

Hallett, D. (2016, Jun 8). City of Guelph eager to collect on $\$ 14$ million in unpaid fines.

GuelphMercuryTribune.com. Retrieved Sept 1, 2018 from: 
https://www.guelphmercury.com/news-story/6713485-city-of-guelph-eager-to-collect-on14-million-in-unpaid-fines/.

Hampson, C. (2016). The New American Debtors' Prisons. American Journal of Criminal Law 44(1): $1-48$.

Hannah-Moffat, K., \& Lynch, M. (2012). Theorizing punishment's boundaries: An introduction. Theoretical Criminology 16(2): 119-121.

Harnick, C. (1997a, Dec. 15). "Streamlining of Administration of Provincial Offences Act, 1997/Loi de 1997 Simplifiant l'Administration enc e qui a trait aux Infractions Provinciales." Ontario. Legislative Assembly. Committee of the Whole House. $36^{\text {th }}$ Parliament, $1^{\text {st }}$ Session. Retrieved March 25, 2018 from the Legislative Assembly of Ontario website (Hansard): http://hansardindex.ontla.on.ca/hansardeissue/361/1261b.htm.

Harnick, C. (1997b, Feb. 12). "Streamlining of Administration of Provincial Offences Act, 1997/Loi de 1997 Simplifiant l'Administration enc e qui a trait aux Infractions Provinciales." Ontario. Legislative Assembly. Second Reading. $36^{\text {th }}$ Parliament, $1^{\text {st }}$ Session. Retrieved March 25, 2018 from the Legislative Assembly of Ontario website (Hansard): https://www.ola.org/en/legislative-business/house-documents/parliament36/session-1/1997-02-12/hansard\#P602 114681.

Harnick, C. (1998, Jun. 9). "Streamlining of Administration of Provincial Offences Act, 1997/Loi de 1997 Simplifiant l'Administration enc e qui a trait aux Infractions Provinciales.” Ontario. Legislative Assembly. Third Reading. $36^{\text {th }}$ Parliament, $2^{\text {nd }}$ Session. Retrieved from the Legislative Assembly of Ontario website (Hansard): http://hansardindex.ontla.on.ca/hansardeissue/36-2/1023a.htm.

Harris, A. (2016). A Pound of Flesh: Monetary Sanctions as Punishment for the Poor. New York, NY: Russell Sage Foundation.

Harris, A., Evans, H., \& Beckett, K. (2010). Drawing Blood from Stones: Legal Debt and Social Inequality in the Contemporary United States. American Journal of Sociology 115(6): 1753-1799.

Harris, A., Evans, H., \& Beckett, K. (2011). Courtesy Stigma and Monetary Sanctions: Toward a Socio-Cultural Theory of Punishment. American Sociological Review 76(2): 234-264.

Harris, A., Huebner, B., Martin, K., Pattillio, M., Pettit, B., Shannon, S., Sykes, B., Uggen, C., \& Fernandes, A. (2017). Monetary Sanctions in the Criminal Justice System: A review of law and policy in California, Georgia, Illinois, Minnesota, Missouri, New York, North Carolina, Texas, and Washington. Retrieved January 13, 2018 from: http://www.monetarysanctions.org/wp-content/uploads/2017/04/Monetary-SanctionsLegal-Review-Final.pdf.

Hermer, J., \& Mosher, J. (Eds.). (2002). Disorderly People: Law and the Politics of Exclusion in Ontario. Halifax, CA: Fernwood Publishing. 
Highway Traffic Act [HTA], Revised Statute of Ontario, 1990, c. H. 8. Retrieved November 8, 2018 from https://www.ontario.ca/laws/statute/90h08.

Hill, A. (2017, April 25). Changes to fine option program could hurt Sask. non-profits. Saskatoon StarPhoenix. Retrieved July 18, 2018 from: https:/thestarphoenix.com/news/local-news/changes-to-fine-option-program-could-hurtsask-non-profits.

Hopper, T. (2015, April 9). Is Winnipeg addicted to traffic tickets? Photo-radar revenue equivalent of $\$ 22$ bill for every person in the city. National Post. Retrieved November 9, 2017 from: http://nationalpost.com/news/canada/winnipeg-traffic-tickets.

Hornqvist, M. (2004). The birth of public order policy. Race \& Class 46(1): 30-52.

Horwitz, A. (1990). The Logic of Social Control. New York, NY: Plenum Press.

Hunt, A. (2006). 'Police and the Regulation of Traffic: Policing as a Civilizing Process?'. In M. Dubber \& M. Valverde (Eds.), The New Police Science: The Police Power in Domestic and International Governance (pp. 168-184). Stanford, CA: Stanford University Press.

Javed, N. (2016, May 26). York Region girds up to go after unpaid fines. Toronto Star. Retrieved Sept. 1, 2018 from: https://www.thestar.com/news/gta/2016/05/26/york-region-girds-upto-go-after-unpaid-fines.html.

Jobb. D. (2015). Seeking Truth from Power: Strategies for Using Access Laws. In J. Brownlee \& K. Walby (Eds.), Access to Information and Social Justice: Critical Research Strategies for Journalists, Scholars, and Activists. Winnipeg, MB: ARP Books.

Jolly, S. (1981, June 9). Preliminary Report on a Survey of Fine Defaulters Incarcerated in the Kenora District Jail for Provincial Offences. Toronto, ON: Ontario Native Council on Justice.

John Howard Society of Saskatchewan [JHS]. (n.d.). Regina Services: Fine Option Program. Retrieved July 16, 2018 from: https://www.sk.johnhoward.ca/services/regina/.

Jones, A. (2017a, Nov. 1). Ontario introduces marijuana legislation with steep fines for illegal dispensaries. Global News. Retrieved November 9, 2017 from: https://globalnews.ca/news/3836502/ontario-marijuana-legislation/.

Jones, A. (2017b, Jan. 15). Ontario drivers with unpaid speeding tickets to be denied licence plates. CBC News. Retrieved April 22, 2017 from: http://www.cbc.ca/news/canada/toronto/speeding-scofflaws-1.3936724.

Jones, A. (2017c, Sept. 20). Ontario boosting penalties for careless and distracted drivers. CTV News. Retrieved December 5, 2017 from: https://www.ctvnews.ca/canada/ontarioboosting-penalties-for-careless-and-distracted-drivers-1.3597891. 
Kamenka, E., \& Tay, A. (1975). 'Beyond bourgeois individualism: the contemporary crisis in law and legal ideology'. In E. Kamenka \& R.S. Neale (eds.), Feudalism, Capitalism, and Beyond (pp. 126-144). London: Edward Arnold.

Kantorowicz-Reznichenko, E. (2015). Day-Fines: Should the Rich Pay More?. Review of Law \& Economics 11(3): 481-501.

Kingston, B. (2018, Apr. 21). Traffic ticket 'red flag': SD\&G has 'financial difficulty' with revenue. Cornwall Newswatch. Retrieved May 1, 2018 from:

http://www.cornwallnewswatch.com/2018/04/21/traffic-ticket-red-flag-sdg-has-financialdifficulty-with-revenue/.

Kitchen, H. (2002). Canadian Municipalities: Fiscal Trends and Sustainability. Canadian Tax Journal/Revue Fiscale Canadienne 50(1): 156-180.

Knox, J. (2017, May 2). Volunteer-based organizations concerned about losing Sask.'s fine option program. Global News. Retrieved July 16, 2018 from: https://globalnews.ca/news/3422150/volunteer-based-organizations-concerned-aboutlosing-sask-s-fine-option-program/.

Kohler-Hausmann, I. (2013). Misdemeanor Justice: Control without Conviction. American Journal of Sociology 119(2): 351-393.

Kormos, P. (1997, Feb. 27). "Streamlining of Administration of Provincial Offences, 1997/Loi de 1997 Simplifiant l'Administration en ce qui a Trait aux Infraction Provinciales." Ontario. Legislative Assembly. Standing Committee on General Government. $36^{\text {th }}$ Parliament, $1^{\text {st }}$ Session. Retrieved March 25, 2018 from the Legislative Assembly of Ontario (Hansard): https://www.ola.org/en/legislative-business/housedocuments/parliament-36/session-1/1997-02-27/hansard\#P875 211236.

Krippendorff, K. (2004). Content Analysis: An Introduction to Its Methodology (2 ${ }^{\text {nd }}$ ed.). Thousand Oaks, CA: Sage.

Kushner, J., \& Ogwang, T. (2017). Why do Per-Household Expenditures Differ between Municipalities?. Public Finance and Management 17(4): 303-324.

Lambert, L. (1978, December 4). Research on Provincial Offences Act and Request for Coordinated Interministerial Approach to Seek Alternatives to Incarceration [Memorandum]. Obtained through provincial FOI request A-2017-00244. Toronto, ON: Ministry of the Attorney General of Ontario.

Langton, L., \& Durose, M. (2013). Police Behaviour during Traffic and Street Stops, 2011. Bureau of Justice Statistics. Retrieved January 13, 2018 from: https://www.bjs.gov/content/pub/pdf/pbtss11.pdf.

Lather, P. (1994). Critical inquiry in qualitative research: Feminist and poststructural perspectives: Science 'after truth.' In B. Crabtree, W. L. Miller, R. B. Addison, V. J. Gilchrist, \& A. Kuzel (Eds.), Exploring collaborative research in primary care (pp. 103114). New York: Sage. 
Law Commission of Ontario [LCO]. (2011). Modernization of the Provincial Offences Act. Retrieved August 1, 2017 from: http://www.lco-cdo.org/POA-Final-Report.pdf.

Lawlor, P. (1978, Nov. 7). "Provincial Offences Act.” Second Reading. $31^{\text {st }}$ Parliament, $2^{\text {nd }}$ Session. Retrieved May 1, 2018 from the Legislative Assembly of Ontario website (Hansard): http://hansardindex.ontla.on.ca/hansardeissue/31-2/1114.htm.

Layder, D. (1993). New strategies in social research: An introduction and guide. Cambridge, UK: Polity Press.

Lea, J. (1979). 'Discipline and capitalist development'. In B. Fine, R. Kinsey, J. Lea, S. Picciotto, \& J. Young, Capitalism and the Rule of Law: From deviancy theory to Marxism (pp. 76-89). London, UK.

Leal, H. Allen. (1978). Re: The Provincial Offences Act, 1978 [Memo]. Obtained through provincial FOI request A-2017-00244. Toronto, ON: Ministry of the Attorney General of Ontario.

Leedy, P.D., \& Ormrod, J.E. (2005). Practical Research: Planning and Design (8 ${ }^{\text {th }}$ ed.). Upper Saddle River, NJ: Pearson/Merrill/Prentice Hall.

Lianos, M. (2000). Dangerization and the End of Deviance. British journal of criminology 40(2): 261-278.

Lianos, M. (2003). Social-Control after Foucault. Surveillance \& Society 1(3), 412-430.

Lianos, M. (2010). 'Periopticon: control beyond freedom and coercion - and two possible advancements in the social sciences'. In K. Haggery \& M. Samatas, Surveillance and Democracy (pp. 69-88). New York, NY: Routledge.

Lianos, M. (2012). The New Social Control: The Institutional Web, Normativity, and the Social Bond. Ottawa: Red Quill Books Ltd.

Lianos, M. (Ed.). (2013). Dangerous Others, Insecure Societies: Fear and Social Division. Farnham, UK: Ashgate Publishing Limited.

Libman, R. (2011). Regulatory offences and principles of sentencing: Is the 'patchwork quilt' in need of reshaping and reform? (Doctoral dissertation). ProQuest Dissertations Publishing. Retrieved November 10, 2017: http://proxy.library.carleton.ca/login?url=https://search-proquestcom.proxy.library.carleton.ca/docview/901259758?accountid=9894.

Libman, R. (2012a). The regulatory cycle and its role in shaping purposes and principles of sentencing for regulatory offences. Criminal Law Quarterly 59(1): 126-162.

Libman, R. (2012b). Sentencing Purposes and Principles for Regulatory Offences: A New Approach for Regulatory Justice. Canadian Criminal Law Review 15(3): 359-385.

Lippert, R. (2012). 'Clean and safe' passage: Business Improvement Districts, urban security modes, and knowledge brokers. European Urban and Regional Studies 19(2): 167-180. 
Lippert, R., \& Sleiman, M. (2012). Ambassadors, Business Improvement District Governance and Knowledge of the Urban. Urban Studies 49(1): 61-76.

Liquor Control Act, Revised Statute of Ontario, 1990, c. L. 18. Retrieved November 8, 2018 : https://www.ontario.ca/laws/statute/90118.

Liquor Licence Act [LLA], Revised Statute of Ontario, 1990, c. L.19. Retrieved November 8, 2018: https://www.ontario.ca/laws/statute/90119.

Lyon, D. (Ed.). (2003). Surveillance as Social Sorting: Privacy, Risk and Digital Discrimination. New York, NY: Routledge.

Lyon, D. (2006). Theorizing Surveillance: The panopticon and beyond. Portland, OR: Willian Publishing.

Mackenzie, H. (2014, Feb. 3). Tackling Ontario's Public Services Deficit. Canadian Centre for Policy Alternatives. Retrieved August 1, 2018 from http://behindthenumbers.ca/2014/02/03/tackling-ontario-public-services-deficit/.

Management Board of Cabinet of Ontario [MBC]. (1996a, Nov. 19). Attorney General [Meeting Minutes]. Obtained through provincial FOI request A-2017-00244 and Appeal PA18-40. Toronto, ON: The Management Board of Cabinet.

Management Board of Cabinet of Ontario [MBC]. (1996b, Nov. 19). Management Board Briefing Note. Obtained through provincial FOI request A-2017-00244 and Appeal PA18-40. Toronto, ON: The Management Board of Cabinet.

Manitoba. Department of Justice. Courts Division. (2018). Fine Option Program. Retrieved July 16, 2018, from https://www.gov.mb.ca/justice/courts/fine.html.

Martel, J., Hogeveen, B., \& Woolford, A. (2006). The State of Critical Scholarship in Criminology and Socio-legal Studies in Canada. Canadian Journal of Criminology and Criminal Justice 48(5): 633-646.

Martin, K., Sykes, B., Shannon, S., Edwards, F., \& Harris, A. (2018). Monetary Sanctions: Legal Financial Obligations in US Systems of Justice. Annual Review of Criminology 2018: 471-495.

Matza, D. (1969). Becoming Deviant. Englewood Cliffs, NJ: Prentice-Hall.

Marx, G. (2007). 'The Engineering of Social Control: Intended and Unintended Consequences'. In J. Byrne \& D. Rebovich (Eds.), The New Technology of Crime, Law and Social Control (pp. 347-371). Monsey, NY: Criminal Justice Press.

McKessock, B. (1984, June 5). "Unpaid Fines.” Ontario. Legislative Assembly. 32 ${ }^{\text {nd }}$ Parliament, $4^{\text {th }}$ Session. Retrieved May 23, 2018 from the Legislative Assembly of Ontario website (Hansard): http://hansardindex.ontla.on.ca/hansardeissue/32-4/1062.htm. 
McCotter, S. (2001). The journey of a beginning researcher. The Qualitative Report, 6(2), [online version - no pages]. Retrieved February 2, 2018 from:

http://www.nova.edu/ssss/QR/QR6-2/mccotter.html.

McDonald, N. (2017, April 7). Ontarians' lives in turmoil over arbitrarily suspended driver's licences. Toronto Star. Retrieved May 23, 2017 from:

https://www.thestar.com/news/gta/2017/04/07/ontarians-lives-in-turmoil-over-arbitrarilysuspended-drivers-licences.html.

McMahon, M. (1992). The Persistent Prison? Rethinking Decarceration and Penal Reform. Toronto, CA: University of Toronto Press.

McMurtry, R. (1978a, Nov. 7). "Provincial Offences Act." Ontario. Legislative Assembly. Second Reading. $31^{\text {st }}$ Parliament, $2^{\text {nd }}$ Session. Retrieved May 1, 2018 from the

Legislative Assembly of Ontario website (Hansard): http://hansardindex.ontla.on.ca/hansardeissue/31-2/1114.htm.

McMurtry, R. (1978b, Apr. 27). "Provincial Offences.” Ontario. Legislative Assembly. First Reading. $31^{\text {st }}$ Parliament, $2^{\text {nd }}$ Session. Retrieved May 1, 2018 from the Legislative Assembly of Ontario website (Hansard): http://hansardindex.ontla.on.ca/hansardeissue/31-2/1048.htm.

McMurtry, R. (1978c). Letter from Attorney General Roy McMurtry to Colleague for Comments on the Legislation. Obtained through provincial FOI request A-2017-00244. Toronto, $\mathrm{ON}$ : Ministry of the Attorney General of Ontario.

McNay, L. (2009). Self as Enterprise: Dilemmas of Control and Resistance in Foucault's The Birth of Biopolitics. Theory, Culture \& Society 26(6): 55-77.

Mills, C.W. (2000). The Sociological Imagination (Fortieth Anniversary Edition). Oxford, UK: Oxford University Press. (Originally published in 1959).

Ministry of the Attorney General of Ontario [MAG]. (n.d.). Explanatory Note [Draft copy with edits in relation to Bill 74]. Obtained through provincial FOI request A-2017-00244. Toronto, ON: Ministry of the Attorney General of Ontario.

Ministry of the Attorney General of Ontario [MAG]. (1977a). Memorandum: Review of the Skelton Act for the Purpose of Restructuring into Parts. Obtained through provincial FOI request A-2017-00244. Toronto, ON: Ministry of the Attorney General of Ontario.

Ministry of the Attorney General of Ontario [MAG]. (1977b, Sept. 20). Re: Provincial Offences Act - Cost Avoidance in Courts Administration [Memo]. Obtained through provincial FOI request A-2017-00244. Toronto, ON: Ministry of the Attorney General of Ontario.

Ministry of the Attorney General of Ontario [MAG]. (1977c). Ministry of the Attorney GeneralProjects Associated with the Provincial Offenses Act: Centralized Control and Collection 
of Fines System [Memo and Cabinet Meeting Minutes]. Obtained through provincial FOI request A-2017-00244. Toronto, ON: Ministry of the Attorney General of Ontario.

Ministry of the Attorney General of Ontario [MAG]. (1978a). Provincial Offences Procedures: An Analysis and Explanation of Legislative Proposals [Booklet]. Toronto, ON: Ministry of the Attorney General of Ontario.

Ministry of the Attorney General of Ontario [MAG]. (1978b). Provincial Offences Act. Obtained through provincial FOI request A-2017-00244. Toronto, ON: Ministry of the Attorney General of Ontario.

Ministry of the Attorney General of Ontario [MAG]. (1978c). Material for Second Reading Debate on The Provincial Offences Act, 1978 and The Provincial Courts Amendment, 1978. Obtained through provincial FOI request A-2017-00244. Toronto, ON: Ministry of the Attorney General of Ontario.

Ministry of the Attorney General of Ontario [MAG]. (1979). Provincial Offences Act 1979: Justice of the Peace Instructional Manual. Obtained through provincial FOI request A2017-00244. Toronto, ON: Ministry of the Attorney General of Ontario.

Ministry of the Attorney General of Ontario [MAG]. (1980a). New Court Procedures Take Effect March 31 [News Release]. Obtained through provincial FOI request A-2017-00244. Toronto, ON: Ministry of the Attorney General of Ontario.

Ministry of the Attorney General of Ontario [MAG]. (1980b). Minor Offences: Read your right. Know your options under the Provincial Offences Act [Pamphlet]. Obtained through provincial FOI request A-2017-00244. Toronto, ON: Ministry of Attorney General of Ontario.

Ministry of the Attorney General of Ontario [MAG]. (1980c). Minor Offences [Booklet]. Toronto, ON: Ministry of the Attorney General of Ontario.

Ministry of the Attorney General of Ontario [MAG]. (1996, Nov. 19). Provincial Offences Act (POA) Transfer Project: Business Case and Report to the Management Board. Obtained through provincial FOI request A-2017-00244 and Appeal PA18-40. Toronto, ON: Business Improvement District, Ministry of the Attorney General of Ontario.

Ministry of the Attorney General of Ontario [MAG]. (1998, Sept. 4). POA Transfer Project. Obtained through provincial FOI request A-2017-00244. Toronto, ON: Ministry of the Attorney General of Ontario.

Ministry of the Attorney General of Ontario [MAG]. (2011). Provincial Offences Act (POA) Oversight and Fine Enforcement [Ministerial Briefing]. Obtained through provincial FOI request MAG-A-2017-02149. Toronto, ON: Ministry of the Attorney General of Ontario.

Ministry of the Attorney General of Ontario [MAG]. (2014a, May 23). Provincial Offences Act (POA) Fine Enforcement [Ministerial Briefing]. Obtained through provincial FOI request MAG-A-2017-02149. Toronto, ON: Ministry of the Attorney General of Ontario. 
Ministry of the Attorney General of Ontario [MAG]. (2014b, May 23). Court Services Division [Ministerial Briefing]. Obtained through provincial FOI request MAG-A-2017-02149. Toronto, ON: Ministry of the Attorney General of Ontario.

Ministry of the Attorney General of Ontario [MAG]. (2015a). AMO-MOU Consultation POA Cost Recovery [Presentation]. Obtained through provincial FOI request MAG-A-201702149. Toronto, ON: Ministry of the Attorney General of Ontario.

Ministry of the Attorney General of Ontario [MAG]. (2015b, Oct.). POA Modernization Expert Discussion Summary. Obtained through provincial FOI request MAG-A-2017-02151. Toronto, ON: Ministry of the Attorney General of Ontario.

Ministry of the Attorney General of Ontario [MAG]. (2015c, Oct. 30). Provincial Offences Act Modernization: Expert Table Meeting 3. Obtained through provincial FOI request MAGA-2017-02151. Toronto, ON: Ministry of the Attorney General of Ontario.

Ministry of the Attorney General of Ontario [MAG]. (2015d, March 3). Exploring an online Administrative Monetary Penalty System for infractions of provincial statutes and municipal by-laws in Ontario. Retrieved March 19, 2018 from:

https://www.attorneygeneral.jus.gov.on.ca/english/POA\%20ConsultationPaper\%20Final ENG.html.

Ministry of the Attorney General of Ontario [MAG]. (2015e, Nov. 19). Provincial Offences Act Modernization: Attorney General Briefing [Presentation]. Obtained through provincial FOI request MAG-A-2017-02151. Toronto, ON: Ministry of the Attorney General of Ontario.

Ministry of the Attorney General of Ontario [MAG]. (2015f, Oct. 16). Provincial Offences Act Modernization: Expert Table Meeting 1 [Presentation]. Obtained through provincial FOI request MAG-A-2017-02151. Toronto, ON: Ministry of the Attorney General of Ontario.

Ministry of the Attorney General of Ontario [MAG]. (2016a, Jun. 13). Provincial Offences ActGeneral [Ministerial Briefing Booklet]. Obtained through provincial FOI request MAGA-2017-02149. Toronto, ON: Ministry of the Attorney General of Ontario.

Ministry of the Attorney General of Ontario [MAG]. (2016b, Sept. 12). Ministry of Attorney General: Provincial Offences Act Modernization - Municipal Law Enforcement Officers' Association Presentation. Obtained through provincial FOI request MAG-A-2017-02149. Toronto, ON: Ministry of the Attorney General of Ontario.

Ministry of the Attorney General of Ontario [MAG]. (2016c, Aug. 16). Provincial Offences Act Modernization [Presentation]. Obtained through provincial FOI request MAG-A-201702149. Toronto, ON: Ministry of the Attorney General of Ontario.

Ministry of the Attorney General of Ontario [MAG]. (2016d, Jun. 13). Provincial Offences ActPart III Prosecutions [Ministerial Briefing Booklet]. Obtained through provincial FOI request MAG-A-2017-02149. Toronto, ON: Ministry of the Attorney General of Ontario. 
Ministry of the Attorney General of Ontario [MAG]. (2016e, Jun. 13). Administrative Monetary Penalty (AMP) (ONLINE DISPUTE RESOLUTION) [Ministerial Briefing Booklet]. Obtained through provincial FOI request MAG-A-2017-02149. Toronto, ON: Ministry of the Attorney General of Ontario.

Ministry of the Attorney General of Ontario [MAG]. (2017a, Apr. 25). Defaulted Provincial Offences Act (POA) Fine Collection: Expansion of Licence Plate Denial Program Communication Package for Municipal Courts. Obtained through provincial FOI request MAG-A-2017-02149. Toronto, ON: Ministry of the Attorney General of Ontario.

Ministry of the Attorney General of Ontario. (2017b). Provincial Offences Act (POA) modernization efforts [Email]. Retrieved March 19, 2018 from: https://lennoxandaddington.civicweb.net/document/29826/County\%20Council\%20Worki ng\%20Session $\% 20$ Meeting\%20\%2013\%20Sep.pdf?handle=63E302F18F364897B5D70975339A9636.

Ministry of the Attorney General of Ontario [MAG]. (2017c, Apr. 10). POA Updates Presentation to the Ontario Municipal Tax and Revenue Association (OMTRA) [Presentation]. Obtained through provincial FOI request MAG-A-2017-02149. Toronto, ON: Ministry of the Attorney General of Ontario.

Ministry of the Attorney General of Ontario [MAG]. (2017d, Sept. 1). POAIB- 276: Expanded Plate Denial [Information Bulletin]. Obtained through provincial FOI request MAG-A2017-02149. Toronto, ON: Ministry of the Attorney General of Ontario.

Ministry of Correctional Services [MCS]. (1978, Nov. 21). The Provincial Offences Act [Memorandum]. Obtained through provincial FOI request A-2017-00244. Toronto, ON: Ministry of Correctional Services.

Ministry of Solicitor General and Correctional Services [MSGCS]. (1997, Mar. 20). Devolution of Provincial Offences to Municipalities. Obtained through provincial FOI request A2017-00244 and Appeal PA18-40. Toronto, ON: Ministry of Solicitor General and Correctional Services.

Ministry of Transportation of Ontario [MTO]. (1996, Nov. 6). Transferring Responsibility for Courts Administration and Prosecution of Provincial Offences Act (Part I and II) to Municipalities: Assessing Impact on Ministry of Transportation. Obtained through provincial FOI request A-2017-00244 and Appeal PA18-40. Toronto, ON: Safety and Regulation Division, Ministry of Transportation.

Ministry of Transportation of Ontario [MTO]. Safety Policy \& Education Branch. (2013). Ontario Road Safety Annual Report 2013. Retrieved September 15, 2018 from: http://www.mto.gov.on.ca/english/publications/pdfs/ontario-road-safety-annual-report2013.pdf.

Ministry of Transportation of Ontario [MTO]. Safety Policy \& Education Branch. (2016). Preliminary 2016 Ontario Road Safety Annual Report Selected Statistics. Retrieved 
September 15, 2018 from:

http://www.mto.gov.on.ca/english/publications/pdfs/preliminary-2016-orsar-selectedstatistics.pdf.

Mitchell, D. (2018, May 11). Licence suspension and wage garnishing, options as Toronto tries to collect \$577M for unpaid fines. Global News. Retrieved Sept 1, 2018 from: https://globalnews.ca/news/4201248/licence-suspension-and-wage-garnishing-options-astoronto-tries-to-collect-577m-for-unpaid-fines/.

Molina, K. (2018, Aug. 24). City parking tickets big business for private companies. CBC News. Retrieved August 26, 2018 from: https://www.cbc.ca/news/canada/ottawa/businessesinstitutions-profit-from-ottawa-parking-tickets-1.4791938.

Monsebraaten, L. (2015, Mar 9). Toronto legal clinic helps homeless fight unpayable 'nuisance' tickets. Toronto Star. Retrieved Sept. 8, 2018 from:

https://www.thestar.com/news/gta/2015/03/09/toronto-legal-clinic-helps-homeless-fightunpayable-nuisance-tickets.html.

Moore, D., \& Hannah-Moffat, K. (2005). Liberal Veil: Revisiting Canadian Penalty. In J. Pratt, D. Brown, M. Brown, S. Hallsworth, \& W. Morrison (eds.), The New Punitiveness: Trends, Theories, Perspectives (pp. 85-100). Portland, OR: Willan Publishing.

Morris, Robert. (1978, Jun.). Ontario's Summary Conviction Ticket Information: The Way It is: The Way It Will Be. Chitty Law Journal 26(6) (pp. 181-186) [Public Consultation]. Obtained through provincial FOI request A-2017-00244. Toronto, ON: Ministry of Attorney General of Ontario.

Morrissey v. Brewer. (1972). 408 US 471. Retrieved from November 9, 2017: https://supreme.justia.com/cases/federal/us/408/471/.

Morse, J.M., \& Richards, L. (2002). Read Me First: For a User's Guide to Qualitative Methods. Thousand Oaks, CA: Sage.

Mukherjee, A. (2018, Sept 2). Policing society's poor is unjust and ineffective. Toronto Star. Retrieved Sept 8, 2018 from: https://www.thestar.com/opinion/contributors/2018/09/02/policing-societys-poor-isunjust-and-ineffective.html.

Murphy, D. (2014, Feb. 16). Mandatory fines for offenders could unduly punish the poor. Nunatsiaq News. Retrieved July 16, 2018 from: http://nunatsiaq.com/stories/article/65674mandatory_fines_for_convicts_could_unduly_p unish the poor/.

Natapoff, A. (2015a). Misdemeanor Decriminalization. Vanderbilt Law Review 68(4): 10551116.

Natapoff, A. (2015b). Misdemeanors. The Annual Review of Law and Social Science 11: 255267. 
Neuendorf, K.A. (2002). The Content Analysis Guidebook. Thousand Oaks, CA: Sage.

New Brunswick. Department of Justice and Public Safety. (2018). Fine Option Program. Retrieved July 16, 2018, from:

http://www2.gnb.ca/content/gnb/en/services/services_renderer.201050.Fine_Option_Prog ram.html.

Newman, D. (1997, Feb. 27). "Streamlining of Administration of Provincial Offences, 1997/Loi de 1997 Simplifiant l'Administration en ce qui a Trait aux Infraction Provinciales." Ontario. Legislative Assembly. Standing Committee on General Government. $36^{\text {th }}$ Parliament, $1^{\text {st }}$ Session. Retrieved March 25, 2017 from the Legislative Assembly of Ontario (Hansard): https://www.ola.org/en/legislative-business/housedocuments/parliament-36/session-1/1997-02-27/hansard\#P875 211236.

Northwest Territories. Service Directory. (2018). Fine Option Program. Retrieved July 16, 2018, from: https://www.gov.nt.ca/services/service/298.

Nova Scotia. Department of Justice. Correctional Services. Fine Option Program. Retrieved July 16, 2018, from: https://novascotia.ca/just/Corrections/fine option.asp.

O’Grady, B., Gaetz S., \& Buccieri, K. (2013). Tickets... and More Tickets: A Case Study of the Enforcement of the Ontario Safe Streets Act. Canadian Public Policy, Vol. XXXIX No. 4, $541-558$.

O'Malley, P. (2009a). The Currency of Justice. New York: Routledge-Cavendish.

O’Malley, P. (2009b). 'Theorizing Fines'. Punishment \& Society 11(1), pp. 67-83. doi: $10.1177 / 1462474508098133$.

O'Malley, P. (2010a). Fines, Risks and Damages: Money Sanctions and Justice in Control Societies. Current Issues in Criminal Justice 21(3), 365-382.

O'Malley, P. (2010b). Simulated justice: risk, money and telemetric policing. British Journal of Criminal 50: 797-807.

O’Malley, P. (2011). 'Politicizing the case for fines'. Criminology \& Public Policy 10(3): 547553. doi: 10.1111/j.1745-9133.2011.00736.x.

O’Malley. P. (2013). 'Monetized Justice: Money and Punishment in Consumer Societies'. In J. Simon \& R. Sparks (Eds.), The SAGE Handbook of Punishment and Society (pp. 375391). London, UK: SAGE Publishing Ltd.

O'Reilly, N. (2018, Mar. 27). Panhandling charge dismissed in Hamilton court. The Hamilton Spectator. Retrieved Sept 1, 2018 from: https://www.thespec.com/news-story/8352306panhandling-charge-dismissed-in-hamilton-court/.

O’Sullivan, E. (2012). Varieties of Punitiveness in Europe: Homelessness and Urban Marginality. European Journal of Homelessness 6(2): 69-97. 
Occupational Health and Safety Act, Revised Statute of Ontario, 1990, c. O.1. Retrieved November 8, 2018 from: https://www.ontario.ca/laws/statute/90o01.

Ontario Association of Police Services Board [OAPSB]. (2011). Provincial Offences Act Unpaid Fines: A \$Billion Problem: White Paper. Ottawa: Canadian Electronic Library. Retrieved September 1, 2017 from: http://books2.scholarsportal.info.proxy.library.carleton.ca/viewdoc.html?id=/ebooks/eboo ks0/gibson_cppc/2015-02-25/1/10993129\#tabview=tab1.

Ontario Court of Justice [OCJ]. (n.d.). Provincial Offences Court Statistics: Part I and Part III charges only. Retrieved November 13, 2018 from: http:/www.ontariocourts.ca/ocj/statsprov/.

Ontario Court of Justice [OCJ]. (2015a). 'Provincial Court Activity (Part I and III only): All Charges Received/All Charges Disposed: Provincial Overview - January 2014 to December 2015. Retrieved May 5, 2018 from: http://www.ontariocourts.ca/ocj/files/stats/poa/2015/2015-POA-Court.pdf.

Ontario Court of Justice [OCJ]. (2015b). 'Provincial Offences Activity (Part I and III only): Charges Received/Charges Disposed by Statute', pp. 1-53. Retrieved May 5, 2018 from: http://www.ontariocourts.ca/ocj/files/stats/poa/2015/2015-POA-Statute.pdf.

Ontario Court of Justice [OCJ]. (2015c). 'Provincial Offences Court Fines by Statute (Part I and III only): Fine Amounts/Fines Collected/Fines in Default'. Retrieved May 5, 2018 from: http://www.ontariocourts.ca/ocj/files/stats/poa/2015/2015-POA-Fines.pdf.

Ontario Court of Justice [OCJ]. (2016a). 'Provincial Offences Activity (Part I and III only): Charges Received/Charges Disposed by Statute', pp. 1-53. Retrieved May 5, 2018 from: http://www.ontariocourts.ca/ocj/files/stats/poa/2016/2016-Q4-POA-Statute.pdf.

Ontario Court of Justice [OCJ]. (2016b). 'Provincial Offences Court Fines by Statute (Part I and III only): Fine Amounts/Fines Collected/Fines in Default'. Retrieved May 5, 2018 from: http://www.ontariocourts.ca/ocj/files/stats/poa/2016/2016-Q4-POA-Fines.pdf.

Ontario Court of Justice [OCJ]. (2017a). 'Provincial Offences Activity (Part I and III only): Charges Received/Charges Disposed by Statute', pp. 1-53. Retrieved May 5, 2018 from: http://www.ontariocourts.ca/ocj/files/stats/poa/2017/2017-POA-Statute.pdf.

Ontario Court of Justice [OCJ]. (2017b). 'Provincial Offences Court Fines by Statute (Part I and III only): Fine Amounts/Fines Collected/Fines in Default'. Retrieved May 5, 2018 from: http:/www.ontariocourts.ca/ocj/files/stats/poa/2017/2017-POA-Fines.pdf.

Ontario Court of Justice [OCJ]. (2018a). Provincial Offences Court Fines by Statute (Part I and III only): Fine Amounts/Fines Collected/Fines in Default'. Retrieved October 23, 2018 from: http://www.ontariocourts.ca/ocj/files/stats/poa/2018/2018-POA-Fines.pdf.

Ontario Court of Justice [OCJ]. (2018b). Changes to the consolidated Set Fine Schedules from Set Fine Orders or provincial Regulations. Retrieved July 12, 2018 from: http://www.ontariocourts.ca/ocj/how-do-i/set-fines/changes-to-the-consolidated-set-fineschedules/. 
Ontario Court of Justice [OCJ]. (2018c). 'Provincial Offences Activity (Part I and III only): Charges Received/Charges Disposed by Statute', pp. 1-53. Retrieved September 7, 2018 from: http://www.ontariocourts.ca/ocj/files/stats/poa/2018/2018-POA-Statute.pdf.

Ontario English Catholic Teachers' Association v. Ontario (Attorney General). (2001). 1 S.C.R. 470. Lexum. Retrieved August 23, 2018 from: https://scc-csc.lexum.com/scc-csc/scccsc/en/1851/1/document.do.

Ontario Law Reform Commission [OLRC]. (1973a). Report on Administration of Ontario Courts: Part II. Toronto, ON: Ministry of Attorney General.

Ontario Law Reform Commission [OLRC]. (1973b). Report on Administration of Ontario Courts: Part I. Toronto, ON: Ministry of Attorney General.

Ontario Law Reform Commission [OLRC]. (1973c). Report on Administration of Ontario Courts: Part III. Toronto, ON: Ministry of Attorney General.

Ontario Law Reform Commission [OLRC]. (1990). Report on the Basis of Liability for Provincial Offences. Toronto, ON: Ontario Government Bookstore.

Ontario Legislative Library [OLL]. (1998). "Who Does What" Reforms. (microfiche). Toronto, ON: Legislative Research Service. (Microlog 98-05925).

Osborne, T., \& Rose, N. (1997). In the name of society, or three theses on the history of social thought. History of the Human Sciences 10(3): 87-104.

Packer, J. (2003). 'Disciplining Mobility' in J. Bratich, J. Packer and C. McCarthy (eds.) Foucault, Cultural Studies and Governmentality (pp. 135-161). New York: University of New York Press.

Pashukanis, E.B. (1978). Law and Marxism: A General Theory (C. Arthur, Ed.). London, UK: Ink Links. (Originally published in 1924).

Peck, J. (2003). Geography and Public Policy: Mapping the Penal state. Progress in Human Geography 27(2): 222-232.

Pelley, L. (May 9, 2018). Careless drivers, law-breaking companies owe cite $\$ 420 \mathrm{M}$ in provincial fines. CBC News. Retrieved Sept 1, 2018 from: https://www.cbc.ca/news/canada/toronto/careless-drivers-law-breaking-companies-owecity-420m-in-provincial-fines-1.4653360.

Pfohl, S. (1994). Images of Deviance and Social Control: A Sociological History (Second Edition). Toronto, CA: McGraw-Hill, Inc.

Piché, J., Kleuskens, S., \& Walby, K. (2017). The front and back stages of carceral expansion marketing in Canada. Contemporary Justice Review 20(1): 26-50.

Pratt, J. (2002). 'Critical criminology and the punitive society: some new 'visions of social control'. In K. Carrington \& R. Hogg (Eds.), Critical Criminology: Issues, debates, challenges. London, UK: Willian Publishing. 
Pringle, J. (2017, Oct. 16). Illegal parking nets city \$19 million in revenue. CTV News. Retrieved May 24, 2018 from: https://ottawa.ctvnews.ca/illegal-parking-nets-city-19-million-inrevenue-1.3633671.

Progressive Conservative Party of Ontario [PC]. (1999). Blueprint: Mike Harris' Plan to Keep Ontario on the Right Track. Retrieved August 2, 2018 from:

https://www.poltext.org/sites/poltext.org/files/plateformes/on1999pc_plt._26122008_848 57.pdf.

Provincial Offences Act, Revised Statute of Ontario, 1990, c. P.33. Retrieved from: https://www.ontario.ca/laws/statute/90p33\#BK2.

Prince Edward Island. Department of Justice and Public Safety. (2018). Adult Fine Option Program. Retrieved July 16, 2018, from:

https://www.princeedwardisland.ca/en/information/justice-and-public-safety/adult-fineoption-program.

Queen, L. (2016, May 21). York Region to get tough on those who have tickets and haven't paid their fines. YorkRegion.com. Retrieved Sept 1, 2018 from:

https://www.yorkregion.com/news-story/6564924-york-region-to-get-tough-on-thosewho-have-tickets-and-haven-t-paid-their-fines/.

R. v. Baritz. (2006). ONCJ 266. CanLII. Retrieved September 12018 from: https://www.canlii.org/en/on/oncj/doc/2006/2006oncj266/2006oncj266.html?resultIndex $=1$.

R. v. Charles. (2017). ONCJ 176. CanLII. Retrieved November 9, 2017 from: https://www.canlii.org/en/on/oncj/doc/2017/2017oncj176/2017oncj176.html?searchUrlH ash=AAAAAQAMdW5wYWlkIGZpbmVzAAAAAQAPUINPIDE5OTAsIGMgSC44A AAAAQAOLzIxMi1jdXJyZW50LTEB\&resultIndex=10.

R. v. Ellis. (2018). ONCJ 520. CanLII. Retrieved August 13, 2018 from https://www.canlii.org/en/on/oncj/doc/2018/2018oncj520/2018oncj520.html?searchUrlH ash=AAAAAQAWcHVibGljIHdlbGZhcmUgb2ZmZW5jZQAAAAAB\&resultIndex=2.

R. v. Houle and Tarty. (2018). MBQB 128. CanLII. Retrieved August 13, 2018 from: https://www.canlii.org/en/mb/mbqb/doc/2018/2018mbqb128/2018mbqb128.html?search $\underline{\text { UrlHash=AAAAAQAWcHVibGljIHdlbGZhcmUgb2ZmZW5jZQAAAAAB\&resultInde }}$ $\underline{x=8}$.

R. v. Hughes. (2004). ABQB 521. CanLII. Retrieved December 5, 2017 from: https://www.canlii.org/en/ab/abqb/doc/2004/2004abqb521/2004abqb521.html?resultInde $\underline{x}=1$.

R. v. Griffin. (2018). PECA 21. CanLII. Retrieved August 13, 2018 from: https:/www.canlii.org/en/pe/pescad/doc/2018/2018peca21/2018peca21.html?searchUrlH ash=AAAAAQAWcHVibGljIHdlbGZhcmUgb2ZmZW5jZQAAAAAB\&resultIndex=13. 
R. v. Jaques. (2015). ONCA 380. CanLII. Retrieved November 9, 2017 from:

https://www.canlii.org/en/on/onca/doc/2015/2015onca380/2015onca380.html?autocompl eteStr=jaques $\% 20201 \&$ autocompletePos $=5$.

R. v. Pellegrini. (2006). ONCJ 297. CanLII. Retrieved November 9, 2017 from: https://www.canlii.org/en/on/oncj/doc/2006/2006oncj297/2006oncj297.html?searchUrlH ash=AAAAAQATcmVndWxhdG9yeSBvZmZlbmNlcwAAAAAB\&resultIndex=1.

R. v. Sault Ste. Marie. (1978). 2 S.C.R. 1299. Lexum. Retrieved November 9, 2017 from: https://scc-csc.lexum.com/scc-csc/scc-csc/en/2605/1/document.do.

R. v. Welcher. (2007). NLTD 87. CanLII. Retrieved December 5, 2017 : https://www.canlii.org/en/nl/nlsctd/doc/2007/2007nltd87/2007nltd87.html?resultIndex=3.

R. v. Wu. (2003). 3 S.C.R. 530. Lexum. Retrieved May 23, 2018 from: https://scccsc.lexum.com/scc-csc/scc-csc/en/item/2108/index.do.

Rankin. M. (2014). The Slow and Rocky Road to Reforming the British Columbia Offence Act. UBC Law Review 47(2): 785-813.

Re B.C. Motor Vehicle Act. (1985). 2 S.C.R. 486. CanLII. Retrieved November 9, 2017 from: https://www.canlii.org/en/ca/scc/doc/1985/1985canlii81/1985canlii81.html?autocomplete $\underline{\text { Str=Re\%20B.C.\%20Motor\%20Vehicle\%20Act\%20\%5B1985\&autocompletePos=1. }}$.

Reed, M., \& Roberts, J. (1998). Adult Correctional Services in Canada 1997-98. (Catalogue 85211). Retrieved on August 15, 2018 from the Statistics Canada website: https://www150.statcan.gc.ca/n1/en/pub/85-002-x/85-002-x1999004eng.pdf? st=HTmcPt2N.

Region of Ottawa-Carleton [ROC]. (1997, Jan. 27). Provincial Offences Act-Transfer [Memo]. Retrieved December 5, 2017 from: http://ottawa.ca/calendar/ottawa/archives/rmoc/Corporate_Services_and_Economic_Dev elopment/04Feb97/POAPROP.PDF.

Region of Ottawa-Carleton [ROC]. (1999, Sept. 24). Provincial Offences Act Transfer [Memo]. Obtained through FOI request A-2017-00693. Ottawa, ON: Region of Ottawa-Carleton.

Regoeczi, W., \& Kent, S. (2014). Race, poverty, and the traffic ticket: Exploring the situational context of the application of police discretion. Policing: An International Journal of Police Strategies \& Management 37(1): 190-205.

Rider, D. (2018, May 4). Scofflaws owe city $\$ 577$ million in unpaid fines, auditor reports. Toronto Star. Retrieved Sept 1, 2018 from: https://www.thestar.com/news/gta/2018/05/04/scofflaws-owe-city-577-million-in-unpaidfines-auditor-reports.html.

Robertson, C. (2015, Oct. 19). For Offenders Who Can't Pay, It's a Pint of Blood or Jail Time. NY Times. Retrieved April 4, 2018 from: https://www.nytimes.com/2015/10/20/us/foroffenders-who-cant-pay-its-a-pint-of-blood-or-jail-time.html. 
Rose, N. (1999). Powers of Freedom: Reframing Political Thought. Cambridge: Cambridge University Press.

Rose, N., \& Miller, P. (2010). Political power beyond the State: problematics of government. The British Journal of Sociology 61(1): 271-303.

Rose, N., O'Malley P., \& Valverde M. (2006). Governmentality. Annual Review of Law and Social Science 2(1): 83-104.

Ruckert, A., Caldbick, S., \& Labonte, R. (2015). Equity in times of austerity: Ontario's revenue crisis in historical perspective. Canadian Review of Social Policy/Revue Canadienne de Politique Sociale 72/73: 1-34.

Rusche, G. (2014). Labour Market and Penal Sanction: Thoughts on the Sociology of Criminal Justice. Social Justice 40(1-2): 252-264. (Originally published in 1933).

Rusche, G. \& Kirchheimer, O. (2003). Punishment and Social Structures. New Jersey: Transaction Publishers. (Originally published in 1939).

Safe Street Act [SSA], Statute of Ontario, 1999, c. 8. Retrieved November 8, 2018 : https://www.ontario.ca/laws/statute/99s08.

Salas, M., \& Ciolfi, A. (2017). Driven by Dollars: A State-By-State Analysis of Driver's License Suspension Laws for Failure to Pay Court Debt. Legal Aid Justice Center. Retrieved January 17, 2018 from: https://www.justice4all.org/wp-content/uploads/2017/09/Drivenby-Dollars.pdf.

Sampson, R. (1996, June 13). "Automobile Insurance Rate Stability Act, 1996/Loi de 1996 sur la Stabilité des Taux d'Assurance-Automobile." Ontario. Legislative Assembly. $36^{\text {th }}$ Parliament, $1^{\text {st }}$ Session. Retrieved September 1, 2018 from the Legislative Assembly of Ontario (Hansard): https://www.ola.org/fr/affaires-legislatives/documentschambre/legislature-36/session-1/1996-06-13/journal-debats\#P834_223949.

Sanchez, M. (2018a, March 2). She Owed \$102,158,40 in Unpaid Tickets, but She's Not in the Story. ProPublica Illinois. Retrieved April 22, 2018 from: https://www.propublica.org/article/chicago-ticket-debt-investigation-interviews.

Sanchez, M. (2018b, March 15). Some States No Longer Suspend Driver's Licenses for Unpaid Fines. Will Illinois Join Them?. ProPublica Illinois. Retrieved April 22, 2018 from: https://www.propublica.org/article/illinois-license-suspensions.

Sanchez, M., \& Kambhampati, S. (2018, Feb. 27). How Chicago Ticket Debt Sends Black Motorists Into Bankruptcy. ProPublica Illinois. Retrieved March 12, 2018 from: https://features.propublica.org/driven-into-debt/chicago-ticket-debt-bankruptcy/.

Sarason, S. B. (1990). The predictable failure of school reform: Can we change course before it's too late? San Francisco: Jossey-Bass. 
Saskatchewan. Ministry of Justice. Courts and Sentencing. (2018). Retrieved July 16, 2018, from: https://www.saskatchewan.ca/residents/justice-crime-and-the-law/courts-andsentencing/alternatives-to-paying-a-provincial-fine/.

Schwartz-Shea, P., \& Yanow, D. (2012). Interpretive Research Design: Concepts and Processes. New York, NY: Routledge.

Scott, I. (1989, Oct. 13). Proposal to Increase Provincial Offence Fines. Obtained through provincial FOI request A-2017-00244. Toronto, ON: Ministry of the Attorney General of Ontario.

Shearing, C. (1989). Decriminalizing Criminology: Reflections on the Literal and Topological Meaning of the Term. Canadian Journal of Criminology 31: 169-178.

Simmel, G. (2004). The Philosophy of Money (Third Enlarged Edition). D. Frisby (ed.). London: Routledge.(Originally published in 1978).

Simon, C. (2017, Nov. 6). Barrie, Orillia provincial offence courts backlogged with 90K outstanding files. Simcoe.com. Retrieved Sept 1, 2018 from: https://www.simcoe.com/news-story/7771897-barrie-orillia-provincial-offence-courtsbacklogged-with-90k-outstanding-files/.

Simon, J., \& Feeley, M. (1992). The New Penology: Notes on the Emerging Strategy of Corrections and Its Implication. Criminology 30(4): 449-474.

Simon, J., \& Feeley, M. (2003). 'The Form and Limit of the New Penology'. In T. Blomberg \& S. Cohen. (Eds.), Punishment and Social Control (Enlarged Second Edition) (pp. 75116). New York, NY: Aldine de Gruyter Inc.

Simon, J. \& Sparks, R. (2013). The SAGE Handbook of Punishment and Society. London, UK: SAGE Publications Ltd.

Slotek, A. (2018, Mar. 26). Trial in absence a real Toronto tragedy. Toronto Star. Retrieved April 1, 2018 from: https://www.thestar.com/opinion/contributors/2018/03/26/trial-inabsence-a-real-toronto-tragedy.html.

Smellie, S. (2017, Nov. 18). Fines worth more than their cars: What should government do about delinquent drivers?. CBC News. Retrieved July 16, 2018 from: https://www.cbc.ca/news/canada/newfoundland-labrador/what-to-do-with-delinquentdrivers-1.4408614.

Smith, R., McGuire, M., O’Gorman, J., \& Walker, J. (1978). The Provincial Offences Act: Potential Impact on the Ontario Correctional System. Obtained through provincial FOI request A-2017-00244. Toronto, ON: Ministry of Correctional Services.

Snider. L. (1993). Bad Business: Corporate Crime in Canada. Toronto: Nelson Canada.

Soupcoff, M. (2012, May 2). Think police really don't have ticket quotas? Check out these leaks. National Post. Retrieved November 10, 2017 from: http://nationalpost.com/opinion/marni-soupcoff-think-police-really-dont-have-ticketquotas-check-out-these-leaks. 
Sparks, R. (2003). 'State Punishment in Advanced Capitalist Countries'. In T. Blomberg \& S. Cohen. (Eds.), Punishment and Social Control (Enlarged Second Edition) (pp. 19-44). New York, NY: Aldine de Gruyter Inc.

Staples, W. (2014). Everyday Surveillance: Vigilance and Visibility in Postmodern Life (Second Edition). Lanham, MD: Rowman \& Littlefield.

Star Editorial Board. (2019, July 11). Fix Canada's legal system. Toronto Star. Retrieved August 1, 2018 from: https://www.thestar.com/opinion/editorials/2018/07/11/fix-canadas-legalsystem.html.

Statistics Canada [StatCan]. (1982). Adult Correctional Services in Canada 1981-82. (Catalogue 85-211). Retrieved August 15, 2018 from: http://publications.gc.ca/collections/collection_2016/statcan/85-211/CS85-211-1982.pdf.

Statistics Canada [StatCan]. (1983). Adult Correctional Services in Canada 1982-83. (Catalogue 85-211). Retrieved August 15, 2018 from: http://publications.gc.ca/collections/collection 2016/statcan/85-211/CS85-211-1983.pdf.

Statistics Canada [StatCan]. (1984). Adult Correctional Services in Canada 1983-84. (Catalogue 85-211). Retrieved August 15, 2018 from: http://publications.gc.ca/collections/collection_2016/statcan/85-211/CS85-211-1984.pdf.

Statistics Canada [StatCan]. (1985). Adult Correctional Services in Canada 1984-85. (Catalogue 85-211). Retrieved August 15, 2018 from: http://publications.gc.ca/collections/collection_2016/statcan/85-211/CS85-211-1985.pdf.

Statistics Canada [StatCan]. (1986). Adult Correctional Services in Canada 1985-86. (Catalogue 85-211). Retrieved August 15, 2018 from: http://publications.gc.ca/collections/collection_2016/statcan/85-211/CS85-211-1986.pdf.

Statistics Canada [StatCan]. (1987). Adult Correctional Services in Canada 1986-87. (Catalogue 85-211). Retrieved August 15, 2018 from: http://publications.gc.ca/collections/collection 2016/statcan/85-211/CS85-211-1987.pdf.

Statistics Canada [StatCan]. (1988). Adult Correctional Services in Canada 1987-88. (Catalogue 85-211). Retrieved August 15, 2018 from: http://publications.gc.ca/collections/collection 2016/statcan/85-211/CS85-211-1988.pdf.

Statistics Canada [StatCan]. (1989). Adult Correctional Services in Canada 1988-89. (Catalogue 85-211). Retrieved August 15, 2018 from: http://publications.gc.ca/collections/collection 2016/statcan/85-211/CS85-211-1989.pdf.

Statistics Canada [StatCan]. (1990). Adult Correctional Services in Canada 1989-90. (Catalogue 85-211). Retrieved August 15, 2018 from: http://publications.gc.ca/collections/collection 2016/statcan/85-211/CS85-211-1990.pdf. 
Statistics Canada [StatCan]. (1991). Adult Correctional Services in Canada 1990-91. (Catalogue 85-211). Retrieved August 15, 2018 from:

http://publications.gc.ca/collections/collection_2016/statcan/85-211/CS85-211-1991.pdf.

Statistics Canada [StatCan]. (1992). Adult Correctional Services in Canada 1991-92. (Catalogue 85-211). Retrieved August 15, 2018 from:

http://publications.gc.ca/collections/collection_2016/statcan/85-211/CS85-211-1992.pdf.

Statistics Canada [StatCan]. (1993). Adult Correctional Services in Canada 1992-93. (Catalogue 85-211). Retrieved August 15, 2018 from:

http://publications.gc.ca/collections/collection 2016/statcan/85-211/CS85-211-1993.pdf.

Statistics Canada [StatCan]. (1994). Adult Correctional Services in Canada 1993-94. (Catalogue 85-211). Retrieved August 15, 2018 from:

http://publications.gc.ca/collections/collection_2016/statcan/85-211/CS85-211-1994.pdf.

Statistics Canada [StatCan]. (1995). Adult Correctional Services in Canada 1994-95. (Catalogue 85-211). Retrieved August 15, 2018 from:

http://publications.gc.ca/collections/collection 2016/statcan/85-211/CS85-211-1995.pdf.

Statistics Canada [StatCan]. (1996). Adult Correctional Services in Canada 1995-96. (Catalogue 85-211). Retrieved August 15, 2018 from:

http://publications.gc.ca/collections/collection 2016/statcan/85-211/CS85-211-1996.pdf.

Statistics Canada [StatCan]. (2007). Canada's growing population and its environmental influence, 1956 to 2006. (Catalogue number 16-002-X). Retrieved August 1, 2017 from: https://www150.statcan.gc.ca/n1/pub/16-002-x/2007001/article/10177-eng.htm/.

Statistics Canada [StatCan]. (2015a). Adult criminal court statistics in Canada, 2014/2015.

Retrieved May 8, 2018 from: https://www.statcan.gc.ca/pub/85-002-

x/2017001/article/14699-eng.htm.

Statistics Canada [StatCan]. (2015b). Estimated population of Canada, 1605 to present. (Catalogue number 98-187-X). Retrieved August 1, 2017 from: https://www150.statcan.gc.ca/n1/pub/98-187-x/4151287-eng.htm.

Statistics Canada [StatCan]. (2017a). Population estimates on July 1st, by age and sex. (Catalogue number 17-10-0005-01). Retrieved May 5, 2018 from https://www150.statcan.gc.ca/t1/tb11/en/cv.action?pid=1710000501.

Statistics Canada [StatCan]. (2017b). Road motor vehicle registrations, by type of vehicle. (Catalogue number 23-10-0067-01). Retrieved May 5, 2018 from https://www150.statcan.gc.ca/t1/tb11/en/cv.action?pid=2310006701.

Statistics Canada [StatCan]. (2017c). Statement of government operations and balance sheet, government finance statistics (x 1,000,000). (Catalogue number 10-10-0015-01).

Retrieved August 23, 2018 from https://www150.statcan.gc.ca/t1/tb11/en/tv.action?pid=1010001501\&pickMembers[0]=2. 4. 
Summary Convictions Act, Revised Statute of Ontario, 1970, c. 450. Retrieved March 25, 2017 from:

https://digitalcommons.osgoode.yorku.ca/cgi/viewcontent.cgi?referer=https://www.googl e.com $/ \&$ httpsredir $=1 \&$ article $=2661 \&$ context $=$ rso.

Summary Conviction Act Review Committee [SCRC]. (1977a, April). Report: Summary Conviction Act Review Committee. Obtained through provincial FOI request A-201700244. Toronto, ON: Ministry of the Attorney General of Ontario.

Summary Conviction Act Review Committee [SCRC]. (1977b, Jun. 23). Summary Conviction Act Review Committee - Summary of Conclusions, Proposals and Recommendations relating to Sentencing Powers, Penalties and Enforcement in respect of Provincial Offences. Obtained through provincial FOI request A-2017-00244. Toronto, ON: Ministry of the Attorney General of Ontario.

Summary Conviction Act Review Committee [SCRC]. (1977c, Apr. 7). Summary Conviction Act - Highlight of Proposals. Obtained through provincial FOI request A-2017-00244. Toronto, ON: Ministry of the Attorney General of Ontario.

Summary Conviction Act Review Committee [SCRC]. (1977d, Jun. 20). Summary Conviction Act - Provincial Offences - Sentencing Powers, Penalties and Enforcement. Obtained through provincial FOI request A-2017-00244. Toronto, ON: Ministry of the Attorney General of Ontario.

Swaigen, J. (1992). Regulatory Offences in Canada: Liability \& Defences. Toronto, CA: Carswell Thomson Professional Publishing.

Sylvestre, M. (2010). Disorder and Public Spaces in Montreal: Repression (And Resistance) Through Law, Politics, and Police Discretion. Urban Geography 31(6): 803-824.

Taylor, I., Walton, P., \& Young, J. (1973). The New Criminology. London, UK: Routledge.

Tencer, D. (2018, Aug. 20). More Than 1 In 5 Canadian Professionals Have Precarious Jobs: Study. Huffington Post. Retrieved November 20, 2018 from: https://www.huffingtonpost.ca/2018/08/20/precarious-work-professionalscanada_a 23505831/.

Town of Orangeville. (1997, May 1). "Streamlining of Administration of Provincial Offences, 1997/Loi de 1997 Simplifiant l'Administration en ce qui a Trait aux Infraction Provinciales (Continued)." Standing Committee on General Government. $36^{\text {th }}$ Parliament, $1^{\text {st }}$ Session. Retrieved March 25, 2018 from the Legislative Assembly of Ontario (Hansard): https://www.ola.org/en/legislative-business/committees/generalgovernment/parliament-36/transcripts/committee-transcript-1997-may-01.

Trinh, J. (2018, Aug. 7). Ottawa court delays slow to budge despite Jordan ruling, numbers show. CBC News. Retrieved August 1, 2018 from: https://www.cbc.ca/news/canada/ottawa/ottawa-court-delays-despite-jordan-ruling1.4775656 . 
Turner, F. (2015). Reducing Failure to Appears through Community Outreach. Retrieved on October 23, 2018 from the National Center for State Courts:

https://www.ncsc.org/ /media/Files/PDF/Education\%20and\%20Careers/CEDP\%20Paper s/2015/Reducing\%20Failure \%20to\%20Appears \%20through $\% 20$ Community $\% 20$ Outreac h.ashx.

United States v. Ward. (1980). 448 U.S. 242. Retrieved November 9, 2017 from: https://supreme.justia.com/cases/federal/us/448/242/.

Valverde, M. (2007). Genealogies of European states: Foucauldian reflections. Economy and Society 36(1): 159-178.

Valverde, M. (2012a). Everyday Law on the Street: City Governance in an Age of Diversity. Chicago: The University of Chicago Press.

Valverde, M. (2012b). Analyzing punishment: Scope and scale. Theoretical Criminology 16(2): 245-253.

Velloso, J. (2013a). Beyond criminocentric dogmatism: Mapping institutional forms of punishment in contemporary societies. Punishment \& Society 15(2): 166-186.

Velloso, J. (2013b). Punishment along, beyond and in addition to criminal law: Immigration control and the challenges to the rule of Law. In D. Rosiers (ed.), Who Belongs?. Vancouver: University of British Columbia Press.

Verhulst, S. (2008). Legislating a Principled Approach to Sentencing in Relation to Regulatory Offences. Canadian Criminal Law Review 12(3): 281-295.

Wacquant, L. (2012). 'The Wedding of Workfare and Prisonfare in the $21^{\text {st }}$ Century: Response to Critics and Commentators. In P. Squires and J. Lea (Eds.), Criminalisation and Advanced Marginality: Critically Exploring the Work of Loic Wacquant (pp. 243-258). Bristol, UK: Policy Press.

Walby, K., \& Larson, M. (2011). Access to Information and Freedom of Information Requests: Neglected Means of Data Production in the Social Sciences. Qualitative Inquiry 18(1): $31-42$.

Walby, K., \& Luscombe, A. (2018). Ethics review and freedom of information requests in qualitative research. Research Ethics: 1-15.

Walby, K., \& Piche, J. (2011). The polysemy of punishment memorialization: Dark tourism and Ontario’s penal history museums. Punishment \& Society 13(4): 451-472.

Walks, A. (Ed.). (2015). The Urban Political Economy and Ecology of Automobility: Driving Cities, Driving Inequality, Driving Politics. Abingdon, UK: Routledge.

Warmington, J. (2013, Mar. 11). Toronto Police inspector's memo lays out ticket goals. Toronto Sun. Retrieved November 10, 2017 from: http://torontosun.com/2013/03/11/torontopolice-inspectors-memo-lays-out-ticket-goals/wcm/305d3be6-1d34-4332-9d5f$\underline{971 \mathrm{~d} 314 \mathrm{af} 410 .}$. 
Weber, M. (1978). Economy and Society. G. Roth \& C. Wittich (eds.). Berkeley, CA: University of California Press. (Originally published in 1920).

Weidner, J. (2017, Dec. 1). Region of Waterloo owed \$35M in defaulted fines. TheRecord.com. Retrieved Sept 1, 2018 from: https:/www.therecord.com/news-story/7973894-region-ofwaterloo-owed-35m-in-defaulted-fines/.

Western Center on Law and Poverty. (2015). Not Just a Ferguson Problem: How Traffic Courts Drive Inequality in California. Retrieved January 18, 2018 from: https://www.lccr.com/wp-content/uploads/Not-Just-a-Ferguson-Problem-How-TrafficCourts-Drive-Inequality-in-California-4.8.15.pdf.

Windsor-Essex POA. (2014). Windsor/Essex Provincial Offences Program: Exhibit 3 - 2014 Annual Report. Retrieved March 20, 2018 from: http://weblink8.countyofessex.on.ca/WebLink/10/edoc/148651/2013\%20POA\%20Annua 1\%20Report.pdf.

Windsor-Essex POA. (2016). Windsor/Essex Provincial Offences (POA) Annual Report. Retrieved March 20, 2018 from: https://coepub.escribemeetings.com/filestream.ashx?DocumentId=2564.

Who Does What Panel [WDW]. (1996, Dec. 20). Letters and Recommendations. Toronto, ON: Who Does What Panel.

Woods, Gordon, \& Co. (1978, Sept. 29). Requirement Study in Support of the Provincial Offences Act. Obtained through provincial FOI request A-2017-00244. Toronto, ON: Ministry of the Attorney General of Ontario

Yalnizyan, A. (2010, Dec.). The Rise of Canada's Richest 1\%. Canadian Centre for Policy Alternatives. Retrieved from: http://ywcacanada.ca/data/research_docs/00000211.pdf.

York Region. (2015). Court Services Annual Report 2015. Retrieved March 19, 2018 from: https://www.york.ca/wps/wcm/connect/yorkpublic/ddc946f5-a76e-4311-bc129093843cf345/jun+16+court+ex.pdf?MOD=AJPERES.

York Region. (2016a). Court Services Annual Report 2016. Retrieved March 19, 2018 from: https://www.york.ca/wps/wcm/connect/yorkpublic/c6b9fa61-1c7f-4cde-ad8c5911540d4419/jun+22+court+ex.pdf?MOD=AJPERES.

York Region. (2016b, Aug. 16). Provincial Offences Act Modernization [Presentation]. Retrieved March 19, 2018 from: https:/www.amo.on.ca/AMOPDFs/Events/16CONF/Proceedings/ConcurrentsB/POAJHulton20160816.aspx.

Young, J. (2002). 'Critical criminology in the twenty-first century: critique, irony and the always unfinished'. In K. Carrington \& R. Hogg (eds.), Critical Criminology: Issues, debates, challenges (pp. 251-274). UK: Willian Publishing.

Young, J. (2011). The Criminological Imagination. Cambridge, UK: Polity Press. 
Young, M., \& Villani, M. (2017, April 25). New legislation to eliminate option of working off parking ticket fines. CTV Saskatoon. Retrieved July 16, 2018 from:

https://saskatoon.ctvnews.ca/new-legislation-to-eliminate-option-of-working-off-parkingticket-fines-1.3383185.

Young, P. (1987). Punishment, Money and Legal Order: An Analysis of the Emergence of Monetary Sanctions with Special Reference to Scotland (Doctoral dissertation). Edinburgh Research Archive. Retrieved November 9, 2017 from: https://www.era.lib.ed.ac.uk/handle/1842/12247.

Young, P. (1989). 'Punishment, money, and a sense of justice'. In P. Carlen \& D. Cook (Eds.), Paying For Crime (pp. 46-65). Bristol, PA: Open University Press.

Zedner, L. (2016). Penal subversions: When is a punishment not punishment, who decides, and on what grounds?. Theoretical Criminology 20(1): 3-20.

Ziegert, K. (1980). ‘A sociologist's view'. In E. Kamenka \& A. Tay (Eds.), Law and Social Control. London, UK: Edward Arnold Ltd. 


\section{Appendix 1: First Round Coding Sheet}

Step 1: Does the Record meet any of the following criteria:

\begin{tabular}{|l|c|}
\hline $\begin{array}{l}\text { Fits within the following time periods: 1977-1980, } \\
\text { 1996-1999, or 2014-2017? }\end{array}$ \\
\hline $\begin{array}{l}\text { Does the record discuss the purpose(s), objective(s), } \\
\text { mandate, vision, and/or role of the POA? }\end{array}$ \\
\hline $\begin{array}{l}\text { Does the record discuss or define notions of justice } \\
\text { and/or punishment at all (in relation to their role in the }\end{array}$ \\
\begin{tabular}{l} 
POA)? \\
\hline $\begin{array}{l}\text { Does the record discuss/help construct, represent, } \\
\text { establish, or understand the 'assumed' or 'implicit' } \\
\text { problems the POA is meant to address and/or focus on? }\end{array}$
\end{tabular} \\
\hline
\end{tabular}

\section{Keep in mind:}

RQs: How does the government(s) construct, represent, establish, or understand the 'implicit problem(s)' the POA needs to address?

As a result, what are the 'master patterns' that exist, guide and/or establish the POA and its related bodies (i.e. enforcement agencies) as a mechanism of social control and punishment?

What discourses (i.e., rationalities and logics) arise and/or are used by the administration as a result of this? What outcomes does this system of punishment and its approach produce?

- How does the POA see its role and objective (what does it ignore in doing this?)

- How are punishment and justice constructed in this administrative system? What are its ramifications and/or limitations in creating a monetized system (i.e. punishment into a monetary transaction)?

Step 2: Categorize the Record:

\begin{tabular}{|c|c|}
\hline $\begin{array}{l}\text { Name of record and number of } \\
\text { pages: }\end{array}$ & $\begin{array}{c}\text { Name: } \\
\text { Page Numbers: }\end{array}$ \\
\hline $\begin{array}{l}\text { Is the record publicly available or } \\
\text { an FOI Request (i.e. front-stage } \\
\text { or back-stage): }\end{array}$ & \\
\hline $\begin{array}{l}\text { Type of record (including if } \\
\text { document is a draft or official } \\
\text { copy): }\end{array}$ & \\
\hline Basic content of record: & \\
\hline
\end{tabular}

Step 3: Coding - Notable Observation and potential themes 


\begin{tabular}{|l|l|}
\hline $\begin{array}{l}\text { Observation (insert/add page number where info } \\
\text { extracted) }\end{array}$ & Potential theme \\
\hline & \\
\hline & \\
\hline & \\
\hline & \\
\hline & \\
\hline & \\
\hline
\end{tabular}

Analytical notes/thoughts (including observations on what was not mentioned or excluded in the record): 


\section{Appendix 2: Second Round Coding Sheet}

\section{SECONDARY CODING CATEGORY 1: THE PROBLEMATIZATION OF THE POA}

1977-1980

Theme 1: Decriminalization and the Need to Simply

Report

Observation

Theme 2: The 'problem' of volume

\begin{tabular}{|l|l}
\hline Report & Observation \\
\hline
\end{tabular}

Theme 3: The problem of cost/savings

\begin{tabular}{|l|l}
\hline Report & Observation \\
\hline
\end{tabular}

Theme 4: The pursuit of clarity, convenience, and efficiency

\begin{tabular}{|l|l|}
\hline Report & Observation \\
\hline & \\
\hline
\end{tabular}

Theme 5: The need for speed (i.e., be swift)

Report

Observation

Theme 6: The Construction of 'Minor Offences'

\begin{tabular}{|l|l|}
\hline Report & Observation \\
\hline & \\
\hline
\end{tabular}

\section{Additional notes/comments:}

1996-1999

Theme 1: The 'problem' of revenue (and/or a goal of the project):

\begin{tabular}{|l|l|}
\hline Report & Observation \\
\hline
\end{tabular}

Theme 2: The need for savings:

\begin{tabular}{|l|l|}
\hline Report & Observation \\
\hline & \\
\hline
\end{tabular}

Theme 3: The 'problem' of downloading (the transfer of various responsibilities to the municipality)

\begin{tabular}{|l|l|}
\hline Report & Observation \\
\hline & \\
\hline
\end{tabular}

Theme 4: The need for volume

\begin{tabular}{|l|l|}
\hline Report & Observation \\
\hline & \\
\hline
\end{tabular}

Theme 5: The utilization of 'business' discourses and justifications

\begin{tabular}{|l|l|}
\hline Report & Observation \\
\hline
\end{tabular}

Theme 6: The need for efficiency Report Observation 
Additional notes/comments:

2014-2017

Theme 1: The 'problem of costs'

Report

Observation

Theme 2: The issue of defaulted fines (i.e. The Billion Dollar Problem)

Report

Observation

Theme 3: "Revenue initiatives" (i.e. collection agency strategies)

\begin{tabular}{|l|l}
\hline Report & Observation \\
\hline
\end{tabular}

Theme 4: The Use of Fees

\begin{tabular}{|l|l|}
\hline Report & Observation \\
\hline & \\
\hline
\end{tabular}

Theme 5: The search for efficiencies/streamlining

\begin{tabular}{|l|l}
\hline Report & Observation \\
\hline &
\end{tabular}

Theme 6: The need for a collection agency strategy

\begin{tabular}{|l|l|}
\hline Report & Observation \\
\hline & \\
\hline
\end{tabular}

\section{Additional notes/comments:}

SECONDARY CODING CATEGORY 2: THE MASTER PATTERNS

Theme 1 - Managerialism (i.e., a need to manage)

\begin{tabular}{|l|l|}
\hline Report & Observation \\
\hline & \\
\hline
\end{tabular}

Theme 2 - Economic Rationality (the economics of the POA, cost-benefit logic)

\begin{tabular}{|l|l|}
\hline Report & Observation \\
\hline & \\
\hline
\end{tabular}

Additional notes/comments:

CODING CATEGORY 3: THE MENTALTY OF RULE (i.e., POWER RELATIONS AND GOVERMENTALITY)

Theme 1: The need for sustainability/preservation

\begin{tabular}{|l|l|}
\hline Report & Observation \\
\hline & \\
\hline
\end{tabular}

Theme 2: Responsibilization on the individual

\begin{tabular}{|l|l|}
\hline Report & Observation \\
\hline & \\
\hline
\end{tabular}

Theme 3: Biopolitics (i.e., population and the political economy)

\begin{tabular}{|l|l|}
\hline Report & Observation \\
\hline & \\
\hline
\end{tabular}




\section{$\underline{\text { Additional notes/comments: }}$}

\section{CODING CATEGORY 4: THE CONSTRUCTION OF PUNISHMENT AND ITS}

OBJECTIVES/FUNCTIONS

Theme 1: Personal Accountability (i.e., Paying one's 'debt to society'):

\begin{tabular}{|l|l}
\hline Report & Observation \\
\hline
\end{tabular}

Theme 2: Cost-Efficient (i.e., Streamlined/Flexible/Convenient)

\begin{tabular}{|l|l|}
\hline Report & Observation \\
\hline & \\
\hline
\end{tabular}

Theme 3: Deterrence

\begin{tabular}{|l|l|}
\hline Report & Observation \\
\hline & \\
\hline
\end{tabular}

Theme 4: Profitability (i.e., The need for (or ability to provide) revenue)

\begin{tabular}{|l|l|}
\hline Report & Observation \\
\hline
\end{tabular}

Additional notes/comments:

SECONDARY CODING CATEGORY 5: THE CONSTRUCTION OF JUSTICE AND ITS

OBJECTIVES/FUNCTIONS (i.e., Machinery of POA justice and its system of justice)

Theme 1: Simple Justice (i.e., streamlined, flexible, convenient)

\begin{tabular}{|l|l|}
\hline Report & Observation \\
\hline & \\
\hline
\end{tabular}

Theme 2: Monetized Justice (i.e., cost-effective, revenue)

\begin{tabular}{|l|l|}
\hline Report & Observation \\
\hline & \\
\hline
\end{tabular}

Theme 3: Local Justice

\begin{tabular}{|l|l|}
\hline Report & Observation \\
\hline & \\
\hline
\end{tabular}

Theme 4: Fair and Effective Justice (e.g., swift and certain)

\begin{tabular}{|l|l|}
\hline Report & Observation \\
\hline & \\
\hline
\end{tabular}

Additional notes/comments: 


\section{Appendix 3: Example of the POA Ticket (i.e., a Certificate of an Offence)}

Important - If you do not exercise one of the following options within 15 days of receiving this notice, you will be deemed not to dispute the charge and a justice may enter a conviction againt you. Upon convi additional costs will be added to the total payable. If the fin goes into dofult, an administrative fee will be additional costs will added to the tola payable.the fine goes into dolaull, an administrative fee will be added and steps wilting and suspended.

Important -Si vous n'exercez pas lune des options suivantes dans un délal de 15 jours à compter de la réception du présent avis, vous serez réputé(e) ne pas contester laccusation et un juge pourra inscrire un déclaration de culpabilité contre vous. Sur déclaration de culpabilití, des frais additionnels s'ajouteront a montant total exigible. En cas de défaut de paiement de P'amende, des frais d'administration s'ajouteront et des mesures seront prises pour faire exécuter le pajement de votre amende. Par exemple, rinformation peut être transmise à une agence de renseignements sur le consommateur et dans le cas de certaines Infractions, dont l'excès de vitesse, votre permis de conduire peut être suspendu.

Plea of Guilty - Voluntary Payment of Total OPTION1 1 Plaidoyer de culpabilité - Paiement volontaire du Payable: I plead guilty and payment of the total payable is enclosed (follow the instructions on the "payment notice"). montant total exigible est joint à la présente (suivre les instructions figurant sur " Fav's de paiement

Plea of guilty - Submissions as to Penalty: I want Plaidoyer de culpabilite - Observations au sujet to appear before a justice to enter a plea of gullty and de la peine : Je désire comparaitre devant un juge make submissions as to penalty (amount of fine or pour inscrive un plaidoyer de culpabilité et prísent

time to pay). Note: You must attend the court office des observations au sujet de la peine (montant de shown below within the times and days shown. Bring shown below within the

this notice with you.

Provincial Offences Office

100 Constellation Crescent

Monday to Friday 9:00am to $12: 00 \mathrm{pm}$

Tuesday, Wednesday and Friday $1: 30 \mathrm{pm}$ to $3: 00 \mathrm{pm}$

613-580-2665

l'amende ou délai de paiement).

Remarque : Vous devez vous présenter au greffe du tribunal cl-après aux dates et heures indiquées. Apportez le présent avis.

bureau des infractions provinciales

100 , croissant Constellation

Lundi à Vendredi de 9:00h à 12:00h

Mardi, Mercredl et Vondredi de 13:30h à 15:00 h 613-580-2665

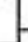

Trial Option, Ontario Court of Justice, Provincial Offences Office

Person: Provinciat Offences Offices 100 Constellation Crescent OR $110 \mathrm{~L}$ Monday to Friday 8:30am to 4:30pm

June 1 to Labour Day 8:30am to 4:00pm

1.

Constellation Crescent, Ottawa, ON

Notice of intention to appear in court:

- intend to appear in court to enter a plea of $n$ guilty at the time and place set for the trial and I wish to have the trial conducted in the English language.

request a anguage interpreter for the trial. (Leave blank if inapplicable.)

[ I intend to challenge the evidence of the Provincial Offences Officer. I request that the officer attend the trial.

Note: If you fail to notify the court office of addres changes, you may not recelve important notices,

e.g., your Notice of Trial. You may be convicted in your absence if you do not attend the trial.

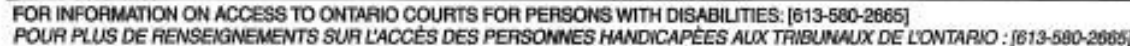
REV-12-11

*Image taken from City of Ottawa (2018) 


\section{Appendix 4: Number of POA Charges with a Jail Sentence between 2004 to 2017*}

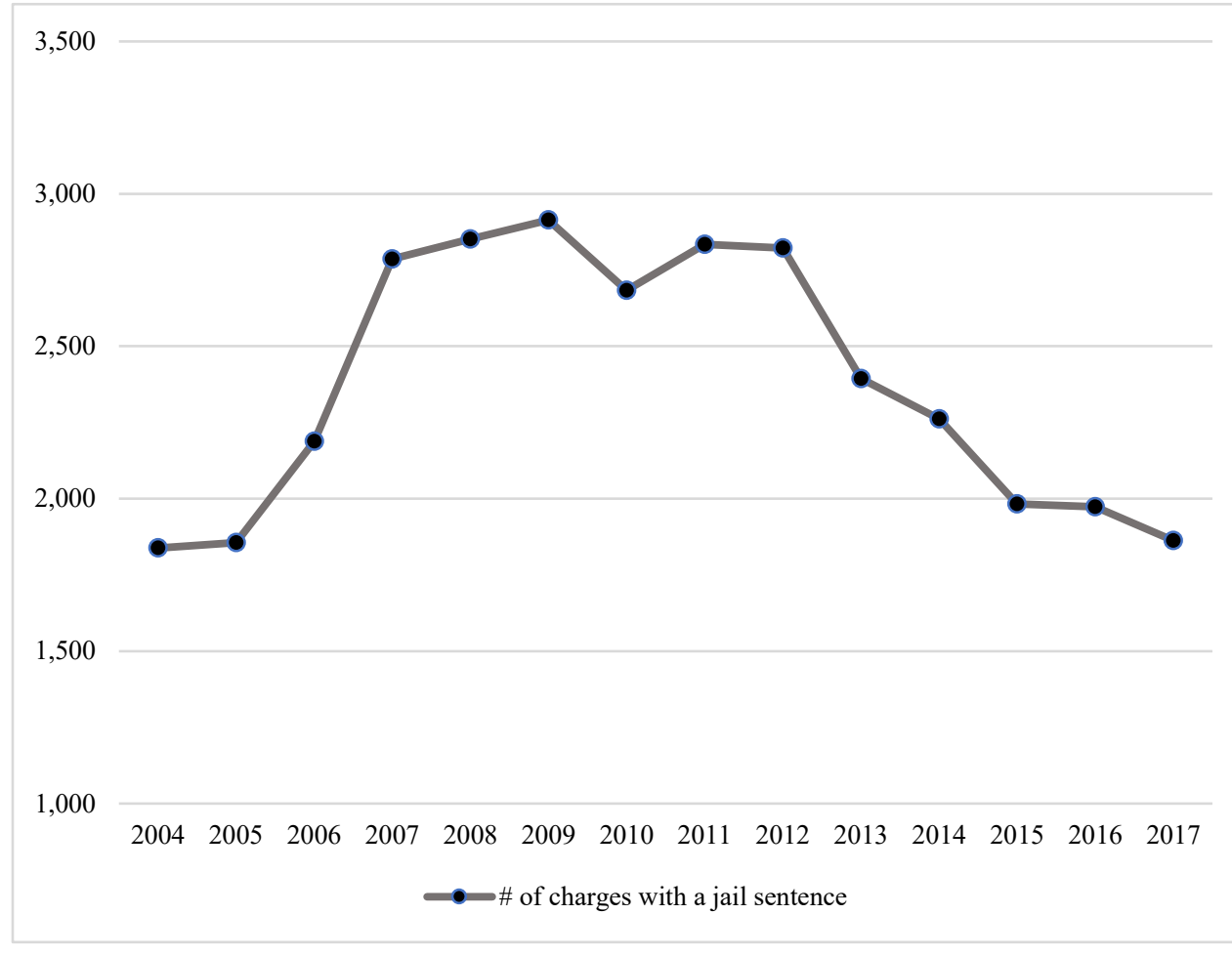

MAG through FOI Requests.

\begin{tabular}{|l|l|}
\hline Year & $\begin{array}{l}\text { \# of } \\
\text { tickets } \\
\text { issued } \\
\text { annually }\end{array}$ \\
\hline 2004 & 1,838 \\
\hline 2005 & 1,856 \\
\hline 2006 & 2,188 \\
\hline 2007 & 2,786 \\
\hline 2008 & 2,852 \\
\hline 2009 & 2,914 \\
\hline 2010 & 2,684 \\
\hline 2011 & 2,834 \\
\hline 2012 & 2,822 \\
\hline 2013 & 2,394 \\
\hline 2014 & 2,262 \\
\hline 2015 & 1,983 \\
\hline 2016 & 1,973 \\
\hline 2017 & 1,862 \\
\hline
\end{tabular}

*Data provided by 
Appendix 5a: Number of POA Charges with Jail Sentences (in relation to specific statutes)*

\begin{tabular}{|c|c|c|c|c|c|c|c|c|c|c|c|c|c|c|}
\hline Statute & 2004 & 2005 & 2006 & 2007 & 2008 & 2009 & 2010 & 2011 & 2012 & 2013 & 2014 & 2015 & 2016 & 2017 \\
\hline Total & 1,838 & 1,856 & 2,187 & 2,786 & 2,915 & 2,684 & 2,684 & 2,834 & 2,822 & 2,394 & 2,262 & 1,983 & 1,973 & 1,862 \\
\hline $\begin{array}{l}\text { Compulsory } \\
\text { Automobile } \\
\text { Insurance } \\
\text { Act (CAIA) }\end{array}$ & 26 & 27 & 29 & 14 & 26 & 36 & 45 & 35 & 18 & 13 & 9 & 12 & 15 & 8 \\
\hline $\begin{array}{l}\text { Highway } \\
\text { Traffic Act } \\
\text { (HTA) }\end{array}$ & 1,432 & 1,532 & 1,808 & 2,086 & 2,294 & 2,440 & 2,249 & 2,373 & 2,400 & 1,990 & 1,943 & 1,680 & 1,720 & 1,615 \\
\hline $\begin{array}{l}\text { Liquor } \\
\text { Licence Act } \\
\text { (LLA) }\end{array}$ & 22 & 16 & 17 & 18 & 7 & 14 & 11 & 12 & 11 & 6 & 4 & & 2 & 1 \\
\hline $\begin{array}{l}\text { Provincial } \\
\text { Offences Act } \\
\text { (POA) } \\
\end{array}$ & 106 & 104 & 130 & 213 & 205 & 137 & 122 & 121 & 151 & 118 & 152 & 114 & 98 & 89 \\
\hline $\begin{array}{l}\text { Safe Street } \\
\text { Act (SSA) }\end{array}$ & 12 & 29 & 21 & 93 & 132 & 77 & 95 & 91 & 45 & 56 & 30 & 19 & 16 & 28 \\
\hline
\end{tabular}

\section{Appendix 5b: Top Five POA Charges with Jail Sentences in 2017*}

\begin{tabular}{|l|l|l|l|l|l|}
\hline Statute and Section & $\begin{array}{l}\text { HTA (s. 53): } \\
\text { Driving while under } \\
\text { suspension }\end{array}$ & $\begin{array}{l}\text { POA (s. 75): Breach } \\
\text { of Probation }\end{array}$ & $\begin{array}{l}\text { Christopher's Law } \\
\text { (s. 11[1]): Failing to } \\
\text { comply with Act or } \\
\text { providing false } \\
\text { information }\end{array}$ & $\begin{array}{l}\text { HTA (s. 130): } \\
\text { Careless Driving }\end{array}$ & $\begin{array}{l}\text { SSA (s. 3[2]): } \\
\text { Obstructing the } \\
\text { path of the person } \\
\text { solicited (before or } \\
\text { after solicitation) }\end{array}$ \\
\hline 2017 & 1,530 & 86 & 31 & 29 & 27 \\
\hline
\end{tabular}

*Data taken from MAG FOI requests. 


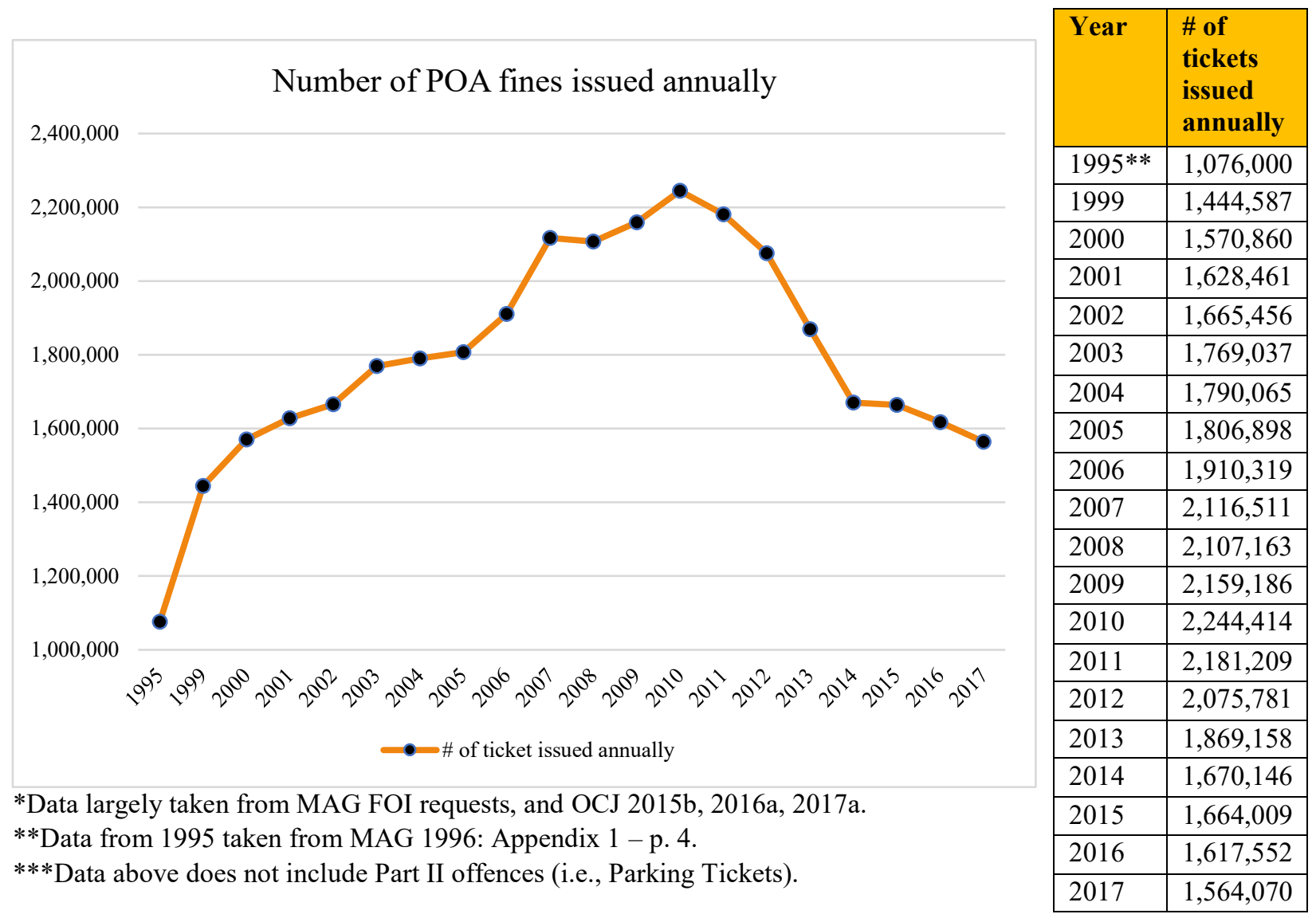


Appendix 7: Defaulted Fines Added and the POA Collection Rates from 2010 to 2018*

\begin{tabular}{|c|c|c|c|c|c|c|c|c|c|}
\hline Year & $\begin{array}{l}\text { \# of } \\
\text { charges } \\
\text { issued } \\
\text { annually }\end{array}$ & $\begin{array}{l}\text { Annual } \\
\text { number of } \\
\text { defaylted } \\
\text { charges } \\
\text { added } * * *\end{array}$ & $\begin{array}{l}\text { Total } \\
\text { Number of } \\
\text { Charges with } \\
\text { Fine } \\
\text { Amounts in } \\
\text { Default }\end{array}$ & $\begin{array}{l}\text { Annual Fine } \\
\text { Amount Owed }\end{array}$ & $\begin{array}{l}\text { Annual } \\
\text { Amount } \\
\text { Collected }\end{array}$ & $\begin{array}{l}\text { Annual Fine } \\
\text { Amounts } \\
\text { Owed but not } \\
\text { in Default }\end{array}$ & $\begin{array}{l}\text { Percent } \\
\text { Collected } \\
\text { (of money } \\
\text { owed) }^{y}\end{array}$ & $\begin{array}{l}\text { Total Fine } \\
\text { Amounts in } \\
\text { Default }\end{array}$ & $\begin{array}{l}\text { Annual } \\
\text { Amount in } \\
\text { Default Fine } \\
\text { Payments } \\
\text { Added*** }\end{array}$ \\
\hline 2010 & $2,244,414$ & N/A & $2,460,191$ & $\$ 262,135,553$ & $\$ 182,156,988$ & $\$ 79,978,565$ & $69.49 \%$ & $\$ 749,102,395$ & $\mathrm{~N} / \mathrm{A}$ \\
\hline 2011 & $2,181,209$ & 135,794 & $2,595,985$ & $\$ 259,560,765$ & $\$ 184,116,816$ & $\$ 75,443,949$ & $70.93 \%$ & $\$ 800,144,343$ & $\$ 51,041,948$ \\
\hline 2012 & $2,075,781$ & 161,227 & $2,751,212$ & $\$ 263,444,416$ & $\$ 187,027,061$ & $\$ 76,417,355$ & $70.99 \%$ & $\$ 850,070,428$ & $\$ 49,926,085$ \\
\hline 2013 & $1,869,158$ & 96,182 & $2,847,394$ & $\$ 243,767,068$ & $\$ 184,411,956$ & $\$ 59,355,112$ & $75.65 \%$ & $\$ 891,769,747$ & $\$ 41,699,319$ \\
\hline 2014 & $1,670,146$ & 101,805 & $2,949,199$ & $\$ 227,710,738$ & $\$ 177,315,348$ & $\$ 50,395,390$ & $77.87 \%$ & $\$ 934,472,002$ & $\$ 42,702,255$ \\
\hline 2015 & $1,664,009$ & 65,274 & $3,014,473$ & $\$ 228,415,635$ & $\$ 182,339,442$ & $\$ 46,076,193$ & $79.83 \%$ & $\$ 958,135,353$ & $\$ 23,663,331$ \\
\hline 2016 & $1,617,552$ & 60,886 & $3,075,359$ & $\$ 237,893,686$ & $\$ 185,917,887$ & $\$ 51,975,799$ & $78.15 \%$ & $\$ 981,692,495$ & $\$ 23,557,142$ \\
\hline 2017 & $1,564,070$ & $(11,617)$ & $3,063,742$ & $\$ 232,505,616$ & $\$ 194,529,172$ & $\$ 37,976,444$ & $83.67 \%$ & $\$ 987,062,469$ & $\$ 5,369,974$ \\
\hline $2018 * *$ & $1,547,918$ & 653 & $3,063,089$ & $\$ 242,640,985$ & $\$ 199,705,880$ & $\$ 42,935,105$ & $82.31 \%$ & $\$ 993,893,594$ & $\$ 6,831,125$ \\
\hline
\end{tabular}

*Data largely taken from MAG FOI request, but also OCJ reports (2015b, 2015c, 2016a, 2016b, 2017a, 2017b, 2018a, 2018c). Figures do not include data on parking tickets, nor does it account for any additional fees added to each charge (e.g., default fees, court costs, victim fine surcharge, or collection agency costs) **Figures used in OCJ report from 2018 contains data from July 2017 to June 2018, as the year is not yet completed.

***To clarify, these numbers were calculated based on the number of defaulted charges added annually (or removed), as well as the number of defaulted payments added annually as a result. Furthermore, as figures were taken from OCJ reports and those provided by MAG, according to disclaimers found in each, both data sets pertaining to payments in default as well as charges recorded exclude any and all charges/payments that have been written off by "Municipal Partners" (i.e. Local POA Branches) or any charge not yet designated as 'in default'.

y Data calculated in relation to fine percentage collected was done based on the 'Annual Amount Collected' divided by the 'Annual Fine Amount Owed'. 
Appendix 8: POA Payments in Default as of March 2016*:

\begin{tabular}{|c|c|c|c|c|}
\hline Statute & $\begin{array}{r}\text { Total Amount of Payment } \\
\text { in Default }\end{array}$ & $\begin{array}{r}\text { Percentage of } \\
\text { Total }\end{array}$ & $\begin{array}{l}\text { Total Number of Charges } \\
\text { with Payments in Default }\end{array}$ & $\begin{array}{r}\text { Percent of } \\
\text { Total }\end{array}$ \\
\hline $\begin{array}{l}\text { Compulsory Automobile } \\
\text { Insurance Act (CAIA) }\end{array}$ & $\$ 520,533,525.21$ & $36.2 \%$ & 207,515 & $6.9 \%$ \\
\hline Highway Traffic Act (HTA) & $\$ 468,550,974.80$ & $32.6 \%$ & $1,326,345$ & $44.0 \%$ \\
\hline Liquor Licence Act (LLA) & $\$ 85,922,530.60$ & $6.0 \%$ & 594,716 & $19.7 \%$ \\
\hline By-Laws (Others) & $\$ 67,062,583.60$ & $4.7 \%$ & 258,479 & $8.6 \%$ \\
\hline $\begin{array}{l}\text { Trespass to Property Act } \\
\text { (TPA) }\end{array}$ & $\$ 32,214,063.69$ & $2.2 \%$ & 277,617 & $9.2 \%$ \\
\hline Other & $\$ 229,509,177.22$ & $16.0 \%$ & 348,006 & $11.5 \%$ \\
\hline Total & $\$ 1,436,867,944.29$ & & $3,017,810$ & \\
\hline
\end{tabular}

*Data located in record MAG 2016a: 11. This data does account for the fine as well as additional costs outstanding (including default fees, court costs, victim fine surcharges, and collection agency costs).

**These number do not account for unpaid fines that have been not yet been designate as being in default as well as charges that have been written off by

Municipal Partners (i.e., Local POA Branches). 
Appendix 9: Annual Number of Driver Licence Suspensions Issued for Defaulting on a Fine from 1995 to $2016{ }^{*}$

\begin{tabular}{|c|c|c|c|}
\hline \multirow[t]{3}{*}{ Year } & \multirow{3}{*}{ Total Non-CCC Suspensions Issued } & \multicolumn{2}{|c|}{ Type of Suspension } \\
\hline & & \multicolumn{2}{|c|}{ Fine Defaulting } \\
\hline & & $\mathbf{N}$ & $\%$ of all Non-CCC \\
\hline 1995 & 124,018 & 85,660 & 69.07 \\
\hline 1999 & 182,082 & 114,444 & 62.85 \\
\hline 2000 & 187,939 & 113,333 & 60.30 \\
\hline 2001 & 198,968 & 120,807 & 60.72 \\
\hline 2002 & 174,425 & 95,909 & 54.99 \\
\hline 2003 & 231,288 & 152,971 & 66.14 \\
\hline 2004 & 234,243 & 155,902 & 66.50 \\
\hline 2005 & 228,667 & 155,484 & 68.00 \\
\hline 2006 & 217,973 & 140,624 & 64.51 \\
\hline 2007 & 243,654 & 155,431 & 63.79 \\
\hline 2008 & 249,536 & 152,370 & 61.06 \\
\hline 2009 & 250,797 & 141,552 & 56.44 \\
\hline 2010 & 265,750 & 151,840 & 57.14 \\
\hline 2011 & 257,042 & 139,824 & 54.40 \\
\hline 2012 & 242,538 & 133,462 & 55.03 \\
\hline 2013 & 232,789 & 126,427 & 54.31 \\
\hline 2014 & 214,680 & 115,407 & 53.76 \\
\hline 2015 & 217,344 & 111,036 & 51.09 \\
\hline 2016 & 218,749 & 109,453 & 50.04 \\
\hline
\end{tabular}

*Statistics obtained from the MTO following an FOI request for such data 